\title{
Geração e refinamento de malhas segmentadas a partir de imagens com textura
}

\author{
Mario Augusto de Souza Liziér
}

Orientador: Prof. Dr. Luis Gustavo Nonato

Tese apresentada ao Instituto de Ciências Matemáticas e de Computação - ICMC-USP, como parte dos requisitos para obtenção do título de Doutor em Ciências - Ciências de Computação e Matemática Computacional. 

Dedico este trabalho aos meus pais, com muito amor. 



\section{Agradecimentos}

Agradeço aos meus pais, Julia e Mingo, pelo amor incondicional e todo o apoio que sempre recebo. Sem eles eu jamais conseguiria realizar este sonho.

Agradeço também aos meus familiares e todo o carinho recebido dos meus avós Dita, Sunta e Nino. Ao meu avô Arlindo, este doutorado também é seu.

Um agradecimento especial dedico ao meu orientador Gustavo. Agradeço muito por ter acreditado em mim desde o início de minha iniciação científica e por ter me conduzido até o término desta tese. Agradeço também aos professores Castelo e Cláudio pela atenção dedicada. Agradeço ao David, Roberto e Alex pelas importantes contribuições neste trabalho.

Agradeço ao Diogo, Kémelli, Milena, Jacob, João Paulo, Alexandre e todos os demais que me acompanham e me aguentam. Agradeço ao laboratório LCAD, pelos amigos e colegas de trabalho que ganhei, além de toda a estrutura oferecida.

Agradeço ainda a todos os demais professores e funcionários do ICMC que, diretamente ou indiretamente, contribuíram para a realização deste trabalho.

Com certeza faltaram muitos nomes aqui, a todos estes um muito obrigado. 



\section{Resumo}

Com a popularização de equipamentos tradicionais de captura de imagens, como câmeras digitais, e o avanço tecnológico dos dispositivos não invasivos, como tomografia e ressonância, cresce também a necessidade e consequente uso de métodos numéricos para simulação de fenômenos físicos em domínios definidos por imagens. Um dos pré-requisitos para a aplicação de tais métodos numéricos consiste na discretização do domínio em questão, num processo denominado geração de malhas. Embora diversos métodos de geração de malha tenham sido propostos para discretizar domínios definidos por primitivas geométricas, pouco tem sido feito no sentido de gerar uma decomposição diretamente a partir de imagens.

Neste trabalho, apresentamos uma abordagem de geração de malhas de qualidade a partir de domínios definidos por imagens com textura. Mais especificamente, a pesquisa descrita nesta tese contribui com a melhoria do algoritmo Imesh, ao sanar três de suas principais limitações: tratamento de imagens com texturas; controle do nível de refinamento da malha e suporte a outros tipos de elementos. Estas contribuições flexibilizam o processo de geração da malha, e ainda ampliam o domínio de aplicações do algoritmo Imesh, à medida que são considerados domínios definidos por imagens com textura e o uso de métodos numéricos para elementos não simpliciais torna-se possível. O algoritmo de melhoria da malha gerada utiliza uma abordagem inovadora de remalhamento baseada em templates e guiada por retalhos de Bézier.

Palavras-chave: geração de malhas, remalhamento, segmentação de malhas, melhoria de malhas, refinamento, Bézier, template, imagem, W-operador, textura 



\section{Abstract}

With the spreading of traditional image capturing devices, such as digital cameras, and the technological advancement of more specific imaging devices such as CT and MRI, also increased the need and the following use of numerical methods for simulation of physical phenomena in domains defined by images. One of the prerequisites for the application of such numerical methods is the discretization of the corresponding domain, in a process called mesh generation. Although several methods of mesh generation have been proposed to discretize domains defined by geometric primitives, little has been done to generate a decomposition directly from images.

We present an approach to generate quality meshes from domains defined by images with texture. More specifically, the research described in this thesis contributes to the improvement of the Imesh algorithm, removing three of its main limitations: treatment textured images, control of the level of the mesh refinement and support for other types of non-simplicial elements. These contributions provide flexibility to the mesh generation process, and extend the range of applications of Imesh by both handling textured images and considering the use of numerical methods for non-simplicial elements. The mesh quality improvement algorithm uses a new approach based on mesh templates and it is guided by Bezier patches.

Keywords: mesh generation, remeshing, refinement, segmented mesh, mesh partitioning, Bézier, template, image, W-operator, texture 



\section{Sumário}

\section{Lista de Figuras}

Lista de Tabelas

1 Introdução $\quad$ p. 19

1.1 Contribuições principais . . . . . . . . . . . . . . p. 20

1.2 Publicações . . . . . . . . . . . . . . . . . . . p. 21

Publicações oriundas da tese $\ldots \ldots \ldots$. . . . . . . . . . . .

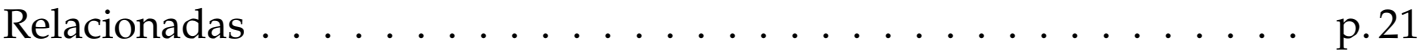

1.3 Visão geral da tese $\ldots \ldots \ldots \ldots \ldots \ldots$ p. 22

2 Revisão bibliográfica $\quad$ p. 23

2.1 Geração de malhas a partir de imagens . . . . . . . . . . . . . . p. 24

2.2 Melhoria de malhas . . . . . . . . . . . . . . . p. 25

2.3 Malhas quadrangulares . . . . . . . . . . . . . p. 26

3 Algoritmo Imesh r p.29

3.1 Conceitos básicos . . . . . . . . . . . . . . . . p. 30

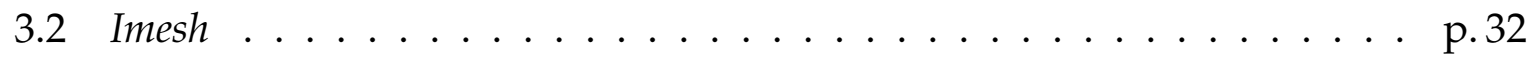

3.2.1 Geração da malha . . . . . . . . . . . . . . . . p.32

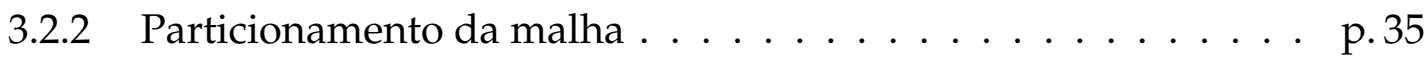

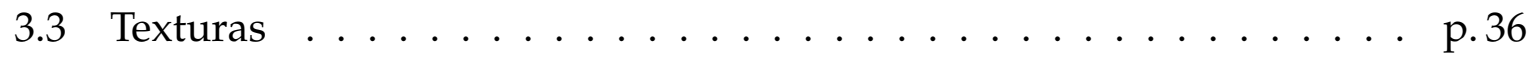

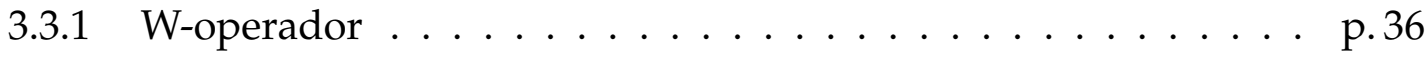


3.3.2 W-operador + Imesh . . . . . . . . . . . . p. 38

4 Remalhamento $\quad$ p. 41

4.1 Conceitos básicos . . . . . . . . . . . . . . p. 41

4.2 Remalhamento baseado em templates . . . . . . . . . . . p. 43

4.2 .1 Pré-processamento . . . . . . . . . . . . p. 43

4.2.2 Definição de templates . . . . . . . . . . . . . p. 45

4.2.3 Otimização dos pontos de controle . . . . . . . . . . . . p. 50

5 Resultados p. 55

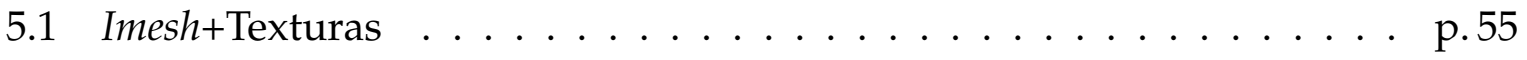

5.1.1 Imagens do Berkeley Segmentation Dataset . . . . . . . . . p. 55

5.1 .2 Imagens do VisTex dataset $\ldots \ldots \ldots \ldots$ p. 66

5.2 Imesh+Texturas+Remalhamento . . . . . . . . . . . p. 66

5.2.1 Imagens do VisTex Dataset . . . . . . . . . . . . . p. 69

5.3 Discussão . . . . . . . . . . . . . . . p. 70

5.4 Limitações . . . . . . . . . . . . . . . . . p. 76

6 Conclusões $\quad$ p. 79

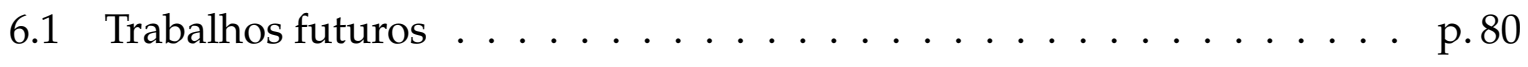

$\begin{array}{ll}\text { Referências Bibliográficas } & \text { p. } 81\end{array}$

$\begin{array}{ll}\text { Apêndice A - Estrutura de dados } & \text { p. } 87\end{array}$

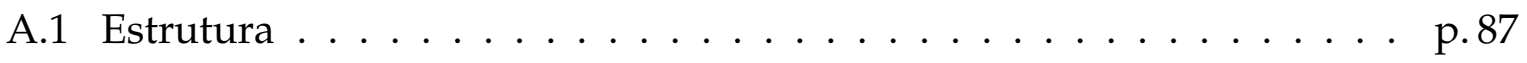

A.2 Implementação $\ldots \ldots \ldots \ldots \ldots \ldots \ldots$ p. $90 \ldots \ldots \ldots$

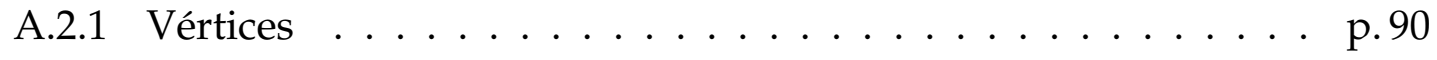

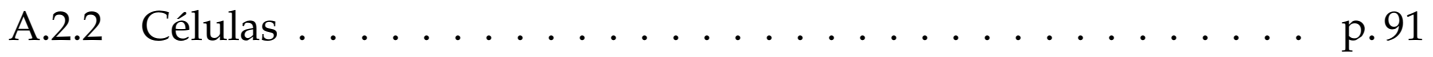

A.2.3 Perfil de tipos . . . . . . . . . . . . . p. 91 
A.2.4 Associação de dados . . . . . . . . . . . . . . . p. 94

A.2.5 Malhas ...................... p. 94

A.2.6 Vetor de elementos . . . . . . . . . . . . p. 95

A.2.7 Cálculos geométricos . . . . . . . . . . . . p. 96

A.2.8 Operações topológicas . . . . . . . . . . . . . . p. 97

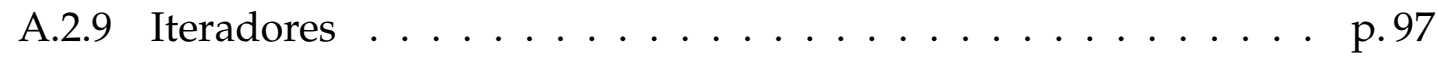

A.2.10 Interface com arquivos . . . . . . . . . . . . p.98

A.2.11 Formato $\mathrm{OF} \ldots \ldots \ldots \ldots \ldots \ldots$ p. $99 \ldots$

A.2.12 Estruturas auxiliares ................. . . . 99 



\section{Lista de Figuras}

3.1 Diagrama de Voronoi e triangulação de Delaunay sobre o mesmo conjunto de pontos (pontos pretos). . . . . . . . . . . . . . p.31

3.2 Escolha do novo vértice. . . . . . . . . . . . . p. 34

3.3 Controle de densidade dos triângulos [Cuadros-Vargas et al. 2005]. . . p.34

3.4 Geração e replicação das amostras de treinamento [Lizier et al. 2009]. p.37

3.5 Um exemplo de sub-janela para a definição do W-operador. A subjanela é composta pelas posições escuras [Lizier et al. 2009]. . . . . . . p. p.37

3.6 Medida de erro em um triângulo. . . . . . . . . . . . p. 38

3.7 Exemplo da pirâmide, extraído do Berkeley Segmentation Dataset. . . . . p.39

3.8 Quatro passos do processo de geração da malha com a rotulação de triângulos. Os triângulos em branco possuem menos de $90 \%$ de rótulos iguais. . . . . . . . . . . . . . . . . p. 40

4.1 Retalhos de Bézier. Extraídos de [Schneider and Eberly 2003]. . . . . . p. p3

4.2 Pré-processamento: (a) Malha original, (b) Subdivisões no bordo da malha, (c) Subdivisões considerando as proporções das arestas. . . . . . p.44

4.3 Template formado por triângulos. . . . . . . . . . . . p. 46

4.4 Templates formados por quadriláteros. . . . . . . . . . . . p.47

4.5 Remalhamento: (a) Malha original, (b) Zoom da ponta do polegar, (c) Remalhamento por triângulos e (d) Remalhamento por quadriláteros. . p.48

4.6 Exemplo em que os elementos da malha estão associados a mais de um retalho de Bézier (quadriláteros escuros). . . . . . . . . . . p. . 49

4.7 Passos do processo iterativo de minimização da função $\mathscr{E}$ utilizando um template de triângulos. . . . . . . . . . . . . . . p.52 
4.8 Passos do processo iterativo de minimização da função $\mathscr{E}$ utilizando um template de quadriláteros. . . . . . . . . . . . . . p.52

4.9 Final do processo iterativo de minimização. (a) Malha original, (b) Modelo de triângulos, (c) Modelo de quadriláteros. . . . . . . . . . p.54

5.1 Imagens e recortes utilizadas neste primeiro conjunto de testes. A cor do recorte indica a classe da textura. . . . . . . . . p.56

5.2 Segmentação manual de referência para cada imagem ilustrada na fi-

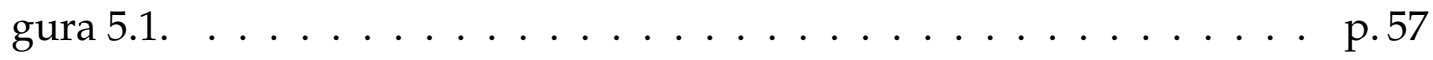

5.3 Sub-janelas resultantes da aplicação do SFFS, utilizando o conjunto de treinamento ilustrado na figura $5.1 \ldots \ldots \ldots \ldots \ldots$ p. 60

5.4 Resultados da aplicação do W-operador nas imagens exibidas na figura 5.1 com seus respectivos erros MAEs. Parâmetros adotados: RGB+HSV, $|W|=3 \times 3, k=16$ e rotação de 45 graus $(d=45) \ldots \ldots \ldots \ldots \ldots$ p. 61

5.5 Representação dos maiores valores da matriz de probabilidade condicional correspondentes a classificação realizada pelo $\mathrm{W}$-operador ilustrada na figura $5.4 \ldots \ldots \ldots \ldots \ldots \ldots \ldots \ldots \ldots$. . . . . . . . .

5.6 Imagens geradas a partir das triangulações ilustradas na figura 5.7. . . p.62

5.7 Malha triangular gerada a partir do Imesh + W-operador. . . . . . . . p. 63

5.8 Melhoramento de malha (Ruppert) aplicado nas triangulações ilustradas nas figuras $5.7(a, b, c, d)$. Em (a) temos o histograma da qualidade dos elementos da pirâmide. . . . . . . . . . . . . . . p. 64

5.9 Resultados gerados a partir do Imesh + MLP. . . . . . . . . . . p. 65

5.10 Imagens originais selecionadas do VisTex Database e seus respectivos conjunto de treinamento $($ tamanho $128 \times 128) \ldots \ldots \ldots \ldots$ p. 67

5.11 Brick Paint: (a) resultado do W-operador, (b) resultado da MLP, (c) resultado do W-operador+Imesh+Ruppert e (d) histograma da qualidade dos elementos da malha exibida em (c). . . . . . . . . . p.68

5.12 Mt Valley: (a) resultado do W-operador, (b) resultado da MLP, (c) resultado do $\mathrm{W}$-operador+Imesh+Ruppert e (d) histograma da qualidade dos elementos da malha exibida em (c). . . . . . . . . . . p. 68 
5.13 Grass Land: (a) resultado do W-operador, (b) resultado da MLP, (c) resultado do $\mathrm{W}$-operador+Imesh+Ruppert e (d) histograma da qualidade dos elementos da malha exibida em (c) . . . . . . . . . . p.68

5.14 Valley Water: (a) resultado do W-operador, (b) resultado da MLP, (c) resultado do $\mathrm{W}$-operador+Imesh+Ruppert e (d) histograma da qualidade dos elementos da malha exibida em (c) . . . . . . . . . . . . . . p.69

5.15 Etapa iniciais: pirâmide. . . . . . . . . . . . . . . p. 69

5.16 Aplicação do template de triângulos com três níveis de refinamento. Abaixo de cada refinamento encontra-se o histograma da qualidade dos elementos da respectiva malha. . . . . . . . . . . . . . p . 70

5.17 Etapas da otimização sobre as malhas da figura 5.16. Em cada coluna encontra-se um nível diferente de refinamento. . . . . . . . . . . p.71

5.18 Aplicação do template de quadriláteros com três níveis de refinamento. Abaixo de cada refinamento encontra-se o histograma da qualidade dos elementos da respectiva malha. . . . . . . . . . . p.72

5.19 Etapas da otimização sobre as malhas da figura 5.18. Em cada coluna encontra-se um nível diferente de refinamento. . . . . . . . . . . p.73

5.20 Remalhamento do exemplo Brick Paint utilizando template de triângulos e quadriláteros. . . . . . . . . . . . . . . p.73

5.21 Remalhamento do exemplo Brick Paint utilizando template de triângulos e quadriláteros. . . . . . . . . . . . . . . p. 74

5.22 Remalhamento do exemplo Mt Valley utilizando template de triângulos e quadriláteros. . . . . . . . . . . . . . . . p. 74

5.23 Remalhamento do exemplo $M t$ Valley utilizando template de triângulos e quadriláteros. . . . . . . . . . . . . . . . p.75

5.24 Remalhamento do exemplo Grass Land utilizando template de triângulos e quadriláteros. . . . . . . . . . . . . . . . . p.75

5.25 Remalhamento do exemplo Grass Land utilizando template de triângulos e quadriláteros. . . . . . . . . . . . . . . . . . . p.75

5.26 Remalhamento do exemplo Valley Water utilizando template de triângulos e quadriláteros. 
5.27 Remalhamento do exemplo Valley Water utilizando template de triângulos e quadriláteros. . . . . . . . . . . . . . p. 76

A.1 Vértices bidimensionais. . . . . . . . . . . . . p. 88

A.2 Células bidimensionais. . . . . . . . . . . . . p. 89

A.3 Células tridimensionais. . . . . . . . . . . . . . p. 89

A.4 Classes de vértices. . . . . . . . . . . . . . . . . p. 92

A.5 Classes de células. . . . . . . . . . . . . . . p. 93

A.6 Vetor de alocação por blocos. . . . . . . . . . . . . . p. 96

A.7 Formato binário de arquivo $(\mathrm{OF}) \ldots \ldots \ldots \ldots \ldots$. . . . . . . . . . 99 


\section{Lista de Tabelas}

5.1 Erro (MAE) da classificação realizada pelo W-operador para a imagem da pirâmide obtidos por toda combinação de valores dos parâmetros considerados. . . . . . . . . . . . . . . . p. 58

5.2 Erro (MAE) da classificação realizada pelo W-operador para a imagem do cavalo obtidos por toda combinação de valores dos parâmetros considerados. . . . . . . . . . . . . . . p. 58

5.3 Erro (MAE) da classificação realizada pelo W-operador para a imagem do lago obtidos por toda combinação de valores dos parâmetros considerados. . . . . . . . . . . . . . . . p. 59

5.4 Erro (MAE) da classificação realizada pelo W-operador para a imagem da cobra obtidos por toda combinação de valores dos parâmetros considerados. . . . . . . . . . . . . . . . . . . 59

5.5 Tempo de processamento dos testes de template de triângulos. . . . . . p.77

5.6 Tempo de processamento dos testes de template de quadriláteros. . . . p.77 



\section{Introdução}

O uso de métodos numéricos para simulação de fenômenos físicos em domínios definidos por imagens tem acompanhado o avanço tecnológico dos dispositivos de captura de imagens. De fato, o acesso a dispositivos não invasivos, como tomografia computadorizada (CT-Computed Tomography) e ressonância magnética (MRI-Magnetic Resonance Imaging), e a popularização de equipamentos tradicionais de captura de imagens, como câmeras digitais, têm ampliado significativamente o uso de ferramentas de simulação numérica para os mais variados fins.

Uma etapa fundamental para viabilizar o uso de métodos numéricos consiste na discretização do domínio. Tradicionalmente, esta discretização é obtida pela decomposição do domínio em elementos poligonais, formando malhas, como triângulos e quadriláteros, no espaço bidimensional; e tetraedros e hexaedros, no espaço tridimensional. Outras aplicações, como visualização científica e modelagem de ambientes virtuais, também fazem uso intensivo de malhas geométricas.

Embora diversos métodos de geração de malha tenham sido propostos para domínios definidos por primitivas geométricas, pouco tem sido feito no sentido de gerar uma decomposição diretamente a partir de imagens. Consequentemente, é bastante comum encontrarmos na literatura abordagens de geração de malhas voltadas para domínios definidos em imagem que utilizam duas etapas independentes: segmentação e geração da malha [Yue 2003, Berti 2004,Zhang et al. 2006, Boissonnat et al. 2009]. Devido a completa separação destes dois processos, encontramos os mesmos desafios tradicionais de cada etapa, ou seja, o problema de segmentação de imagens e geração de malhas a partir de contornos ou funções implícitas. No caso de imagens com textura, o problema de segmentação é maior.

Neste trabalho apresentamos uma nova abordagem para geração de malhas diretamente a partir de imagens, buscando atender os requisitos necessários para o uso em aplicações de simulação numérica. Utilizamos nesta abordagem as idéias propos- 
tas pelo algoritmo Imesh [Cuadros-Vargas et al. 2005], técnica que não realiza uma etapa de segmentação independente. O algoritmo Imesh foi proposto visando superar as dificuldades encontradas pelas abordagens baseadas em segmentação de imagem independente, conseguindo auxiliar a detecção de regiões de interesse com o processo de geração de malhas.

Entretanto, o algoritmo Imesh é capaz de gerar apenas malhas simpliciais, ou seja, triângulos e tetraedros. Esta limitação elimina a possibilidade do uso de métodos numéricos baseados em quadriláteros e hexaedros. O algoritmo Imesh, em sua versão original, não é capaz de identificar corretamente objetos com textura. Outra limitação do Imesh refere-se à utilização do refinamento baseado no algoritmo de Ruppert [Ruppert 1995], o qual não possui um controle eficiente de refinamento, além de utilizar apenas malhas simpliciais.

\subsection{Contribuições principais}

Considerando as características do algoritmo Imesh, uma das contribuições desta pesquisa é a adequação da etapa de construção da malha para abranger o processamento de imagens com textura. Outra contribuição consiste na substituição, na etapa de refinamento de qualidade, do refinamento baseado em Ruppert por uma técnica inovadora de remalhamento guiada por retalhos de Bézier.

Mais especificamente, a pesquisa descrita nesta tese contribui com a melhoria do algoritmo Imesh, ao sanar três de suas principais limitações: tratamento de imagens com texturas; controle do nível de refinamento da malha e suporte a outros tipos de elementos. Estas contribuições flexibilizam o processo de geração da malha, e ainda amplia o domínio de aplicações do algoritmo Imesh, a medida que são considerados domínios definidos por imagens com textura e permite o uso métodos numéricos para elementos não simpliciais.

Com as novas funcionalidades incorporadas durante este projeto de doutorado, a técnica Imesh se tornou uma das únicas a possibilitar a criação de malhas com qualidade que respeitam características dos objetos contidos em imagens com textura. $\mathrm{Na}$ verdade, não temos conhecimento de outro método capaz de produzir resultados semelhantes, ou seja, gerar malhas segmentadas de triângulos ou quadriláteros a partir de imagens com textura, evitando a detecção prévia de curvas de bordo ou binarização da imagem. 


\subsection{Publicações}

Listamos aqui as principais publicações oriundas deste trabalho, divididas em duas categorias: publicações diretamente oriundas da tese e as publicações relacionadas.

\section{Publicações oriundas da tese}

\section{Generating Segmented Meshes from Textured Color Images}

Lizier, M. A. S.; Martins Jr, D. C.; Cuadros Vargas, A. J.; César Jr, R. M.; Nonato, L. G.

Journal of Visual Communication and Image Representation, v.20, p. 190-203, 2009

\section{Generating Segmented Quality Meshes from Images}

Cuadros Vargas, A. J.; Lizier, M. A. S.; Minghim, R.; Nonato, L. G.

Journal of Mathematical Imaging and Vision, v. 33, p. 11-23, 2009

W-operator window design for color texture classification (resumo)

Martins Jr, D. C.; César Jr, R. M.; Barrera Jr; Lizier, M. A. S.; Nonato, L. G.

XIX Brazilian Symposium on Computer Graphics and Image Processing (SIBGRAPI) Manaus-AM, 2006

\section{Relacionadas}

Topological triangle characterization with application to object detection from images

Nonato, L. G.; Lizier, M. A. S.; Batista, J.; Oliveira, M. C. F.; Castelo Filho, A. Image and Vision Computing, v. 26, p. 1081-1093, 2008

\section{Comparing Techniques for Tetrahedral Mesh Generation}

Lizier, M. A. S.; Shepherd, J. F.; Nonato, L. G.; Comba, J. L. D.; Silva, C. T. Advances In Mesh Generation For Computational Mechanics, International Conference of the Engineering Mechanics Institute, Minneapolis-MN, 2008

Topological approach for detecting objects from images

Nonato, L. G.; Castelo Filho, A.; Oliveira, M. C. F.; Lizier, M. A. S.

Vision Geometry XII, Proceedings of SPIE, v. 5300. p. 62-73, San Jose-CA, 2004 
A Topological Approach for Detecting and Extracting 2D Object Models from Images

Lizier, M. A. S.; Nonato, L. G.; Castelo Filho, A.; Oliveira, M. C. F.

WICCGPI / XVI Brazilian Symposium on Computer Graphics and Image Processing (SIBGRAPI), p. 10-17, São Carlos-SP, 2003

\subsection{Visão geral da tese}

Este trabalho apresenta o desenvolvimento e os resultados obtidos da metodologia proposta para a geração de malhas com qualidade a partir de imagens. Organizamos a tese nos seguintes capítulos:

Capítulo 2: Neste capítulo apresentamos a revisão bibliográfica dos trabalhos relacionados a esta tese.

Capítulo 3: Apresentamos o algoritmo Imesh, assim como as contribuições realizadas.

Capítulo 4: Este capítulo apresenta a metodologia do remalhamento e melhoria de qualidade da malha.

Capítulo 5: Os resultados obtidos com as técnicas propostas neste trabalho são apresentados neste capítulo. Encontram-se também as discussões pertinentes aos resultados.

Capítulo 6: Este capítulo apresenta as conclusões, os comentários finais deste trabalho e as propostas de trabalhos futuros. 


\section{Revisão bibliográfica}

De modo geral, podemos dividir os métodos de geração de malhas a partir de imagem em duas categorias: modelagem de imagem e simulação numérica. Os métodos dedicados à modelagem visam a uma representação fiel e compacta da imagem original. Estes métodos são ideais para compressão de imagens. Já os métodos dedicados à simulação numérica visam representar estruturas internas da imagem, além de utilizar malhas restritas a um critério de qualidade.

Embora estes dois grupos de métodos possuam objetivos similares, os critérios definidos por cada domínio de aplicação alteram substancialmente as etapas empregadas por cada algoritmo. A maioria dos métodos voltados para modelagem de imagem utilizam alguma métrica de erro durante o processo automático de geração da malha [Yang et al. 2003], já a maioria dos métodos voltados para simulação numérica possuem uma custosa etapa de pré-processamento, que usualmente requer intervenções humanas durante o processo, visando a identificar os objetos contidos nas imagens [Cebral and Lohner 1999].

O algoritmo Imesh, utilizado neste trabalho, une características de ambos os grupos de métodos, sendo capaz de gerar malhas voltadas tanto para a modelagem de imagens, quanto para simulações. Diferentemente das abordagens descritas na literatura, o algoritmo Imesh assume como entrada uma imagem que não tenha sido préprocessada, procura gerar uma malha já segmentada e ainda considera critérios de qualidade nos elementos da malha.

Apresentamos a seguir, as diferentes abordagens encontradas na literatura para geração de malhas a partir de imagens (seção 2.1); alguns dos principais algoritmos de refinamento de malhas (seção 2.2); por fim, os métodos relacionados à geração de malhas de quadriláteros (seção 2.3). 


\subsection{Geração de malhas a partir de imagens}

Os métodos para geração de malhas podem ser divididos em dois grupos: as técnicas voltadas para modelagem de imagem e as técnicas utilizadas para geração de malhas a partir de imagens para simulação numérica.

As técnicas para modelagem de imagens possuem como objetivo central a geração de uma malha que minimize um erro de aproximação entre a imagem original e a imagem representada pela malha triangular. Os vértices são posicionados propositalmente visando minimizar o erro de interpolação definido. [García et al. 1999], por exemplo, apresenta um algoritmo que posiciona os vértices da malha na região de maior curvatura da imagem, controlando assim o maior valor do erro médio (RMS Root-mean-square). A malha então é gerada pela triangulação de Delaunay [Delaunay 1934, Fortune 1992] a partir do vértices definidos. As regiões que não estejam bem aproximadas, ou seja, com um alto valor de RMS, são reamostradas com novos vértices e a triangulação de Delaunay é então atualizada. Tal método proposto por Garcia é um típico exemplo de abordagem adaptativa, caracterizada por partir de uma malha inicial grossa e iterativamente refiná-la a fim de reduzir o erro de interpolação.

Diversos algoritmos que utilizam imagens representadas por malhas são baseados em abordagens adaptativas [Coleman and Scotney 2005, Garland and Heckbert 1995, Gevers and Smeulders 1997, Demaret et al. 2006, Sarkis and Diepold 2009]. Alternativamente, algumas técnicas adotam uma estratégia oposta, ou seja, partindo de uma malha fina e iterativamente simplificando-a até o erro de aproximação atingir uma determinada tolerância [Ciampalini et al. 1997]. Abordagens mistas também são encontradas na literatura, combinando refinamento e simplificação de malhas [Kocharoen et al. 2005] ou então reposicionando vértices a fim de minimizar erros locais [Terzopoulos and Vasilescu 1991]. Ainda dentre os algoritmos de modelagem de imagem, [Yang et al. 2003] propõe um método não iterativo para escolha e determinação do posicionamento de vértices no qual, posteriormente, a triangulação de Delaunay é construída. Embora estas técnicas reduzam o erro de aproximação entre a imagem e a representação por malha, a qualidade dos elementos da malha não é apropriada para aplicações numéricas.

As técnicas de modelagem de imagem para simulação numérica podem ser descritas basicamente em duas etapas principais: pré-processamento e geração da ma- 
lha. A etapa de pré-processamento consiste na aplicação de filtros, geralmente para remoção de ruídos, e segmentação da imagem para a detecção de regiões de interesse, que serão posteriormente discretizadas por sub-malhas. [Cebral and Lohner 2001] por exemplo, binariza a imagem original para a extração dos contornos, os quais definirão a malha gerada. O processo de binarização também é utilizado como etapa de pré-processamento por [Zhang et al. 2003, Zhang et al. 2006] e [Berti 2004]. Ambos algoritmos descritos nestes trabalhos partem da imagem binária que define uma função implícita e guia a estratégia de particionamento espacial, por meio de uma estrutura quad-tree, para então seguir o processo de geração da malha. Estes métodos também propõem uma etapa de pós-processamento para a melhoria da malha gerada. [Peiró et al. 2007] utiliza também uma abordagem baseada em função implícita para gerar uma malha que define os bordos de interesse. Como esta malha inicial é formada por elementos de qualidade baixa, uma etapa posterior é aplicada visando à melhoria dos elementos gerados.

No método proposto por [Ito et al. 2006], após a extração dos bordos da imagem, utiliza-se um algoritmo baseado em avanço de fronteira e reamostragem para garantir elementos de boa qualidade e modelos biomédicos realísticos. De modo semelhante, [Rizzi et al. 2007] possui como objetivo obter modelos para realidade virtual e simulações de contato. A etapa de pré-processamento utilizada por [Hale 2001] visa à redução de ruídos e destaque das características da imagem. Na geração da malha, Hale propõe o uso de uma função de energia potencial para o alinhamento de pontos nas características da imagem, e em seguida uma malha Delaunay é gerada a partir dos pontos alinhados. O principal problema da técnica de Hale reside no fato de que as regiões de interesse não são identificadas, impossibilitando a definição das condições de bordo nas aplicações que simulam fluidos multifásicos.

\subsection{Melhoria de malhas}

Em geral, os métodos de geração de malha requerem uma etapa de pós-processamento [Owen 1998] para garantir elementos de boa qualidade. As técnicas de suavização buscam a melhoria da malha por meio de processos iterativos para o reposicionamento dos vértices atuais. Dentre as abordagens mais utilizadas, estão a suavização Lapaciana [Field 1988, Canann et al. 1998], que reposiciona os vértices para a posição média em relação aos vértices vizinhos, e o uso de molas [Lohner et al. 1987, Shimada 
et al. 1997] para simulação de forças físicas responsáveis pelo movimento dos vértices. Transformações locais, como flipping e colapso de arestas, também são utilizadas para melhorar a qualidade da malha [Hoppe et al. 1993, Rivara 2001].

A maioria dos métodos de refinamento, durante o processo iterativo, visam também à melhoria da qualidade dos elementos da malha refinada. As abordagens propostas por [Ruppert 1995, Shewchuk 2002, Secchi 2003], baseadas em triangulações de Delaunay, estão dentre as técnicas mais utilizadas.

\subsection{Malhas quadrangulares}

Em comparação com as técnicas de geração de malhas triangulares, o número de métodos de geração de malhas quadrangulares é bastante inferior. Podemos dividir os métodos de geração de malha quadrangulares basicamente em duas categorias: métodos indiretos e diretos. Os métodos indiretos discretizam primeiro o domínio por malhas de triângulos, para em seguida, converter esta malha em uma malha de quadriláteros. Já os métodos diretos, buscam discretizar o domínio diretamente por meio de quadriláteros.

A técnica mais simples para converter uma malha de triângulos em quadriláteros consiste na subdivisão de cada triângulo em três quadriláteros, inserindo um vértice no interior do triângulo. O problema deste método está na baixa qualidade dos quadriláteros formados [Owen 1998]. [Lo 1989, Lee and Lo 1994] apresentam métodos baseados no agrupamento de dois triângulos vizinhos, formando assim a malha de quadriláteros. Os métodos propostos por [Owen et al. 1999, Lee 2003] também utilizam uma abordagem de agrupamento de triângulos, porém com uma técnica de avanço de fronteira. [Petersen 2000,Su 2004] baseiam-se em um grid regular para triangular a região de fronteira, para em seguida gerar a malha retangular. De modo geral, a principal vantagem dos métodos indiretos estão no desempenho computacional.

Com relação aos métodos diretos, [Baehmann et al. 1987] utiliza uma abordagem baseada na divisão espacial quad-tree [Finkel and Bentley 1974], onde após ajustar os bordos dos nós folhas, gera a malha por meio de um algoritmo de avanço de fronteira. Também utilizando avanço de fronteira, [Park et al. 2007] busca respeitar restrições definidas por arestas na malha de quadriláteros gerada. Por meio de subdivisão do 
domínio, para regiões de menor complexidade, [Talbert and Parkinson 1990, Chae and Jeong 1997, Nowottny 1997] utilizam templates para a discretização de regiões conhecidas. As técnicas diretas são capazes de gerar elementos de qualidade superior, porém ainda são limitadas a domínios não muito complicados.

Até o momento, não temos conhecimento de técnicas de geração de malhas quadrangulares especialmente voltadas a domínios definidos por imagens, característica encontrada na metodologia apresentada neste trabalho. 


\section{Algoritmo Imesh}

Diferentemente do que ocorreu com o problema clássico de geração de malha [Bern and Eppstein 1992], no qual importantes avanços teóricos e práticos foram obtidos, pouco tem sido feito no sentido de automatizar o processo de geração de malhas a partir das imagens, uma vez que a abordagem convencional é baseada em uma extensiva etapa de pré-processamento. De fato, a abordagem típica consiste na segmentação das regiões de interesse nas imagens, utilizando os bordos destas regiões como entrada para o gerador de malhas [Cebral and Lohner 1999]. Embora largamente utilizada, esta abordagem demanda a intervenção do usuário e o emprego de programas específicos de segmentação para a obtenção dos modelos desejados.

Recentemente, algumas técnicas que atuam diretamente em imagens têm sido apresentadas [Hale 2001] [Yang et al. 2003] [Demaret et al. 2006] [Sarkis and Diepold 2009], porém estas técnicas não são capazes de distinguir diferentes estruturas na imagem, nem garantir malhas de boa qualidade. A identificação de diferentes estruturas nas imagens é essencial em aplicações como iterações de múltiplos fluídos [Sousa et al. 2004] e fluido-estrutura [Čanića et al. 2005], visto que estas aplicações levam em consideração a interface entre regiões para definir a força interfacial.

Adicionalmente, malhas de boa qualidade são primordiais para a eficácia de métodos numéricos voltados para a solução de equações diferenciais. Portanto, geradores de malhas que atuam diretamente em imagens devem assegurar, além de propriedades usuais como robustez e qualidade de malha, a correta segmentação de estruturas de interesse, adicionando assim um desafio a mais no já complexo problema de malhamento.

Neste capítulo apresentamos uma descrição do algoritmo Imesh. Este algoritmo é capaz de gerar automaticamente uma malha a partir de uma imagem de entrada, proporcionando ainda a identificação de estruturas da imagem. Regiões da imagem são identificadas incorporando-se estratégias de segmentação no processo de geração de 
malha. De fato, esta segmentação guia uma etapa inicial de refinamento que ajusta os vértices da malha às características da imagem. Os desenvolvimentos descritos neste capítulo também podem ser encontrados nos artigos [Cuadros-Vargas et al. 2009] [Lizier et al. 2009].

O restante deste capítulo está organizado da seguinte forma: na seção 3.1 apresentamos conceitos iniciais para o entendimento do algoritmo Imesh. Na seção 3.2 fornecemos uma breve descrição do algoritmo Imesh. E na seção 3.3 descrevemos a integração do classificador W-operador com o algoritmo Imesh.

\subsection{Conceitos básicos}

Nesta seção apresentamos apenas os conceitos básicos e a notação empregada para o entendimento das seções seguintes deste capítulo.

Seja $A=\left\{x_{1}, \ldots, x_{k}\right\}$ um conjunto de pontos em posição geral em $\mathbb{R}^{n}$, ou seja, não existe nenhum subespaço afim de $\mathbb{R}^{n}$ contendo $A$ ou um subconjunto de $A$ com mais do que $n+1$ pontos co-esféricos.

O diagrama de Voronoi de $A$ é a decomposição de $\mathbb{R}^{n}$ em células convexas (de dimensão $n) V_{1}, \ldots, V_{k}$ que possui as seguintes propriedades:

1. Cada $V_{i}$ contém somente um ponto $x_{i}$ de $A$;

2. Dado $x \in \mathbb{R}^{n}, x \in V_{i}$, se e somente se, $d\left(x, x_{i}\right) \leq d\left(x, x_{j}\right)$, para todo $i \neq j$, onde $d$ é a distância euclidiana.

A triangulação de Delaunay [Delaunay 1934] pode ser obtida a partir do diagrama de Voronoi associando-se cada célula $p$-dimensional do diagrama um $(n-p)$-simplexo. Esta relação entre a triangulação de Delaunay e o diagrama de Voronoi, chamada dualidade, é explorada por diversos algoritmos de reconstrução [Boissonnat 1988] [Bajaj et al. 1996] [Geiger 1993].

Devido à dualidade e à hipótese de posição geral, temos que cada célula 0-dimensional do diagrama é o centro de uma esfera vazia de pontos (esfera de Delaunay) que circunscreve um $n$-simplexo. A figura 3.1 ilustra o diagrama de Voronoi e a triangulação de Delaunay sobre o mesmo conjunto de pontos. Mais detalhes da triangulação de 
Delaunay e do diagrama de Voronoi podem ser encontrados em [Fortune 1992] [Aurenhammer 1991].

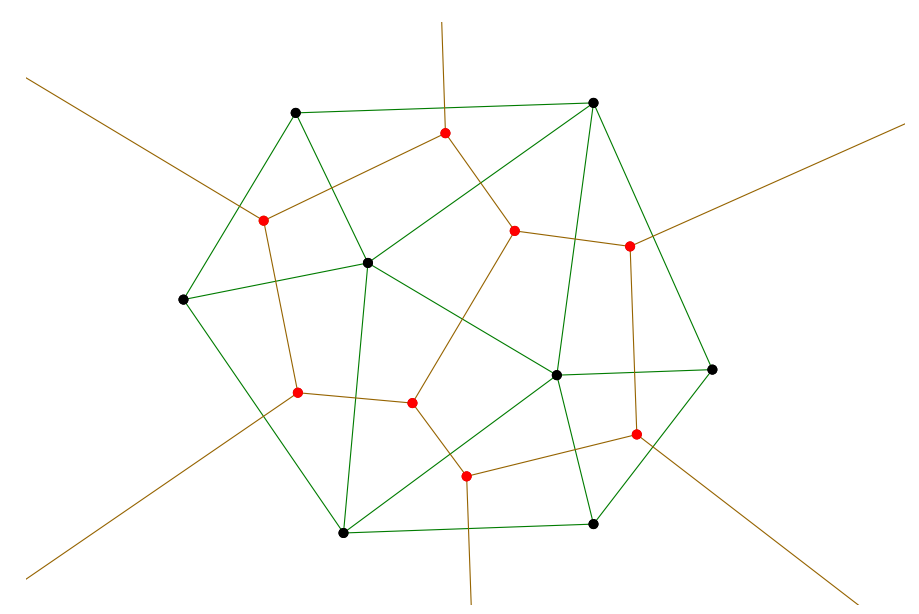

Figura 3.1: Diagrama de Voronoi e triangulação de Delaunay sobre o mesmo conjunto de pontos (pontos pretos).

A triangulação de Delaunay é um exemplo particular do que denominamos triangulação, a qual definimos de forma mais geral como um complexo simplicial regularizado. Dizemos que um complexo simplicial é regularizado quando todo simplexo de dimensão $d<n$ está contido em um simplexo de dimensão $n$.

Uma malha bidimensional com boa qualidade é uma triangulação onde todos os triângulos satisfazem uma medida de qualidade. Discutiremos mais adiante critérios que definem precisamente medidas de qualidade.

Um grafo planar é um grafo $G$ com vértices em $\mathbb{R}^{2}$ onde cada aresta é um segmento de reta com terminações em vértices de $G$ e se $e_{1}$ e $e_{2}$ são duas arestas de $G, e_{1} \cap e_{2}$ ou é vazia ou é um vértice de $G$. Dado um grafo planar $G$, uma malha restrita por $G$ é uma triangulação $M$ onde cada vértice de $G$ está em $M$ e se $e$ é uma aresta de $G$ então $|e|=\left|e_{1} \cup e_{2} \cup \ldots \cup e_{r}\right|$, onde $e_{i} \in M, i=1, \ldots, r$ são arestas de $M$ e $|\cdot|$ representa o espaço gerado, isto é, cada aresta de $G$ pode aparecer subdividida como um conjunto de arestas em $M$.

Seja $S$ um conjunto de pontos e $M$ uma malha (triangulação) de $S$, se $M=M_{1} \cup M_{2} \cup$ $\ldots \cup M_{r}$, onde cada $M_{i}$ é uma triangulação e $M_{i} \cap M_{j}, i \neq j$ é vazia ou é um grafo planar então $\left\{M_{1}, M_{2}, \ldots, M_{r}\right\}$ é dito uma $r$-partição de $M$ em sub-malhas $M_{i}, i=1, \ldots, r$.

Uma imagem $m \times n$ é uma função $I:[0, \ldots, m] \times[0, \ldots, n] \rightarrow \mathbb{R}^{+q}$ que indica para cada ponto $p \in[0, \ldots, m] \times[0, \ldots, n] \subset \mathbb{Z}^{2} q$ escalares não negativos $I(p)$. O par $(p, I(p))$ é chamado pixel. Para imagens em tom de cinza $q=1$; em imagens $\operatorname{RGB} q=3$. 


\subsection{Imesh}

O principal objetivo do algoritmo Imesh é a geração, a partir da imagem fornecida, de uma malha que represente os objetos de interesse contido nesta imagem. Para isso, além da imagem de entrada, é necessário definir uma função que oriente sobre o que são os objetos de interesse.

O algoritmo Imesh é dividido em três etapas principais: geração da malha, particionamento da malha e melhoria da malha. A primeira etapa consiste na geração da malha inicial, ajustando-a às características da imagem. O particionamento é a etapa encarregada de segmentar a malha. A etapa final, melhoria da malha, refina a malha obtida na etapa anterior para garantir a qualidade dos elementos.

Descrições detalhadas da etapa de geração de malha (seção 3.2.1) e da etapa de particionamento da malha (seção 3.2.2), referentes ao algoritmo Imesh, são apresentadas a seguir. A etapa final, remalhamento, será detalhada no próximo capítulo.

\subsubsection{Geração da malha}

O processo de geração de malha inicia-se com uma triangulação de Delaunay $M$ construída a partir de pontos posicionados sobre as fronteiras da imagem $I$ de entrada. Os cantos superiores e inferiores da imagem precisam estar contidos em $M$ para que a malha e a imagem possuam o mesmo domínio.

Como desejamos uma malha adapada às características da imagem, é necessário definir uma métrica que indique o grau de representatividade da malha com relação às características de interesse da imagem.

Mais especificamente, seja $T$ o conjunto de triângulos da malha Delaunay $M$, cujos vértices são pontos da imagem $I$ e $E: T \rightarrow \mathbb{R}^{+}$uma função que associa uma medida de erro para cada triangulo em $T$.

Diferentemente de outras estratégias descritas na literatura, onde geralmente o cálculo de $E$ envolve uma varredura de todos os pixels no interior de cada triângulo de $T$, o Imesh define $E$ percorrendo apenas as três medianas de cada triângulo em $T$. 
Mais especificamente, seja $h_{1}, h_{2}$ e $h_{3}$ as três medianas de um dado triângulo $\sigma \in T$. Considerando o conjuntos de pontos $P^{h_{j}}=\left\{p \in h_{j} \mid \mathscr{E}(p) \geq e_{\mathscr{E}}\right\}$, onde $\mathscr{E}$ é uma medida de erro local e $c_{\mathscr{E}}$ é um escalar definido pelo usuário. Desta maneira, $P_{j}^{h}$ é o conjunto dos pontos (pixels) sob a mediana $h_{j}$ cujos erros locais $\mathscr{E}$ são maiores que o aceitável $\left(c_{\mathscr{E}}\right)$.

Convém destacar a flexibilidade proporcionada por considerar um erro local $\mathscr{E}$. Em [Cuadros-Vargas et al. 2009], duas medidas de erro local são definidas:

1. $\mathscr{E}$ como erro de interpolação linear: o valor de cada pixel é estimado a partir da interpolação linear obtida a partir dos vértices do triângulo que contém o pixel;

2. $\mathscr{E}$ como detecção de bordas: filtros de detecção de altas frequências, como por exemplo, Sobel Prewitt, Roberts ou Canny [Zuniga and Haralick 1987, Jain 1989].

Neste trabalho redefinimos a função $\mathscr{E}$ de modo a manipularmos imagens com textura, como será detalhado mais adiante na seção 3.3.

Denotamos como $d_{M}(p)$ a distância Euclidiana ao quadrado do ponto $p$ para o vértice mais próximo contido em $M$, ou seja, $d_{M}(p)=\min _{v \in M}\left\{d^{2}(p, v)\right\}$, onde $d(\cdot, \cdot)$ é a distância Euclidiana e $v$ é um vértice de $M$. É definido também $p_{n}$ como o ponto que maximiza $d_{M}(p)$ para todos os $p \in P^{h_{j}}, j=1,2,3$.

A partir destas definições, a função de erro $E$ é definida como:

$$
E(\sigma)= \begin{cases}\left\{\mathscr{E}\left(p_{n}\right)\right\} & \text { se } P^{h_{j}} \neq \emptyset \text { para todo } j=1,2,3 \\ 0 & \text { caso contrário }\end{cases}
$$

Se a medida de erro $E(\sigma)>0$, o pixel mais distante $\left(p_{n}\right)$ dos vértices existentes é inserido na triangulação (Figura 3.2).

O processo acima é repetido até que $E(\sigma)=0$ para todos os triângulos de $M$ ou então quando $d_{M}\left(p_{n}\right)$ é menor que uma constante $\left(d_{\mathscr{E}}\right)$ em todos os triângulos que precisam ser refinados. Ambos os parâmetros $c_{\mathscr{E}}$ e $d_{\mathscr{E}}$ afetam a densidade de triângulos. A figura 3.3 ilustra este comportamento. Na figura 3.3(a) e (b) o parâmetro $c_{\mathscr{E}}$ é definido com um valor pequeno e grande respectivamente e $d_{\mathscr{E}}$ é fixado de maneira que o refinamento termine devido $c_{\mathscr{E}}$. Note que na figura 3.3(a), devido ao ruído, o fundo 


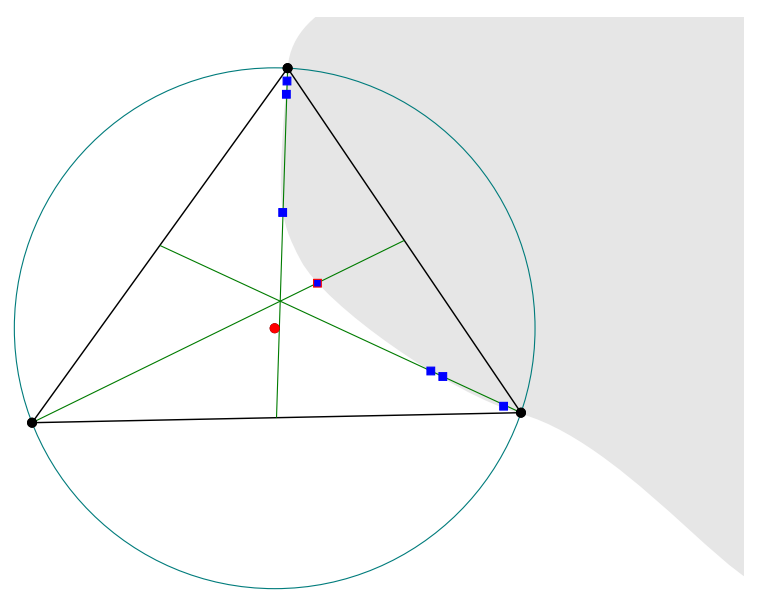

Figura 3.2: Escolha do novo vértice.

também é refinado. Na figura 3.3(c) e (d) o parâmetro $c_{\mathscr{E}}$ é fixado perto de zero e $d_{\mathscr{E}}$ recebe um valor pequeno e grande respectivamente, então o refinamento é parado pelo $d_{\mathscr{E}}$.

A partir da figura 3.3 podemos ver que valores menores para $c_{\mathscr{E}}$ e $d_{\mathscr{E}}$ tendem a gerar malhas densas enquanto que malhas mais grossas são geradas com valores maiores.

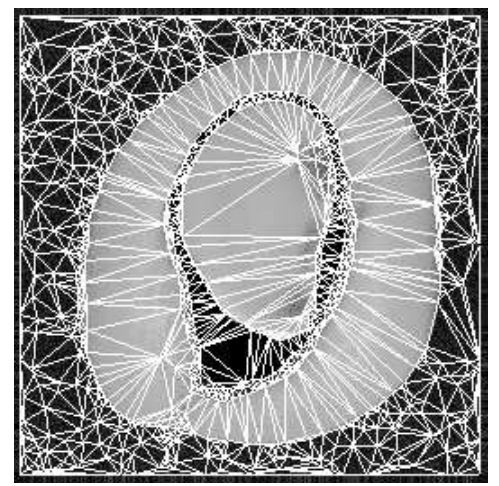

(a)

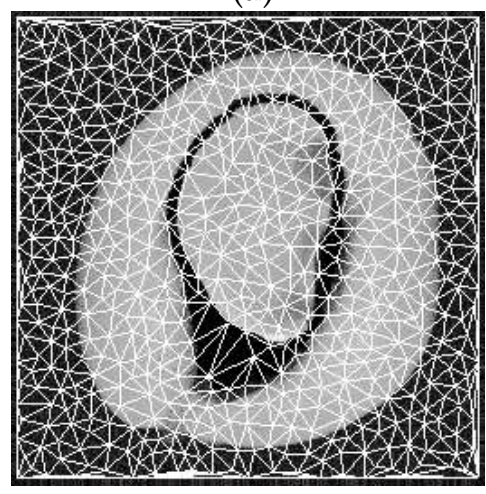

(c)

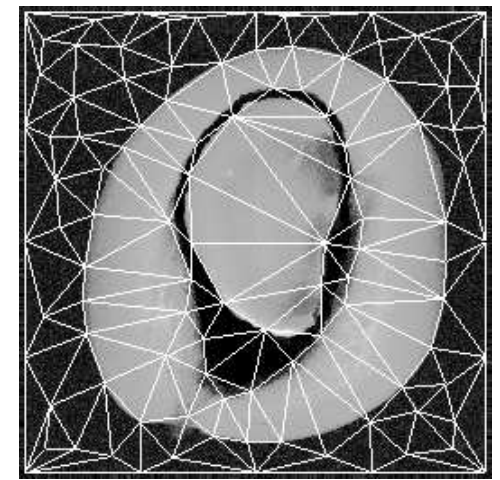

(b)

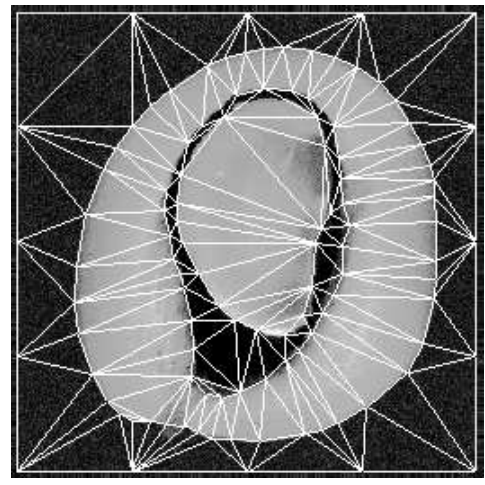

(d)

Figura 3.3: Controle de densidade dos triângulos [Cuadros-Vargas et al. 2005].

Esta abordagem adaptativa apresenta algumas propriedades desejáveis não encon- 
tradas nos esquemas tradicionais: a inserção de novos pontos distantes de vértices já existentes evita o acúmulo de pontos em regiões específicas da imagem. Além disso, esta estratégia tende a gerar triângulos com uma melhor qualidade, melhorando a imagem interpolada (mais detalhes sobre o modo pelo qual a qualidade dos triângulos afeta a imagem interpolada podem ser encontrados em [Yang et al. 2003]).

\subsubsection{Particionamento da malha}

A segunda etapa do algoritmo Imesh consiste no particionamento da malha. O objetivo desta etapa é rotular cada triângulo da malha de acordo com regiões de interesse. Visto que o processo de geração da malha acima evita introduzir arestas que cruzem o bordo entre duas ou mais regiões distintas da imagem, principalmente quando a medida de erro local é baseada em filtros de detecção de bordas, torna-se viável a segmentação da malha gerada na primeira etapa em sub-malhas, onde cada sub-malha representa a triangulação de uma região de interesse.

No algoritmo Imesh original [Cuadros-Vargas 2006,Cuadros-Vargas et al. 2009] esta etapa recebe bastante atenção devido aos critérios de erros utilizados. Por exemplo, no caso de uma medida baseada em filtros de detecção de bordas, a rotulação dos elementos da malha, classificando-os como pertencentes a uma determinada região de interesse, não é imediata.

Para o algoritmo porposto neste trabalho, utilizamos como medida de erro o resultado do classificador de textura [Lizier et al. 2009]. Esta abordagem nos fornece diretamente a informação necessária para rotularmos cada elemento da malha, não necessitando assim de um processamento específico para realizar o particionamento. Na subseção 3.3.2 apresentamos detalhes desta etapa.

Embora o processo acima seja capaz de gerar uma malha segmentada que respeita as características da imagem, a qualidade dos triângulos gerados é muito ruim. Como melhorar a qualidade da triangulação será o tema do próximo capítulo. 


\subsection{Texturas}

Nesta seção apresentamos como a função de erro pode ser modificada a fim de tratar imagens com textura. A função de erro local é modificada de modo a combinar a metodologia de W-operador, proposto por [Martins-Jr et al. 2006], com o algoritmo Imesh. Este trabalho pode ser visto também em [Lizier et al. 2009].

Antes de iniciarmos a integração dos dois algoritmos, veremos a seguir uma breve explicação sobre os W-operadores.

\subsubsection{W-operador}

Um W-operador é uma transformação de imagem que é localmente definida sobre um janela $(W)$ e invariante por translação [Dougherty and Barrera 2002]. Isto significa que o W-operador depende apenas das características da imagem de entrada vistas através da janela $W$ e que a mesma regra de transformação é aplicada a todos os pixels da imagem. Em [Martins-Jr et al. 2006] é introduzida uma técnica baseada nos conceitos da teoria da informação para estimar um W-operador capaz de realizar filtragem de ruídos, e análise de tons de cinza, visando o reconhecimento de texturas. Utilizamos neste projeto uma nova versão de W-operador capaz de classificar texturas em imagens coloridas.

A concepção de W-operadores depende de um conjunto de imagens para treinamento. Estas imagem precisam ter associada a informação da classe de textura a que cada uma pertence. A partir de cada imagem de treinamento, é extraída uma amostragem feita através de uma janela de tamanho $W$. O rótulo da imagem de treinamento é associado a cada amostra extraída. Cada amostra é então replicada, utilizando-se as suas rotações como réplicas. Esta estratégia é importante para, além de ampliar o conjunto de treinamento, tornar o reconhecimento de textura invariante a rotações, característica útil em diversas aplicações. Posteriormente a esta etapa, cada amostra é transformada em um vetor, colocando sequencialmente cada canal de cor. Finalmente, cada vetor é então quantizado em k níveis, ou seja, cada escalar é quantizado em 256 níveis. Para isto, o espaço de intensidade é subdividido em 256 intervalos iguais. Este processo é ilustrado na figura 3.4.

A partir da extração de todas as amostras de treinamento, a próxima etapa consiste 


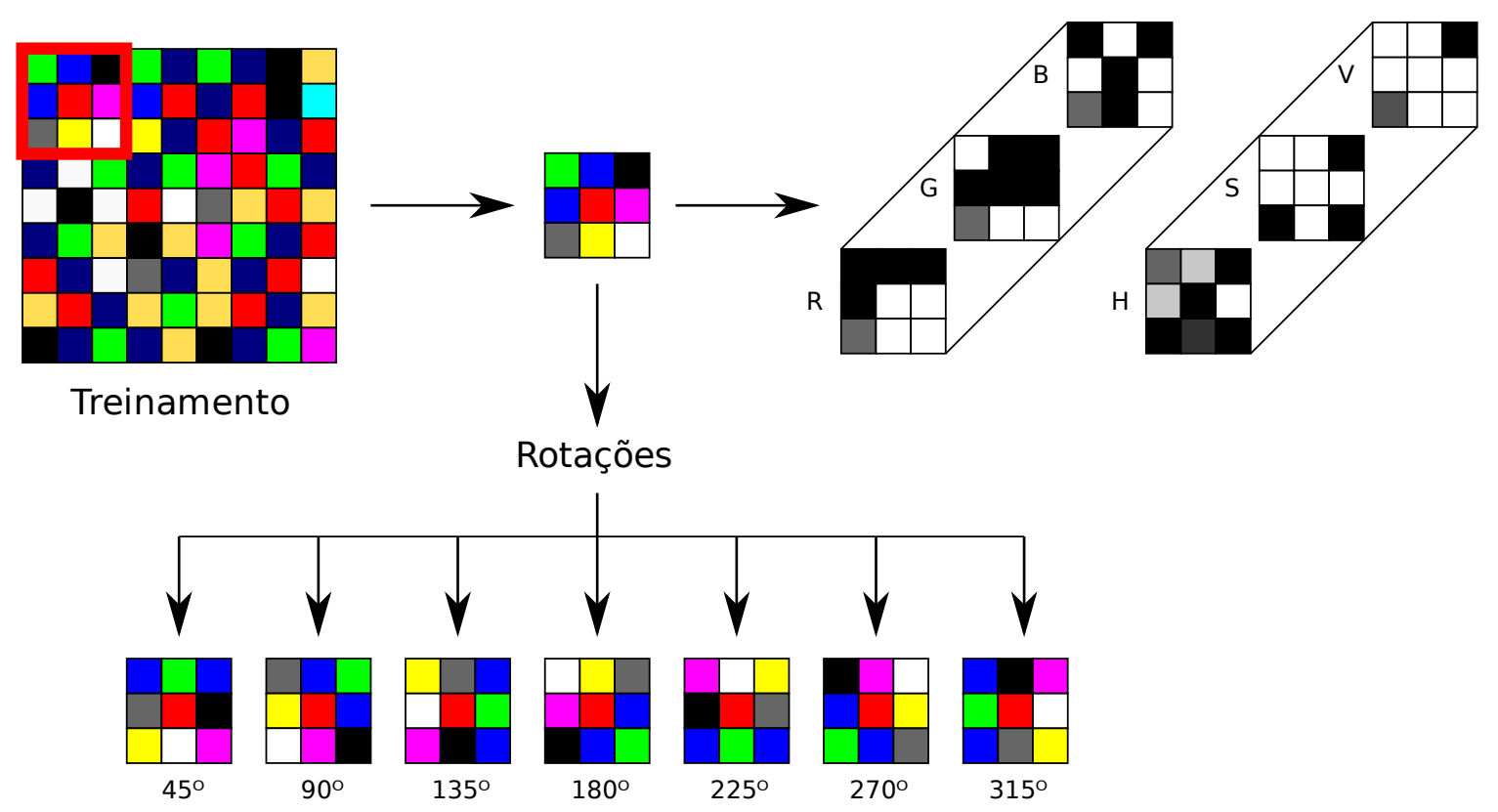

Figura 3.4: Geração e replicação das amostras de treinamento [Lizier et al. 2009].

na seleção de um subconjunto representativo para cada classe de textura (extração de características). Esta operação consiste na definição das sub-janelas, como ilustrado na figura 3.5. Para obter estas sub-janelas, é utilizado o algoritmo Sequential Floating Forward Search [Pudil et al. 1994] guiado pelo critério de entropia condicional média. Maiores detalhes podem ser consultados em [Martins-Jr et al. 2006].

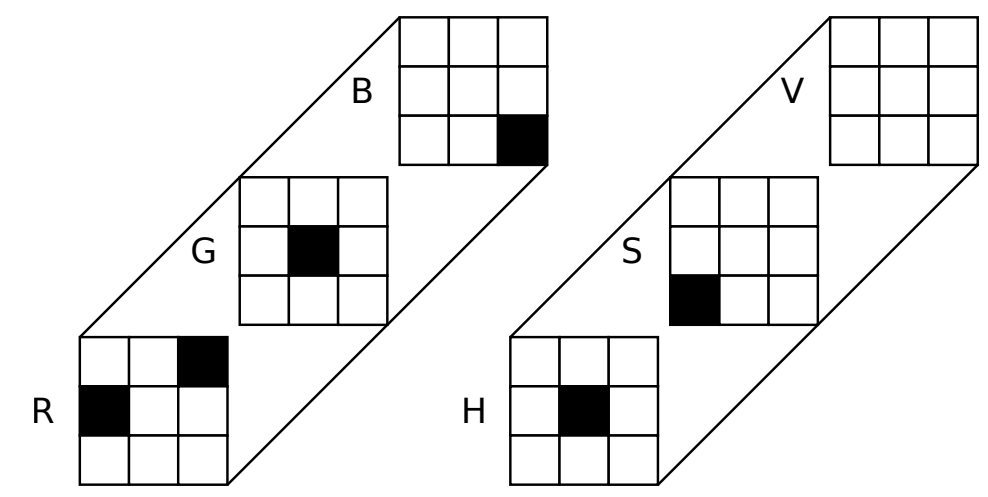

Figura 3.5: Um exemplo de sub-janela para a definição do W-operador. A sub-janela é composta pelas posições escuras [Lizier et al. 2009].

A saída do classificador W-operador que é utilizada no Imesh é a matriz de probabilidade da amostra $(i, j)$ pertencer a uma dada classe de textura, correspondendo ao padrão observado na região do pixel $(i, j)$ da imagem. 


\subsubsection{W-operador + Imesh}

A medida de erro local $\mathscr{E}$ utilizada na função $E$ é o mecanismo que nos permite explorar os W-operadores no algoritmo Imesh.

Seja $p$ um pixel sob a mediana $h_{j}$ do triângulo $\sigma, y(p)$ o rótulo associado a $p$ (fornecido pelo W-operador), e $D y(p)$ a "derivada"direcional em $p$ de $y(p)$ pela direção de $h_{j}$. Seja $\alpha_{i}, i=1,2,3$ as coordenadas baricêntricas de $p$ com relação a $\sigma$ e $A(p)=\min _{i}\left\{\alpha_{i}\right\}, i=$ $1,2,3$, a função que associa $p$ a menor coordenada baricêntrica. O erro local $\mathscr{E}$ é definido como segue:

$$
\mathscr{E}(p)= \begin{cases}0 & \text { se } D y(p)=0 \\ A(p) & \text { se } D y(p) \neq 0\end{cases}
$$

O erro local definido pela equação 3.1 atribui a cada ponto, cujo rótulo muda na direção da mediana, sua menor coordenada baricêntrica. A coordenada baricêntrica de um um ponto $p$ está relacionada a área do triângulo formado por $p$ e os vértices de $\sigma$ (Figura 3.6). Como $p$ é a transição entre regiões diferentes da imagem, a função $\mathscr{E}$ pode ser vista como uma medida de quão bem apropriado é um triângulo com relação a uma imagem de entrada.

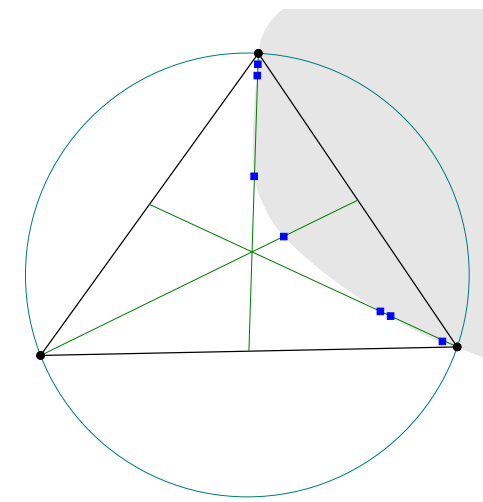

(a) Pontos de bordo na mediana

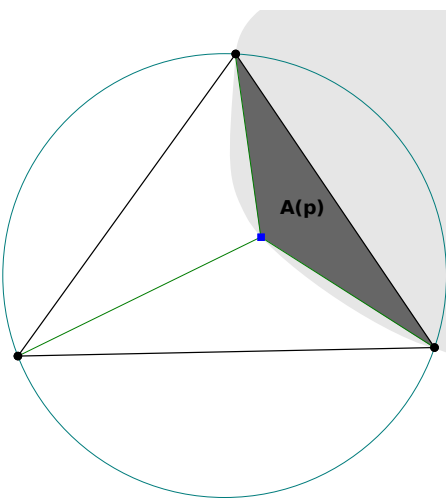

(a) Interpretação geométrica da função $\mathscr{E}$

Figura 3.6: Medida de erro em um triângulo.

De fato, um baixo valor de $A(p)$ indica que $h_{j}$ intersecta uma aresta da imagem perto do bordo do triângulo. Assim, valores de $E(\sigma)$ perto de zero indica que o triângulo $\sigma$ é uma boa aproximação da região da imagem. 
Logo, um triângulo $\sigma$ é considerado uma aproximação ruim se $E(\sigma)>c_{E}$, onde $0 \leq c_{E} \leq 1$ é um escalar definido pelo usuário.

Triângulos que não são boas aproximações são eliminados pela inserção, na triangulação de Delaunay, do ponto $p$, considerando que $E(\sigma)=A(p)$. Uma vez que $p$ é um ponto escolhido para ser o mais longe possível dos vértices de $M$, o problema do acúmulo de pontos ao redor de vértices existentes ainda é garantido.

A figura 3.7b) ilustra a malha gerada a partir da imagem da figura 3.7a). Observem que os triângulos tendem a estar contidos na mesma região da imagem e não entre mais de uma região.

Esta característica é explorada durante a segunda etapa do algoritmo Imesh, na partição da malha, conforme descrito a seguir.

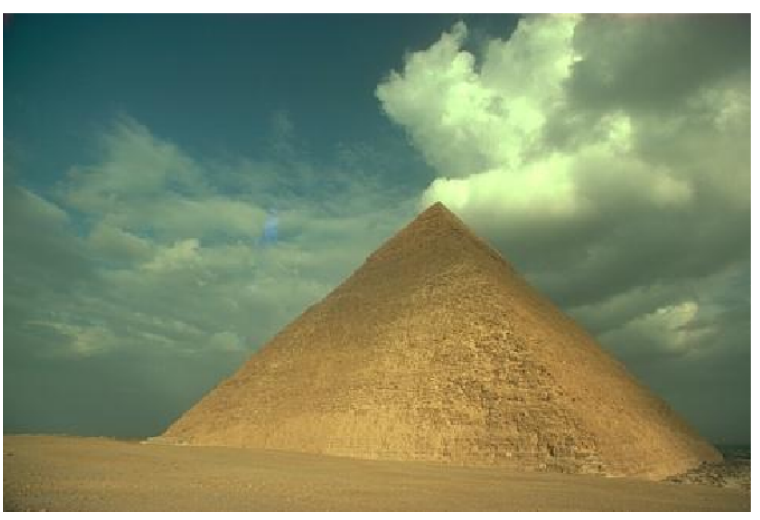

(a) Imagem original

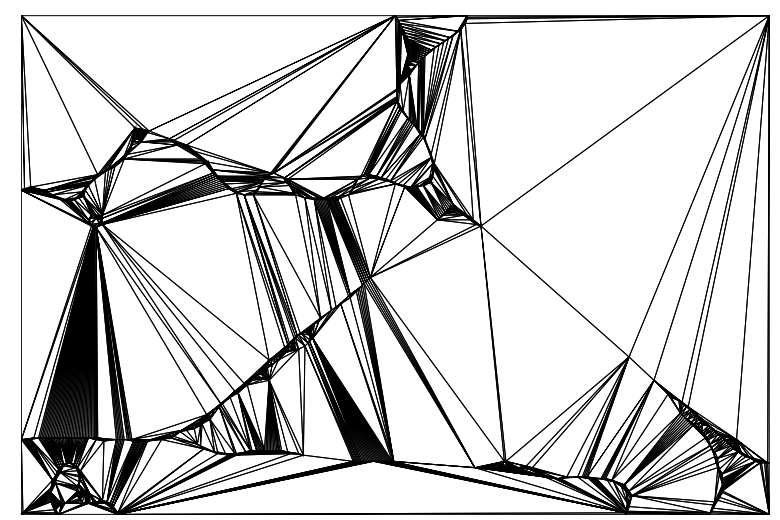

(b)Malha gerada pelo Imesh

Figura 3.7: Exemplo da pirâmide, extraído do Berkeley Segmentation Dataset.

Diferentemente de utilizar uma abordagem baseada no algoritmo $k$-means [CuadrosVargas et al. 2009], podemos aproveitar o uso do W-operador para rotular a classe de textura em cada triângulo da malha durante a fase de geração da malha, unificando assim as duas primeiras etapas do algoritmo Imesh original. Ao percorrer cada mediana o W-operador nos fornece, além da informação de detecção de borda, a classe a qual cada pixel pertence. Desta forma, durante o processo de geração de malha, armazenamos a classe predominante em cada triângulo. Ao final do processo de geração da malha, a maioria (senão todos) os triângulos possuem associado uma classe de textura com uma precisão maior que $90 \%$ (de acordo com o W-operador). Assim, a malha é diretamente segmentada, o que não é possível obter com outros métodos de geração de malhas a partir de imagens.

A figura 3.8 ilustra 4 passos do processo de geração de malhas com os triângulos 
rotulados em cada iteração, onde os triângulos em branco não alcançaram um número maior que $90 \%$ de rótulos iguais durante o percorrimento das medianas. Ao longo do processo iterativo, a porcentagem de rótulos semelhantes no interior dos triângulos aumenta, eliminando os triângulos brancos, como na figura 3.8d, onde temos como resultado a malha segmentada.

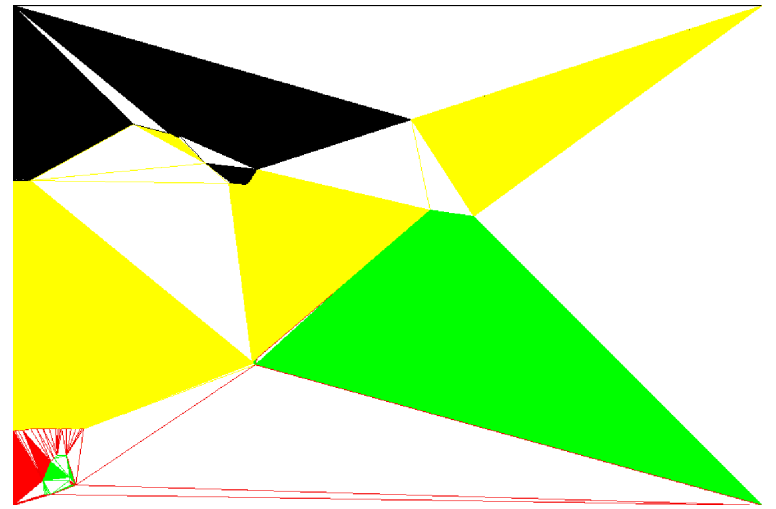

(a)

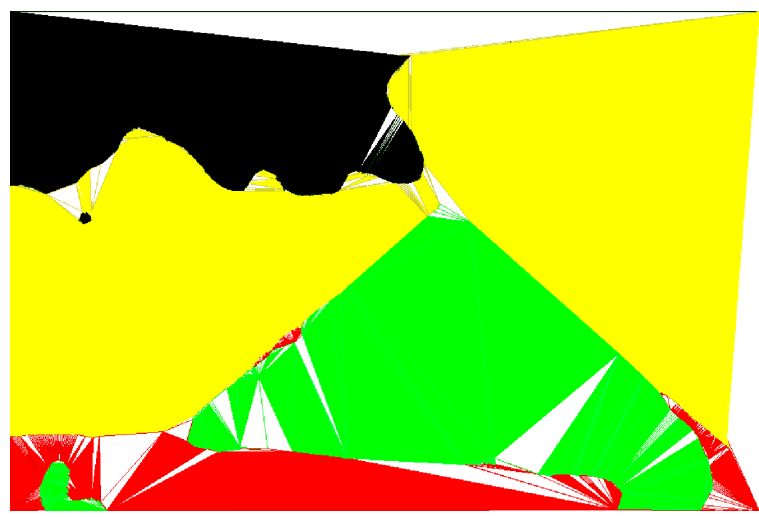

(c)

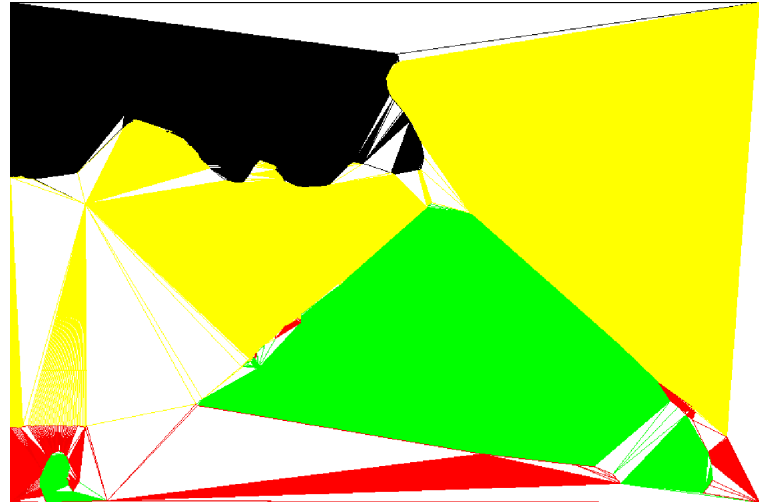

(b)

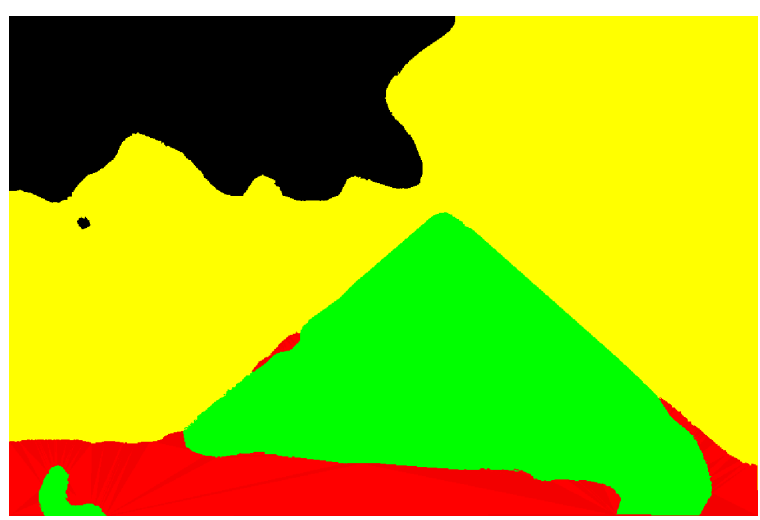

(d)

Figura 3.8: Quatro passos do processo de geração da malha com a rotulação de triângulos. Os triângulos em branco possuem menos de 90\% de rótulos iguais.

Em suma, este capítulo apresentou a integração do algoritmo Imesh com o classificador de texturas W-operador. Os resultados desta integração encontram-se no capítulo 5, assim como a determinação dos parâmetros exigidos. No próximo capítulo, apresentamos em detalhes a técnica de remalhamento, etapa final da técnica Imesh. 


\section{Remalhamento}

Neste capítulo apresentamos uma nova abordagem para a etapa de remalhamento no algoritmo Imesh. Em sua versão original, o algoritmo Imesh utiliza uma abordagem baseada no algoritmo de Ruppert [Ruppert 1995] [Shewchuk 2002] [Cuadros-Vargas 2006] para garantir qualidade para a malha final gerada. Esta abordagem é limitada ao uso de triângulos e não permite um controle do grau de refinamento desejado em cada região. O processo de remalhamento aqui proposto é baseado em modelos prédefinidos (templates), o que introduz maior flexibilidade com relação ao refinamento de regiões e permite a geração de malhas quadrangulares, assim como malhas mistas. A abordagem proposta preserva o particionamento da malha, característica importante no contexto da técnica Imesh.

Antes de iniciarmos a descrição do algoritmo proposto, introduzimos alguns conceitos básicos necessários para melhor compreensão da metodologia proposta.

\subsection{Conceitos básicos}

Uma curva de Bézier é uma parametrização construída a partir de um conjunto de pontos $P_{i} \in \mathbb{R}^{m}, 0 \leq i \leq n$, chamados de pontos de controle, os quais são ponderados por funções polinomiais. Em termos mais matemáticos podemos escrever:

$$
X(t)=\sum_{i=0}^{n} B_{i}(t) P_{i} \quad t \in[0,1]
$$

onde

$$
B_{n, i}(u)=\left(\begin{array}{c}
n \\
i
\end{array}\right) u^{i}(1-u)^{n-i}
$$


sendo

$$
\left(\begin{array}{l}
n \\
i
\end{array}\right)=\frac{n !}{i !(n-i) !}
$$

Os polinômios $B_{i}(t)$ são chamados de polinômios de Bernstein.

Uma superfície ou retalho de Bézier pode ser definida utilizando polinômios de Bernstein independentemente de cada um dos parâmetros que regem a superfície. Mais precisamente, seja $P_{i_{0}, i_{1}}$ um conjunto de pontos de controle, onde $0 \leq i_{0} \leq n_{0}$ e $0 \leq i_{1} \leq n_{1}$. Um retalho de Bézier retangular definido pelos pontos $P_{i_{0}, i_{1}}$ pode ser escrito como:

$$
X(r, s)=\sum_{i_{0}=0}^{n_{0}} \sum_{i_{1}=0}^{n_{1}} B_{n_{0}, i_{0}}(r) B_{n_{1}, i_{1}}(s) P_{i_{0}, i_{1}} \quad(r, s) \in[0,1]^{2}
$$

O domínio $[0,1]^{2}$ é um retângulo no plano $r s$. A figura 4.1a ilustra uma superfície de Bézier retangular de grau 3, isto é, polinômios de Bernstein utilizados possuem grau 3.

Seja $P_{i_{0}, i_{1}, i_{2}}$ um conjunto de pontos de controle, onde $0 \leq i_{0} \leq n_{0}, 0 \leq i_{1} \leq n_{1}$ e $0 \leq i_{\leq} n_{2}$, o retalho de Bézier triangular do conjunto $P_{i_{0}, i_{1}, i_{2}}$ é definido como segue:

$$
X(r, s, t)=\sum_{|I|=n} B_{n, I}(r, s, t) P_{I}
$$

sendo $I=\left(i_{0}, i_{1}, i_{2}\right),|I|=i_{0}+i_{1}+i_{2}, r \geq 0, s \geq 0, t \geq 0$ e $r+s+t=1$, onde

$$
B_{n, I}(r, s, t)=\left(\begin{array}{c}
n \\
i_{0}, i_{1}, i_{2}
\end{array}\right) r^{i_{0}} s^{i_{1}} t^{i_{2}}=\frac{n !}{i_{0} ! i_{1} ! i_{2} !} r^{i_{0}} s^{i_{1}} t^{i_{2}}
$$

Embora utilizamos três variáveis, temos um espaço bidimensional, visto que $t=$ $1-r-s$. A figura 4.1b ilustra uma superfície de Bézier triangular de grau 3. 


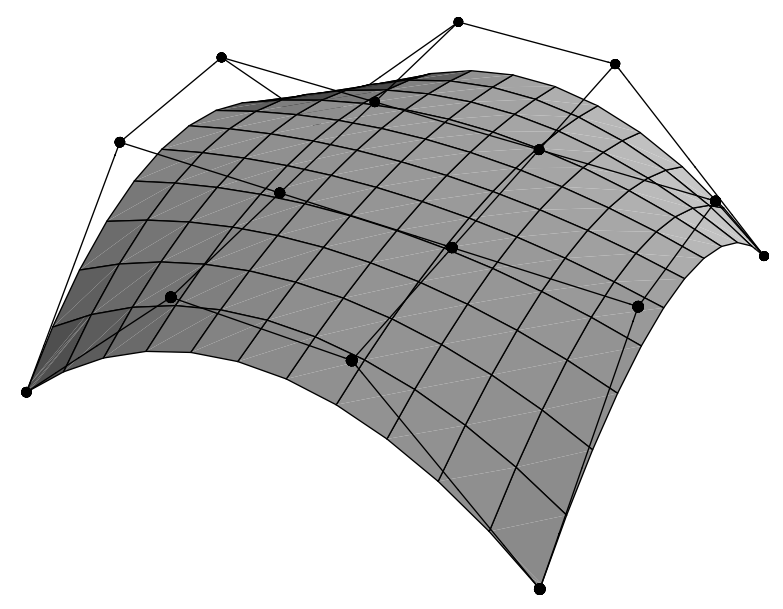

(a) Retangular

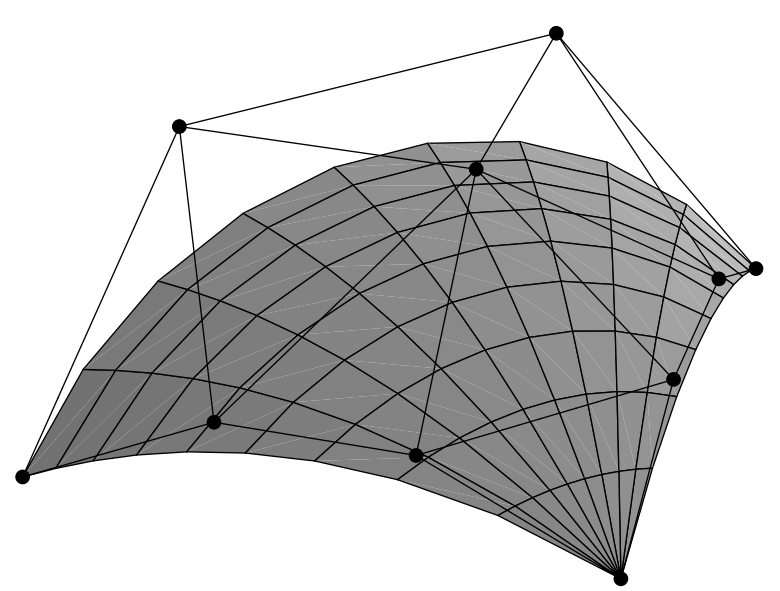

(b) Triangular

Figura 4.1: Retalhos de Bézier. Extraídos de [Schneider and Eberly 2003].

\subsection{Remalhamento baseado em templates}

Podemos dividir o algoritmo de remalhamento aqui proposto em três etapas: préprocessamento da malha, definição dos templates e otimização dos pontos de controle. A etapa de pré-processamento visa adequar a malha de entrada para as etapas seguintes do algoritmo, sendo definido neste estágio o nível de refinamento de cada região da malha. Na etapa seguinte, definição dos templates, o remalhamento é realizado considerando-se retalhos de Bézier triangulares, deixando para a etapa de otimização a melhoria da qualidade dos elementos remalhados.

As seções seguintes descrevem cada uma das etapas do processo de remalhamento.

\subsubsection{Pré-processamento}

A figura 4.2a ilustra um exemplo típico de malha gerada pelo Imesh, sem a execução da etapa de refinamento. Como podemos observar, as malhas a serem refinadas não possuem qualquer informação sobre a adaptatividade desejada, além de serem formadas por vértices de grau bastante alto.

Nesta etapa de pré-processamento são definidas as regiões em que a aplicação necessita de um maior refinamento dos elementos, ou seja, regiões onde teremos uma maior quantidade de elementos em relação a área (adaptatividade local). Esta informação pode ser fornecida pela definição de critérios simples, como refinamento por arestas, ou ainda, por meio de uma função densidade definida sobre a imagem (refina- 
mento por região).

Dividimos esta etapa em três passos:

- Refinamento por aresta;

- Refinamento por região;

- Limitação do gradiente.

Como refinamento por aresta, podemos exemplificar o caso onde desejamos uma adaptatividade nos bordos dos objetos de interesse. Neste caso, aplicamos um processo de subdivisão das arestas de bordo. Para cada aresta do bordo, esta é subdividida de maneira que respeite o critério especificado, ou seja, que as novas arestas sejam menores que uma constante definida. Após as subdivisões, precisamos atualizar a triangulação de Delaunay na região restrita ao bordo. Na figura $4.2 \mathrm{~b}$ subdividimos as arestas de bordo da figura $4.2 \mathrm{a}$.

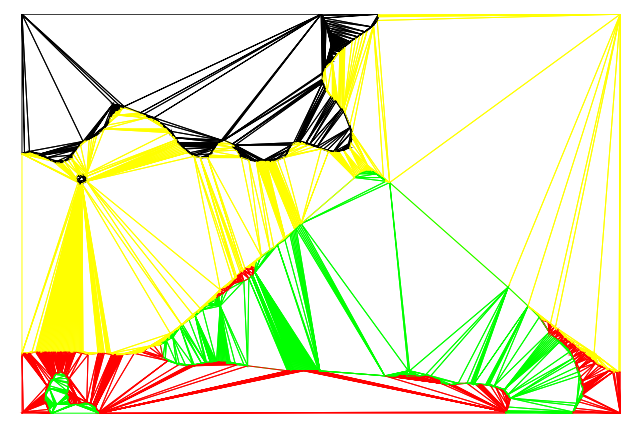

(a)

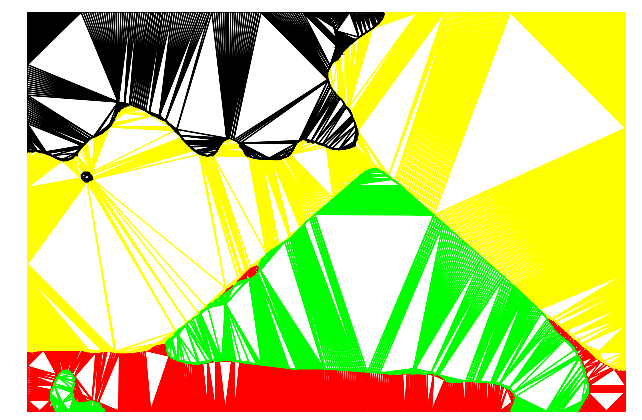

(b)

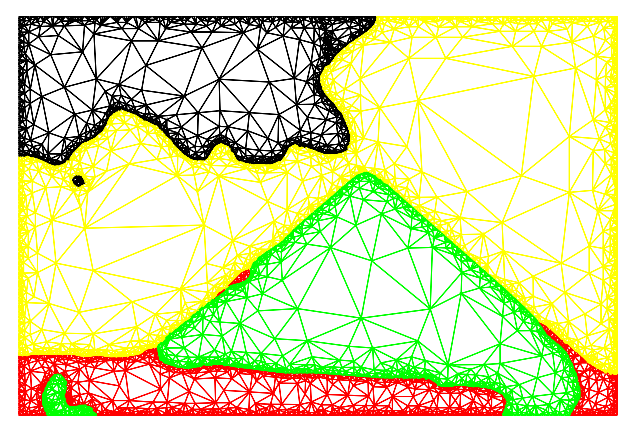

(c)

Figura 4.2: Pré-processamento: (a) Malha original, (b) Subdivisões no bordo da malha, (c) Subdivisões considerando as proporções das arestas.

Para o refinamento por região, precisamos adequar o tamanho de todas as arestas da malha com o tamanho definido pela função densidade, ou seja, arestas maiores que o desejável em uma região, precisam ser subdividas. Este processo é semelhante ao 
refinamento por aresta, mas neste caso, precisamos definir qual o tamanho desejável de uma aresta que está no interior do objeto.

Em ambos os casos, refinamento por aresta ou região, precisamos limitar o gradiente da função densidade, ou seja, não podemos permitir mudanças muito grande entre arestas vizinhas [Owen and Saigal 2000,Zhu et al. 2002, Persson 2004]. Esta restrição se deve ao fato de não conseguimos garantir elementos de boa qualidade em malhas onde um triângulo muito pequeno precisa estar ao lado de um triângulo muito maior [Persson 2005].

Para realizar esta limitação, utilizamos um processo iterativo de divisão de arestas conforme o critério de proporção das arestas de um triângulo. Para todos os triângulos da malha, verificamos se a proporção entre os tamanhos das arestas é maior que uma constante definida, subdividindo arestas muito maiores que as demais. A figura 4.2c ilustra o resultado desta adequação de tamanho de arestas.

Após a execução dos três passos desta etapa de pré-processamento, temos uma malha onde toda aresta é igual ou menor que o esperado em cada região, e ainda, não temos triângulos com arestas de tamanho muito diferentes.

Outro ponto importante, é a redução do grau dos vértices de entrada. A malha a ser processada pela próxima etapa, definição de templates não deve conter vértices de grau muito elevado. Esta característica se deve à manutenção da topologia da malha na etapa de otimização, ou seja, vértices de grau elevados são mantidos até o final do processo. Visto que as malhas geradas pelo algoritmo Imesh possuem a maior parte dos vértices como sendo de grau elevados, a implementação desta etapa de préprocessamento é de fundamental importância. Nas etapas seguintes esta característica ficará mais evidente.

\subsubsection{Definição de templates}

Nesta etapa o remalhamento é realizado sobre a malha pré-processada. O primeiro passo consiste na associação de cada triângulo $t=\left(p_{0}, p_{1}, p_{2}\right)$ oriundo da etapa de préprocessamento a um retalho de Bézier de grau $n$, de acordo com as seguintes regras:

- $P_{n, 0,0}=p_{0}$

- $P_{0, n, 0}=p_{1}$ 
- $P_{0,0, n}=p_{2}$

- $P_{i, j, k}=\frac{i \cdot P_{n, 0,0}+j \cdot P_{0, n, 0}+k \cdot P_{0,0, n}}{n}, \quad \forall i+j+k=n$, onde $0 \leq i, j, k<n$

Após o mapeamento de cada triângulo a um retalho de Bézier, iniciamos a geração de cada template no espaço paramétrico definido pelo retalho. Esta etapa oferece a flexibilidade de definirmos templates de acordo com a necessidade da aplicação. Com isso, conseguimos definir além do grau de refinamento, o tipo de elemento que constituirá a malha final. Neste trabalho utilizamos dois tipos de templates, formado por triângulos ou por quadriláteros, e com diferentes níveis de refinamento.

\section{Template de triângulos}

Definimos os templates de triângulos como sendo a subdivisão do espaço paramétrico conforme pode ser visto na figura 4.3 , onde a densidade de triângulos no template pode ser ajustada.

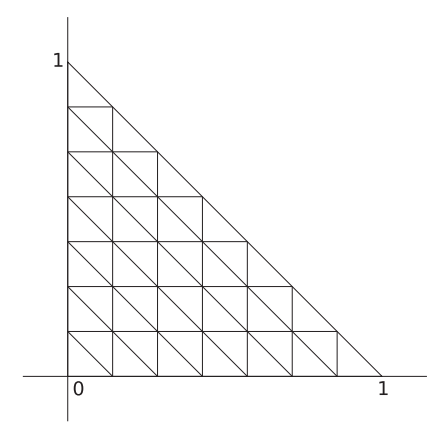

Figura 4.3: Template formado por triângulos.

\section{Templates de quadriláteros}

O remalhamento utilizando template formado por quadriláteros pode ser realizado de diversas modos. Neste trabalho utilizamos dois templates baseados na técnica de Bern [Bern and Gilbert 1992].

O primeiro modelo, ilustrado pela figura 4.4a, inicia com três quadriláteros que compartilham o centróide do triângulo e aplica refinamentos sucessivos em cada um dos quadriláteros de acordo com o nível de refinamento desejado. No segundo modelo 
(figura 4.4b), o processo é dividido em dois passos. Primeiro, utilizamos um template misto, formado por triângulos e quadriláteros. O segundo passo consiste na conversão da malha mista em malha de quadriláteros, agrupando triângulos vizinhos e em seguida removendo os triângulos restantes, utilizando a técnica de Bern [Bern and Gilbert 1992].

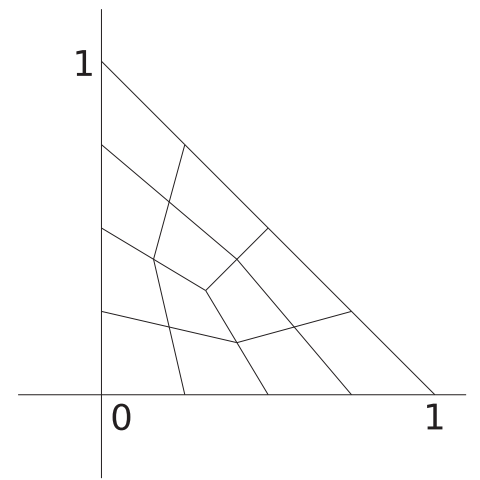

(a)

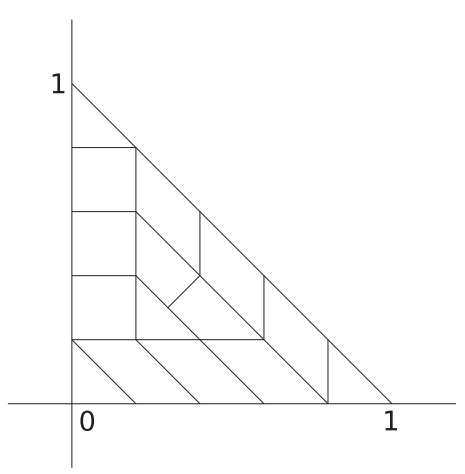

(b)

Figura 4.4: Templates formados por quadriláteros.

A figura 4.5c ilustra o remalhamento realizado por um template de triângulos. A malha original pode ser vista nas figuras 4.5a-b. A figura 4.5d ilustra o resultado da aplicação do segundo modelo formado por quadriláteros.

Ao final desta etapa, temos uma malha formando uma rede de retalhos de Bézier triangulares, onde cada retalho possui seus respectivos pontos de controle, e a nova malha gerada a partir dos templates. Vale ressaltar que cada vértice possui sua coordenada paramétrica, pois foram gerados a partir de retalhos de Bézier. em cada template definido por um retalho de Bézier. Já os triângulos ou quadriláteros gerados, podem não ser formados por vértices de apenas um retalho. Como exemplo, podemos citar o segundo modelo de quadriláteros (figura 4.4b), onde o segundo passo de geração agrupa elementos de retalhos vizinhos. A figura 4.6 ilusta esta situação.

\section{Compatibilidade entre retalhos vizinhos}

Como será explicado mais adiante, a qualidade da malha é gerada a partir de um processo de otimização sobre os pontos de controle. O movimento dos pontos de controle precisam levar em consideração a compatibilidade entre retalhos de Bézier vizinhos. Para garantirmos que a interface entre retalhos vizinhos sejam coincidentes, precisamos utilizar os mesmos pontos de controle para definir a interface entre triân- 

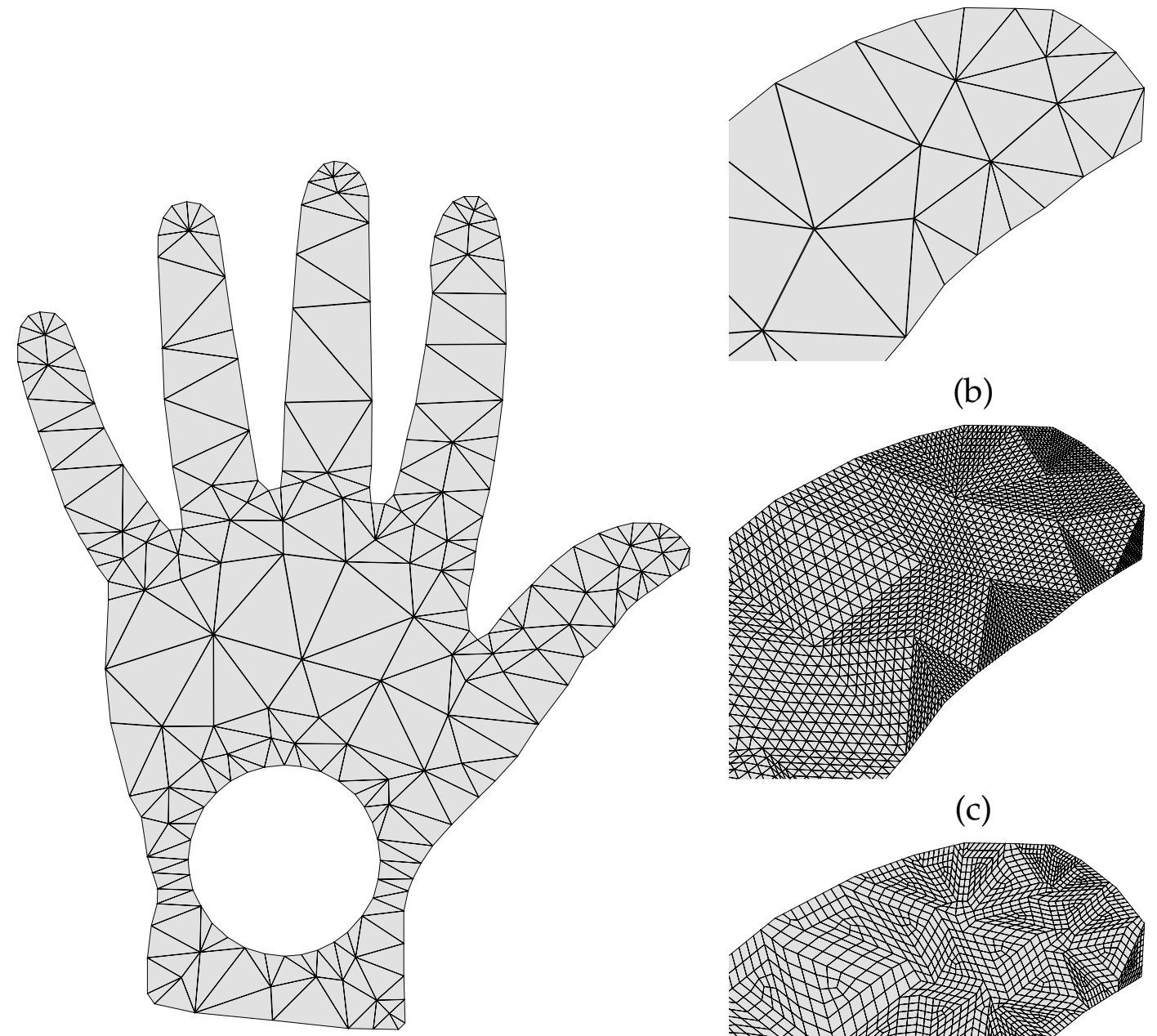

(b)

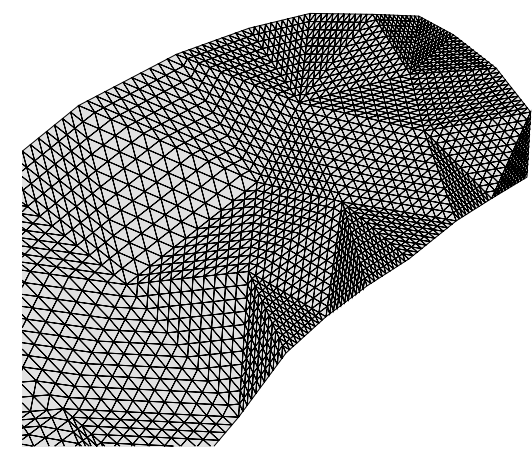

(c)

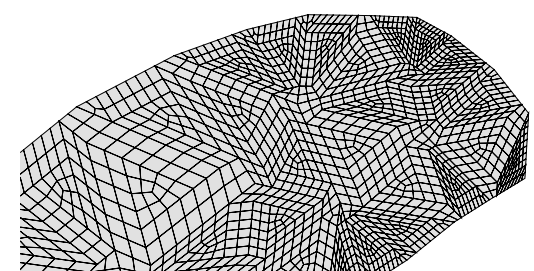

(d)

Figura 4.5: Remalhamento: (a) Malha original, (b) Zoom da ponta do polegar, (c) Remalhamento por triângulos e (d) Remalhamento por quadriláteros. 


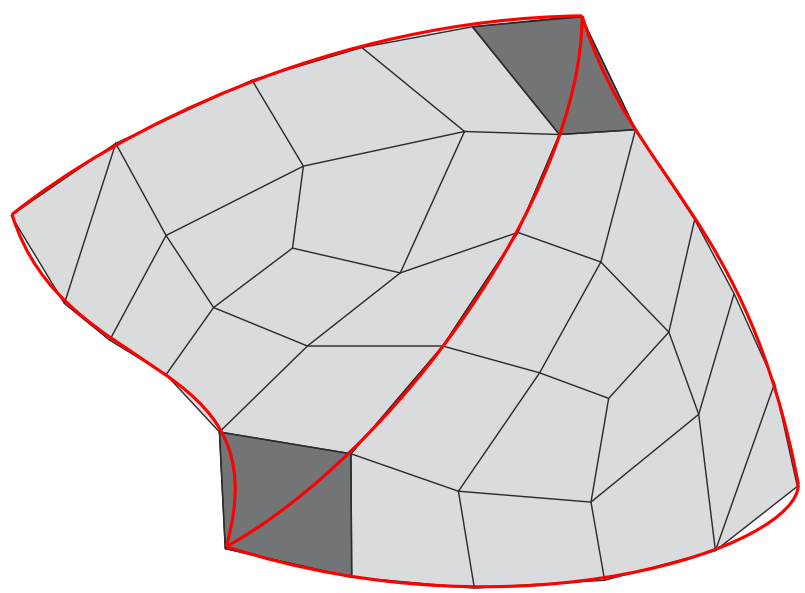

Figura 4.6: Exemplo em que os elementos da malha estão associados a mais de um retalho de Bézier (quadriláteros escuros).

gulos vizinhos.

Como exemplo, podemos citar a curva que define o bordo de um patch de Bézier. No caso de dois triângulos adjacentes por uma aresta, ambos os retalhos definidos por estes triângulos terão em comum uma curva de Bézier, com os dois vértices que definem a aresta adjacente como extremidades. Para que tal curva seja a mesma em ambos os retalhos, esta precisa ser definida pelos mesmos pontos de controle. Ao mover qualquer ponto de controle $P_{\left(i_{0}, i_{1}, i_{2}\right)}$ do bordo de um retalho, ou seja, pontos de controle onde $i_{0}$ ou $i_{1}$ ou $i_{2}$ sejam igual a 0 , precisamos mover também o ponto de controle correspondente no retalho adjacente, se houver. Este requisito é necessário para mantermos a continuidade da malha, pois caso contrário, buracos poderão surgir no modelo.

Desta maneira, classificamos os pontos de controle em três categorias:

- Interno - Pontos de controle interno ao retalho, ou seja, todos os pontos $P_{\left(i_{0}, i_{1}, i_{2}\right)}$, onde $i_{0}$ e $i_{1}$ e $i_{2}$ são diferentes de 0 ;

- Aresta - Pontos de controle $P_{\left(i_{0}, i_{1}, i_{2}\right)}$, onde $i_{0}$ ou $i_{1}$ ou $i_{2}$, exclusivamente, seja igual a 0 ;

- Vértice - Pontos de controle $P_{\left(i_{0}, i_{1}, i_{2}\right)}$, onde $i_{0}$ ou $i_{1}$ ou $i_{2}$, exclusivamente, seja igual a $n$, isto é, dois índices são iguais a 0.

Cada ponto de controle possui influência sobre um determinado número de elementos, ou seja, ao mover um ponto de controle $P$ estamos alterando as coordenadas 
de um número fixo de vértices, sejam pertencentes ao mesmo retalho ou pertencentes a retalhos adjacentes.

\subsubsection{Otimização dos pontos de controle}

Em geral, a malha gerada pela etapa anterior conserva a qualidade dos elementos da malha de entrada, ou seja, triângulos de entrada ruins, serão mapeados a um retalho de Bézier, que provavelmente será discretizado por um template com elementos de má qualidade. Por este motivo, aplicamos uma etapa de otimização sobre os pontos de controle de cada retalho, a fim de melhorar a qualidade dos elementos na malha final.

Nesta etapa, temos o controle sobre todos os vértices da malha gerada por meio dos retalhos de Bézier, pois cada vértice pertence a um determinado retalho. Ao deslocarmos um ponto de controle, estamos deslocando também todos os vértices pertencentes ao retalho de Bézier correspondente a este ponto de controle. Nossa estratégia é encontrar novas posições para os pontos de controle, de maneira que as novas posições dos vértices da malha formem elementos de boa qualidade.

Definimos uma função $\mathscr{E}$, chamada de energia, que forneça uma medida de a qualidade para um conjunto de elementos, ou seja,

$$
\mathscr{E}(T)=\sum_{t \in T}(1-\mathscr{Q}(t))^{2}
$$

onde, $T$ é o conjunto de elementos e $\mathscr{Q}$ é um critério de qualidade normalizado para cada elemento da malha, assumindo valor 1 para elementos ideais e 0 para elementos degenerados.

Como critério de qualidade de um elemento, podemos utilizar o critério mais apropriado para a aplicação-foco do processo de geração de malha, desde que esta medida esteja normalizada. Neste trabalho utilizamos o menor valor Jacobiano normalizado (Scaled-Jacobian [Knupp 2000, Zhang et al. 2007]) para os elementos triangulares. Para os quadriláteros utilizamos a medida de forma definida em [Knupp 2003] (chamada shape). Ambas as medidas assumem valores entre 0 e 1 para os respetivos elementos 
válidos, considerando 1 para o elemento ideal, ou seja, um triângulo equilátero ou um quadrado. Considerando estes critérios, para a maior parte das aplicações temos 0.3 como o valor mínimo aceitável em uma malha.

Considerando $T_{P}$ o conjunto de elementos, triângulos ou quadriláteros, onde ao menos um dos vértices é influenciado por $P$; ao movimentarmos $P$ estamos alterando o valor da função energia $\mathscr{E}\left(T_{P}\right)$. A fim de formar elementos com melhor qualidade, definimos um processo iterativo de minimização da função $\mathscr{E}(M)$, o que corresponde a encontrar as posições ótimas de todos os pontos de controle. Para mover cada ponto de controle, utilizamos o método de Powell [Powell 1964]. Para garantir que este processo iterativo seja finalizado, interrompemos a minimização quando é pelo menos uma das seguintes condições é satisfeita:

- os movimentos dos pontos de controle tornam-se insignificantes, ou seja, são menores que uma contante $c_{m o v}$ pré-definida;

- a qualidade do pior elemento da malha é aceitável, ou seja, $\min (\mathscr{Q}(t))<c_{\text {qualidade }}$, para todo $t \in M$, onde $c_{\text {qualidade }}$ é uma constante pré-definida;

- um número máximo de iterações é alcançado.

Após a execução de um número determinado de iterações, aplicamos uma reorganização da malha regerada com relação aos retalhos de Bézier. Esta reorganização consiste na reinicialização das posições dos pontos de controle, ou seja, nas respectivas posições iniciais. Os elementos da malha regerada são mantidos, mas vértices que antes pertenciam a um determinado retalho, podem passar a pertencer a outro retalho de Bézier.

As figuras 4.7 e 4.8 ilustram três passos do processo iterativo aplicado na região ilustrada na figura $4.5 \mathrm{~b}$. Na figura 4.7 utilizamos o modelo de triângulo apresentado na figura 4.3, e na figura 4.8 utilizamos o modelo de quadriláteros ilustrado na figura $4.4 \mathrm{~b}$. Em ambas as figuras, apresentamos os seguintes quatro passos:

1. Inicial: aplicação do template

2. 5 iterações da otimização dos pontos de controle

3. 10 iterações, sendo realizada uma reorganização da malha

4. 50 iterações, sendo realizadas 5 reorganizações da malha 

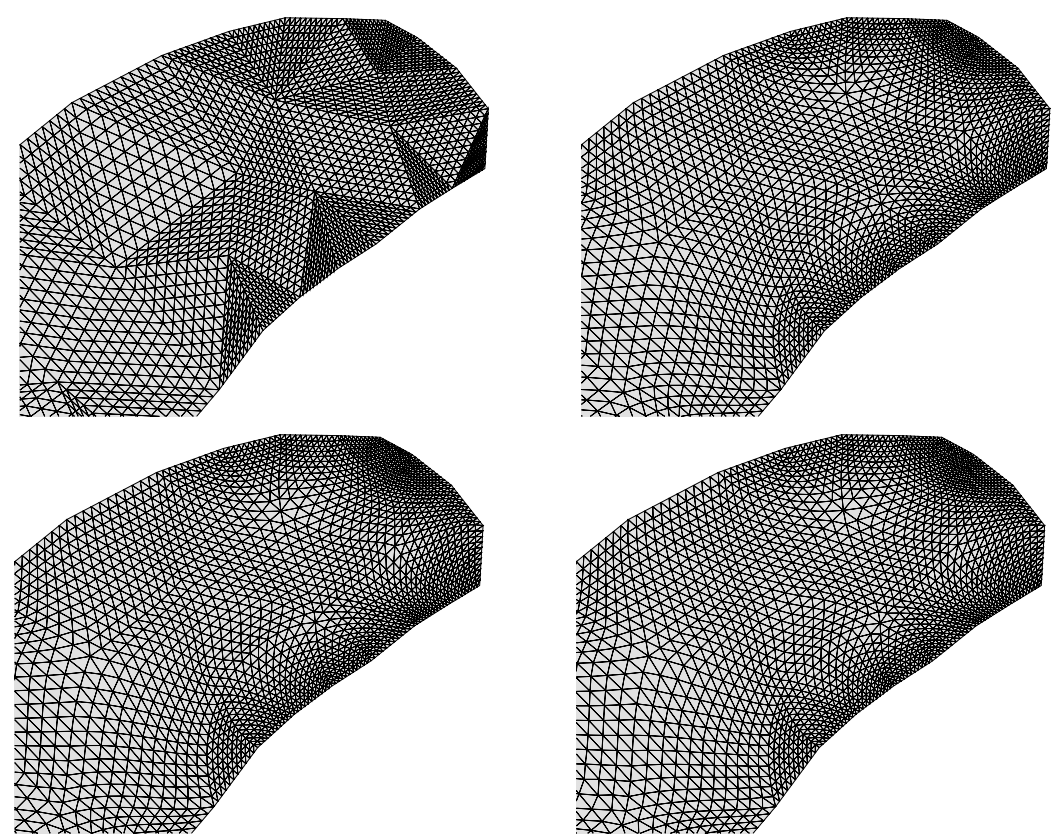

Figura 4.7: Passos do processo iterativo de minimização da função $\mathscr{E}$ utilizando um template de triângulos.
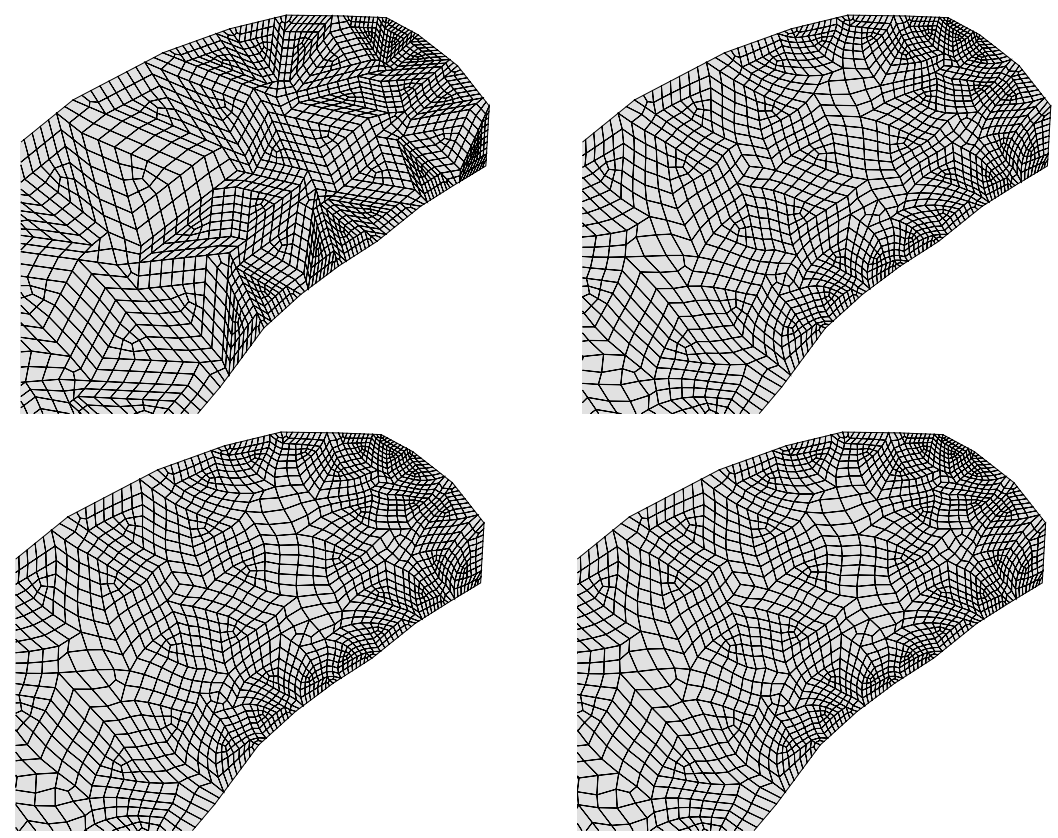

Figura 4.8: Passos do processo iterativo de minimização da função $\mathscr{E}$ utilizando um template de quadriláteros. 
Na figura 4.9b-c encontra-se o final do processo iterativo de minimização aplicado na malha original apresentada na figura 4.9a. Juntamente com cada malha, encontra-se os respectivos histogramas da qualidade dos elementos.

Em suma, apresentamos neste capítulo a técnica de remalhamento baseada em templates. A partir da malha gerada pelo algoritmo Imesh, substituímos a etapa de refinamento do Imesh original pela técnica apresentada. No capítulo seguinte, os resultados desta técnica de remalhamento são apresentados. 


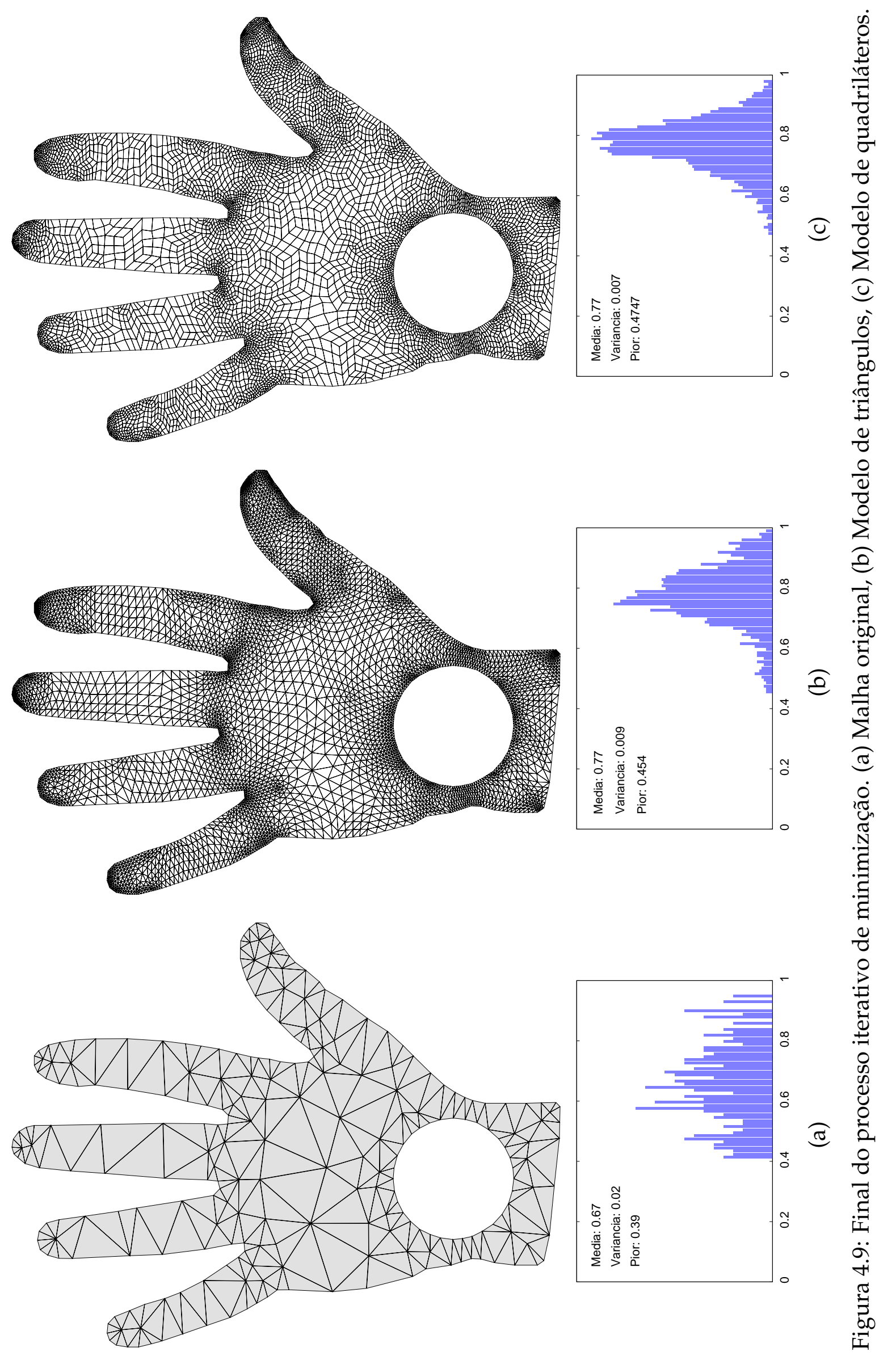




\section{$5 \quad$ Resultados}

Neste capítulo apresentamos os resultados obtidos na aplicação das duas metodologias propostas neste trabalho. Utilizamos a linguagem de programação C++ [Stroustrup 2000] para implementar os algoritmos propostos. Desenvolvemos também uma estrutura de dados topológica para auxilar na implementação. Descrevemos esta estrutura de dados, na qual denominamos OF - Opposite Face, no apêndice A.

\subsection{Imesh+Texturas}

Nesta seção apresentamos os resultados obtidos com a aplicação da metodologia proposta na seção 3.3.2. Dividimos os testes segundo a origem das imagens. O primeiro grupo é formado por imagens do Berkeley Segmentation Dataset ${ }^{1}$ e o segundo grupo contém imagens do VisTex Database ${ }^{2}$. Escolhemos utilizar imagens de bancos abertos por facilitar a comparação com novas metodologias. Como podemos observar, estes resultados ilustram a eficiência da metodologia proposta (W-operator + Imesh).

\subsubsection{Imagens do Berkeley Segmentation Dataset}

A figura 5.1 apresenta quatro imagens e seus respetivos $15 \times 15$ recortes de treinamento para o W-operador. Estas imagens, assim como as respectivas segmentações de referência (figura 5.2), foram obtidas do Berkeley Segmentation Dataset. Todos os recortes estão identificados aqui por cores, sendo que recortes de uma mesma cor pertencem a uma mesma classe de textura. Utilizamos cinco recortes para cada classe, representando $2.91 \%, 2.91 \%, 3.64 \%$ e $2.19 \%$ do total das respectivas imagens de entrada.

Como discutido na seção 3.3.1, a técnica do W-operador exige a definição de três

\footnotetext{
${ }^{1}$ http://www.eecs.berkeley.edu/Research/Projects/CS/vision/bsds

${ }^{2}$ http://vismod.media.mit.edu/vismod/imagery/VisionTexture/vistex.html
} 


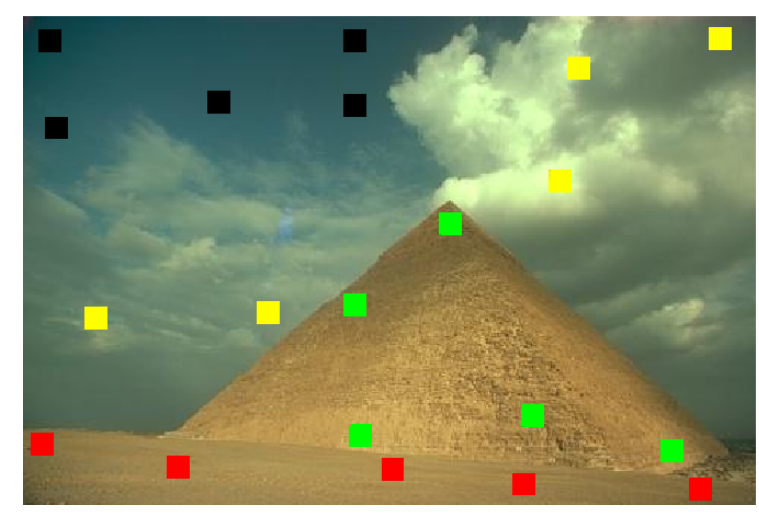

(a) Pirâmide

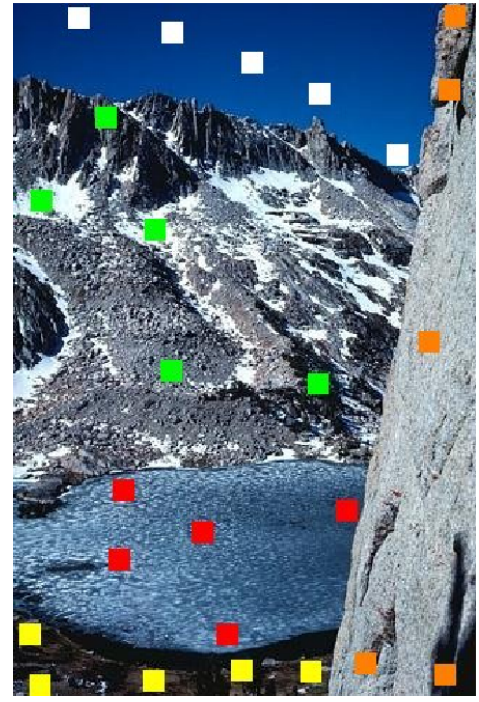

(c) Lago

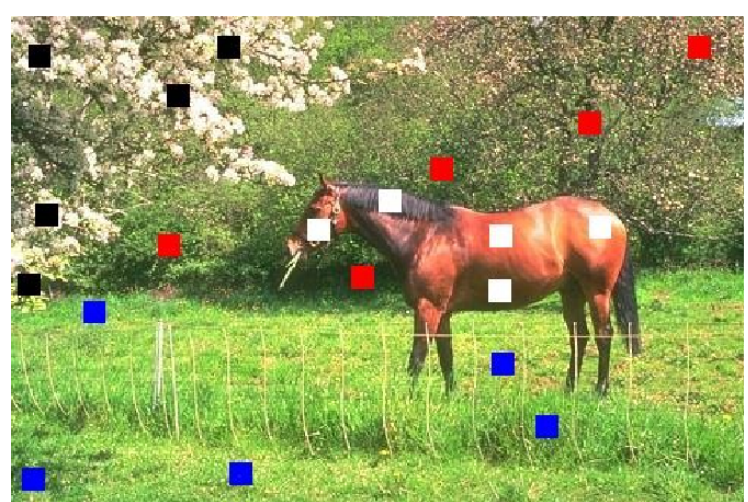

(b) Cavalo

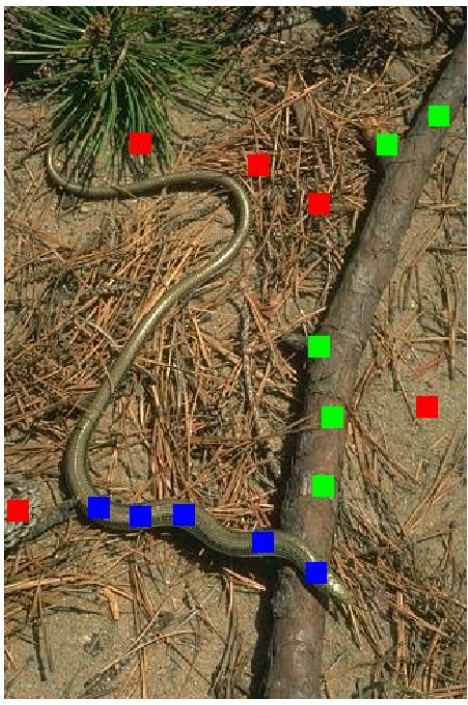

(d) Cobra

Figura 5.1: Imagens e recortes utilizadas neste primeiro conjunto de testes. A cor do recorte indica a classe da textura.

parâmetros. O primeiro corresponde ao tamanho da janela (denotado por $|W|$ ), esta janela é transladada sobre os recortes de treinamento. O segundo parâmetro é o grau ( $k$ ) de quantização. Por fim, o terceiro parâmetro é relacionado ao grau $d$ de rotações para a replicação de amostras. Foram realizados a classificação de textura sobre diversas combinações de parâmetros nas quatro imagens da figura 5.1, considerando quatro tamanhos de janelas $(|W|=\{1 \times 1,3 \times 3,5 \times 5,7 \times 7\}$, três valores de quantização $(k=\{4,8,16\})$, e dois valores de rotação $(d=\{0,45\})$. Estes testes foram realizados utilizando os canais RGB e HSV. Observe que o tamanho da janela $1 \times 1$ significa uma classificação no nível de um pixel, e $d=0$ significa a não realização da replicação das amostras utilizando rotações.

O erro MAE, ou seja, a porcentagem de pixel classificados erroneamente tendo como referência as segmentações apresentadas na figura 5.2, foi adotado como medida de erro de classificação. As tabelas 5.1, 5.2, 5.3 e 5.4 ilustram os erros MAE correspon- 


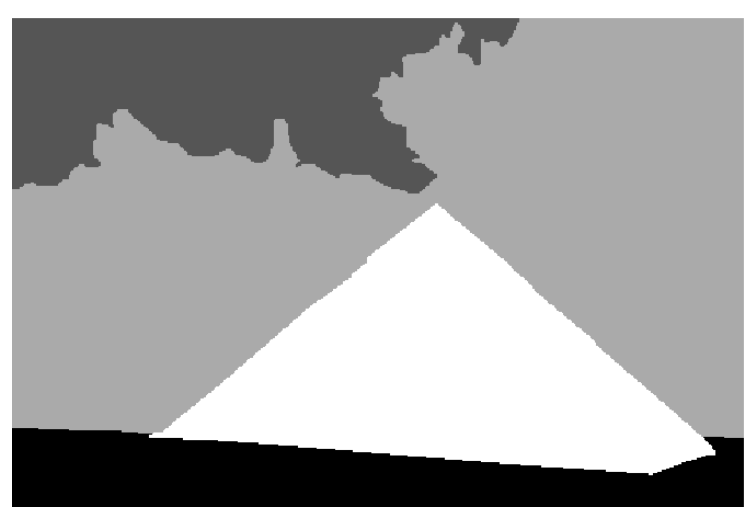

(a) Pirâmide

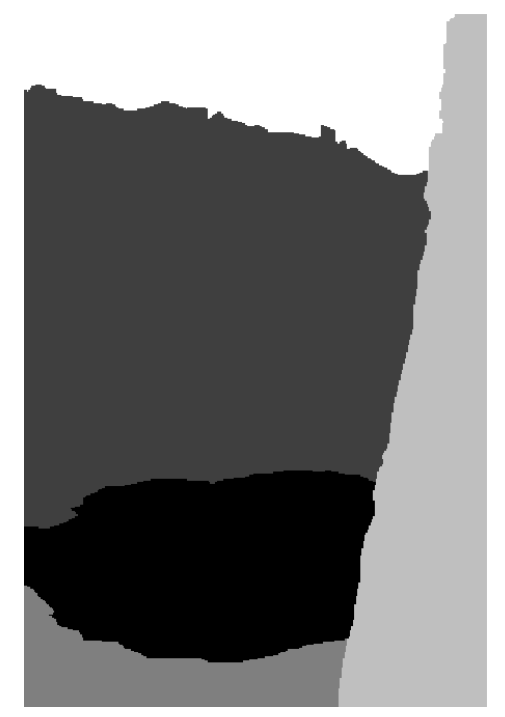

(c) Lago

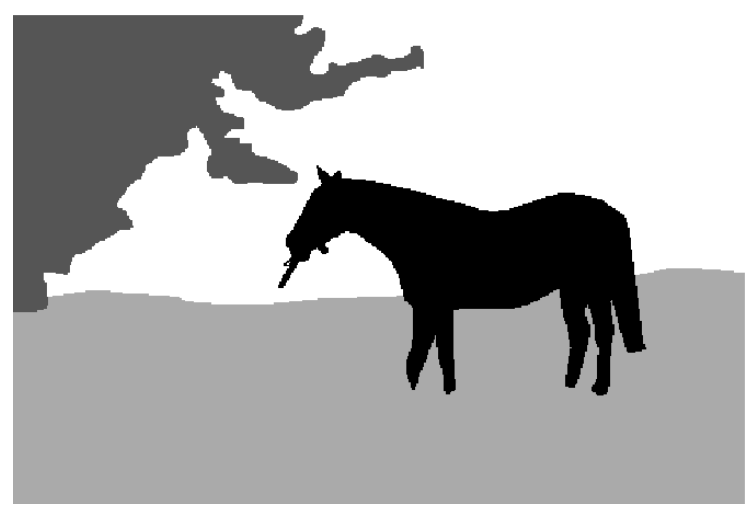

(b) Cavalo

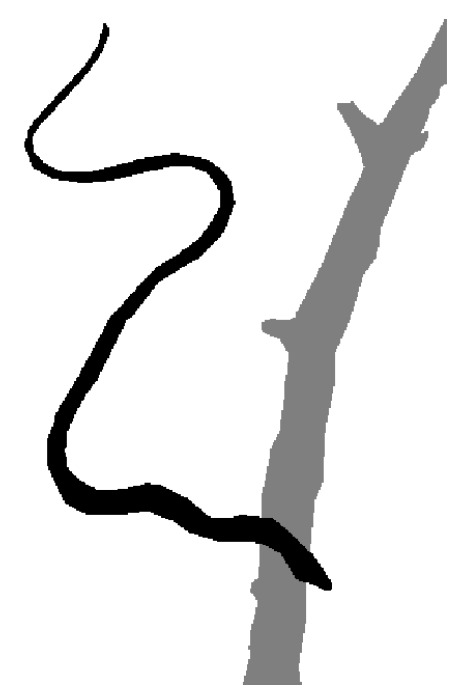

(d) Cobra

Figura 5.2: Segmentação manual de referência para cada imagem ilustrada na figura 5.1.

dentes a classificação das imagens da pirâmide, cavalo, lago e cobra, respectivamente, para cada combinação de parâmetros.

Uma primeira conclusão que podemos ter a partir destes testes é que a rotação e o uso dos canais HSV, em geral, obtiveram melhores resultados. Por este motivo, iremos nos concentrar nas análises do quadrante inferior à direita das tabelas, ou seja, consideramos o uso dos canais RGB+HSV com rotação, e variaremos $s$ e $W$. Para a imagem da pirâmide, obtivemos resultados melhores com valores maiores de $k$, mas para a imagem do cavalo, os melhores resultados foram obtidos com valores menores de $k$. Para as outras duas imagens, todos os valores de $k$ produziram resultados similares. Logo, não é trivial escolher o valor ideal para $k$, considerando que este valor depende das particularidades de cada imagem. Também não existe uma resposta definitiva para determinar o tamanho ideal da janela. Teoricamente, valores de janelas maiores geraria melhores resultados. Na prática isto não ocorre por dois motivos. Primeiro, valores 
maiores de janelas coletam uma quantidade menor de amostras nos bordos da imagem (no caso dos conjuntos de treino utilizados nestes experimentos, os recortes fornecidos das imagens para o treinamento são de exatamente $15 \times 15)$. Segundo, janelas maiores aumentam o espaço de busca. Neste sentido, algoritmos de seleção como o SFFS tendem a não obter resultados satisfatórios para janelas grandes. Considerando estas características e observando as quatros tabelas, os parametros responsáveis por bons resultados para todas as imagens, exceto a imagem do lago, são RGB+HSV, rotação $(d=45), k=16$ e $|W|=3 \times 3$. Logo, utilizaremos estes valores a partir deste instante.

\begin{tabular}{|c|c|ccc|ccc|}
\hline & & \multicolumn{3}{|c|}{ sem rotação } & \multicolumn{3}{c|}{ Com rotação } \\
& & $k=4$ & $k=8$ & $k=16$ & $k=4$ & $k=8$ & $k=16$ \\
\hline \multirow{3}{*}{ RGB } & $|W|=1 \times 1$ & 0.2268 & 0.1870 & 0.1077 & - & - & - \\
& $|W|=3 \times 3$ & 0.1613 & 0.1377 & 0.0960 & 0.1473 & 0.1259 & 0.0895 \\
& $|W|=5 \times 5$ & 0.1459 & 0.1383 & 0.1040 & 0.1271 & 0.1249 & 0.0875 \\
& $|W|=7 \times 7$ & 0.1651 & 0.1838 & 0.1051 & 0.1316 & 0.1372 & 0.0949 \\
\hline \multirow{2}{*}{ RGB } & $|W|=1 \times 1$ & 0.1839 & 0.1694 & 0.1025 & - & - & - \\
HSV & $|W|=3 \times 3$ & 0.1727 & 0.1296 & 0.0918 & 0.1571 & 0.1144 & 0.0853 \\
& $|W|=5 \times 5$ & 0.1509 & 0.1238 & 0.1026 & 0.1214 & 0.1135 & 0.0865 \\
& $|W|=7 \times 7$ & 0.1873 & 0.1299 & 0.1037 & 0.1497 & 0.1115 & 0.0913 \\
\hline
\end{tabular}

Tabela 5.1: Erro (MAE) da classificação realizada pelo W-operador para a imagem da pirâmide obtidos por toda combinação de valores dos parâmetros considerados.

\begin{tabular}{|c|c|ccc|ccc|}
\hline & & \multicolumn{3}{|c|}{ sem rotação } & \multicolumn{3}{c|}{ Com rotação } \\
& & $k=4$ & $k=8$ & $k=16$ & $k=4$ & $k=8$ & $k=16$ \\
\hline \multirow{3}{*}{ RGB } & $|W|=1 \times 1$ & 0.3728 & 0.2843 & 0.2793 & - & - & - \\
& $|W|=3 \times 3$ & 0.3062 & 0.3048 & 0.2835 & 0.2892 & 0.2796 & 0.2891 \\
& $|W|=5 \times 5$ & 0.3121 & 0.3113 & 0.2778 & 0.2834 & 0.2792 & 0.2915 \\
& $|W|=7 \times 7$ & 0.2904 & 0.2928 & 0.3410 & 0.2843 & 0.3022 & 0.2970 \\
\hline \multirow{2}{*}{ RGB } & $|W|=1 \times 1$ & 0.3438 & 0.2959 & 0.2802 & - & - & - \\
HSV & $|W|=3 \times 3$ & 0.2627 & 0.2743 & 0.2838 & 0.2515 & 0.2669 & 0.2759 \\
& $|W|=5 \times 5$ & 0.2557 & 0.2907 & 0.2876 & 0.2463 & 0.2864 & 0.2757 \\
& $|W|=7 \times 7$ & 0.2857 & 0.2779 & 0.3029 & 0.2421 & 0.2903 & 0.2860 \\
\hline
\end{tabular}

Tabela 5.2: Erro (MAE) da classificação realizada pelo W-operador para a imagem do cavalo obtidos por toda combinação de valores dos parâmetros considerados.

Para estes parâmetros fixos, os pontos na sub-janela escolhidos pelo método de seleção de características (SFFS) estão ilustrados na figura 5.3. Os resultados da aplicação do W-operador utilizando os pontos selecionados é apresentado na figura 5.4. Utilizando apenas a classificação baseada em um único pixel, ou seja, com janela de tamanho $1 \times 1$, todos os erros foram aumentados em $12.45 \%, 1.02 \%, 7.19 \%$ e $25.16 \%$, respectivamente. Portanto, a classificação utilizando a informação contida na vizinhança, ao invés de apenas um pixel, possui uma melhor performance com texturas, conforme é 


\begin{tabular}{|c|c|ccc|ccc|}
\hline & & \multicolumn{3}{|c|}{ sem rotação } & \multicolumn{3}{c|}{ com rotação } \\
& & $k=4$ & $k=8$ & $k=16$ & $k=4$ & $k=8$ & $k=16$ \\
\hline \multirow{3}{*}{ RGB } & $|W|=1 \times 1$ & 0.4050 & 0.3088 & 0.2789 & - & - & - \\
& $|W|=3 \times 3$ & 0.3462 & 0.2456 & 0.2342 & 0.3236 & 0.2365 & 0.2125 \\
& $|W|=5 \times 5$ & 0.3591 & 0.2629 & 0.2440 & 0.3306 & 0.2759 & 0.2280 \\
& $|W|=7 \times 7$ & 0.3895 & 0.2980 & 0.2650 & 0.3373 & 0.2569 & 0.2366 \\
\hline \multirow{2}{*}{ RGB } & $|W|=1 \times 1$ & 0.2666 & 0.2145 & 0.2291 & - & - & - \\
HSV & $|W|=3 \times 3$ & 0.2604 & 0.2075 & 0.2186 & 0.2191 & 0.2048 & 0.2065 \\
& $|W|=5 \times 5$ & 0.2492 & 0.2294 & 0.2343 & 0.2276 & 0.2048 & 0.2218 \\
& $|W|=7 \times 7$ & 0.2579 & 0.2166 & 0.2022 & 0.2342 & 0.2228 & 0.2498 \\
\hline
\end{tabular}

Tabela 5.3: Erro (MAE) da classificação realizada pelo W-operador para a imagem do lago obtidos por toda combinação de valores dos parâmetros considerados.

\begin{tabular}{|c|c|ccc|ccc|}
\hline & & \multicolumn{3}{|c|}{ sem rotação } & \multicolumn{3}{c|}{ com rotação } \\
& & $k=4$ & $k=8$ & $k=16$ & $k=4$ & $k=8$ & $k=16$ \\
\hline \multirow{3}{*}{ RGB } & $|W|=1 \times 1$ & 0.5086 & 0.6013 & 0.4989 & - & - & - \\
& $|W|=3 \times 3$ & 0.5632 & 0.5544 & 0.4473 & 0.5467 & 0.5000 & 0.4343 \\
& $|W|=5 \times 5$ & 0.6051 & 0.5158 & 0.4468 & 0.6286 & 0.4978 & 0.4455 \\
& $|W|=7 \times 7$ & 0.5692 & 0.5078 & 0.4813 & 0.6538 & 0.4832 & 0.4371 \\
\hline \multirow{2}{*}{ RGB } & $|W|=1 \times 1$ & 0.4655 & 0.4982 & 0.4855 & - & - & - \\
HSV & $|W|=3 \times 3$ & 0.5025 & 0.4370 & 0.4061 & 0.5086 & 0.3876 & 0.3879 \\
& $|W|=7 \times 5$ & 0.5676 & 0.4775 & 0.4407 & 0.5859 & 0.3835 & 0.4144 \\
& $|W|=7$ & 0.5886 & 0.4190 & 0.4073 & 0.5650 & 0.3621 & 0.4065 \\
\hline
\end{tabular}

Tabela 5.4: Erro (MAE) da classificação realizada pelo W-operador para a imagem da cobra obtidos por toda combinação de valores dos parâmetros considerados.

esperado. Vale ressaltar que a figura 5.4 a aplicação do W-operador foi realizada ainda sem qualquer combinação com o Imesh, ou seja, o W-operador associou um tipo de textura para cada pixel, baseando-se apenas nos valores das matrizes de probabilidade condicional.

Como podemos observar na figura 5.5, a maioria dos pixels possui um alto valor de probabilidade condicional, assegurando definições confiáveis de textura. Entretanto, em algumas regiões, como por exemplo as figuras 5.5(c e d), os tipos de texturas são definidos baseando-se em baixos valores, causando ruídos como mostram as figuras 5.4(c e d).

Por outro lado, a combinação da técnica W-operadores com o Imesh reduz drasticamente o problema de ruídos na definição da textura, pois as texturas passam a ser definidas por triângulos ao invés de pixels. Este fato pode ser claramente observado nas figuras 5.6(a, b, c e d), onde o erro MAE foi reduzido em 25.2\%, 22.1\%, 70.0\% e $45.4 \%$ com relação as imagens da figura 5.4(a, b, c e d), respectivamente. 


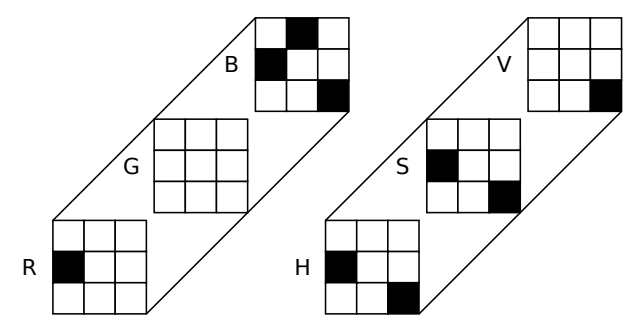

(a) Pirâmide

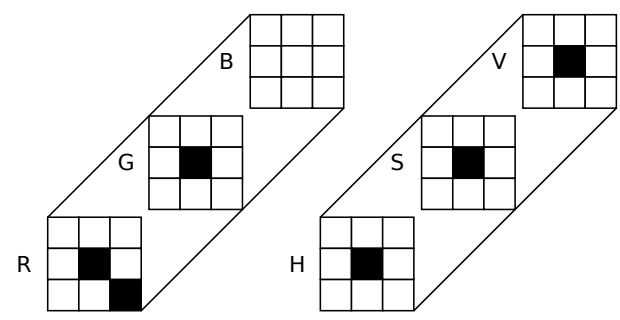

(c) Lago

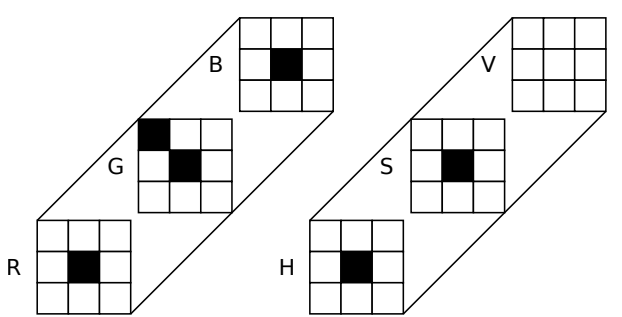

(b) Cavalo

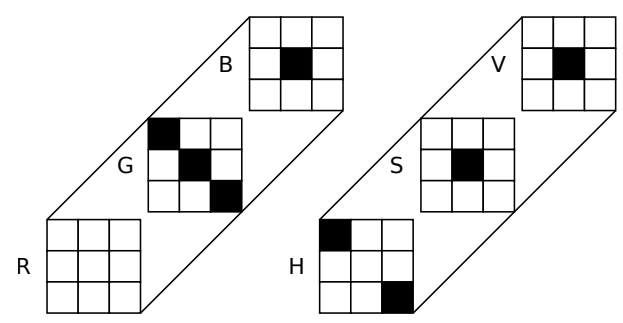

(d) cobra

Figura 5.3: Sub-janelas resultantes da aplicação do SFFS, utilizando o conjunto de treinamento ilustrado na figura 5.1.

A figura 5.7 ilustra as malhas triangulares obtidas a partir de cada imagem da figura 5.6. Na figura 5.8 foi aplicado o refinamento de Ruppert modificado, descrito em [Cuadros-Vargas et al. 2009], nas malhas da figura 5.7.

\section{Substituindo o classificador}

Apenas com o objetivo de comparação, substituímos o classificador W-operador por outra técnica capaz de classificar texturas coloridas. Implementamos uma rede neural do tipo Multi-Layer Perceptron (MLP) para realizar a classificação de texturas. Nossa implementação é baseada em MLP comumente utilizada em reconhecimento de texturas e padrões [Kachouie and Alirezaie 2003]. Esta MLP foi treinada utilizando o algoritmo padrão backpropagation, onde as entradas foram as mesmas utilizadas pelo algoritmo $\mathrm{W}$-operador.

A topologia da MLP utilizada consiste em três camadas: a primeira é definida a partir do tamanho da janela (13 por canal); a camada intermediária é definida empiricamente, dependendo da convergência da MLP (adotamos 11 neurônios); e a última camada contém apenas um neurônio, que nos irá fornecer o valor que definirá a classe de textura que provavelmente a amostra perterce. Após a etapa de aprendizado, a MLP contém os pesos que classificará qualquer amostra de entrada.

O resultado da aplicação da MLP é utilizado para definir o tipo de textura durante 


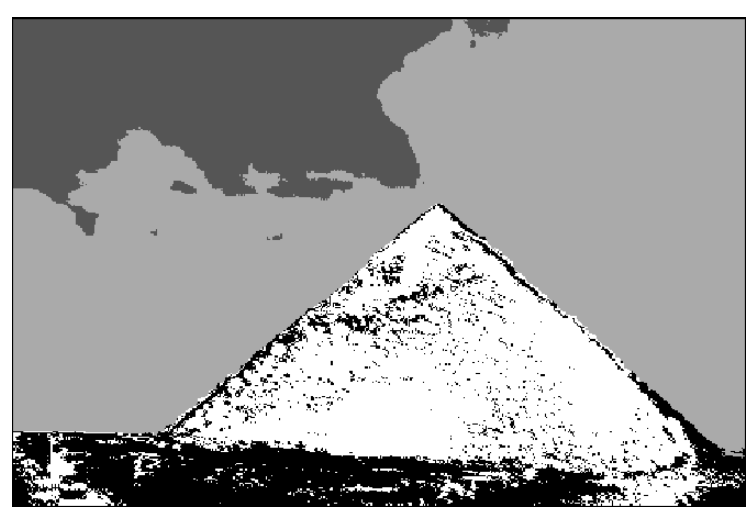

(a) Pirâmide (MAE = 8.53\%)

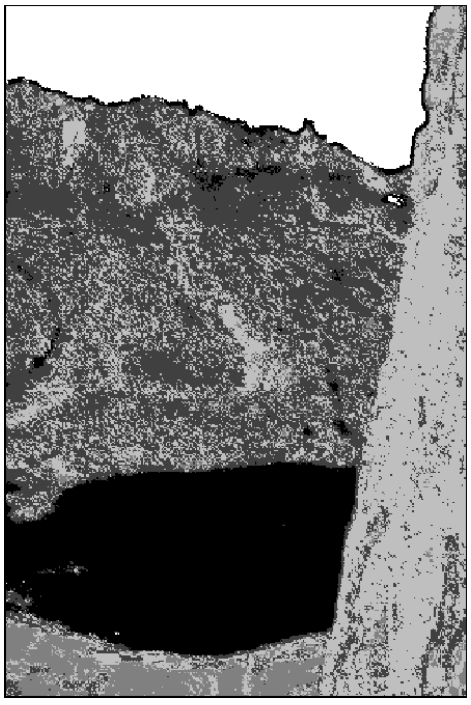

(c) Lago (MAE $=20.65 \%)$

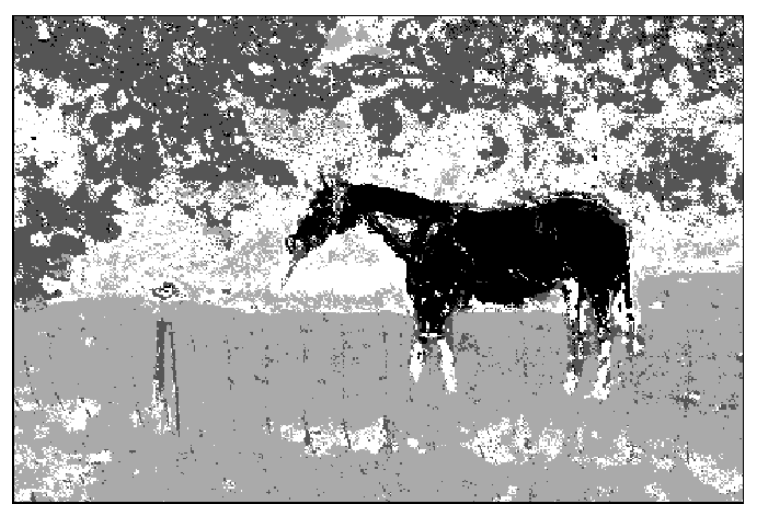

(b) Cavalo (MAE $=27.59 \%$ )

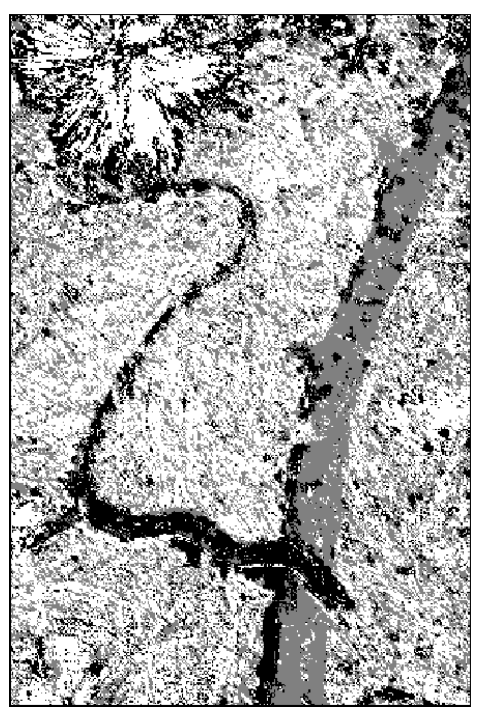

(d) Cobra $(\mathrm{MAE}=38.79 \%)$

Figura 5.4: Resultados da aplicação do W-operador nas imagens exibidas na figura 5.1 com seus respectivos erros MAEs. Parâmetros adotados: RGB+HSV, $|W|=3 \times 3, k=16$ e rotação de 45 graus $(d=45)$.

a aplicação do Imesh. O resultado final aplicado nas imagens da piramide, cavalo, lago e cobra são mostrados na figura 5.9. Como podemos observar, o erro MAE obtido com a MLP como classificador são muito superiores aos apresentados na figura 5.6, mostrando que a combinação W-operador e Imesh nos fornecem um efetivo classificador de textura. Adicionalmente, esta abordagem nos fornece, além da imagem segmentada, uma malha triangular. 


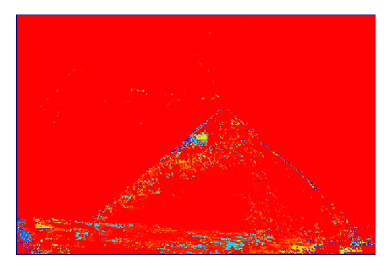

(a) Pirâmide

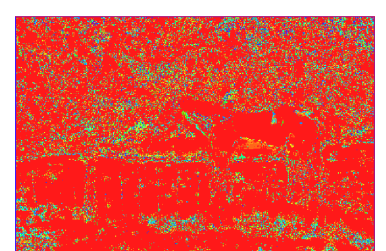

(b) Cavalo

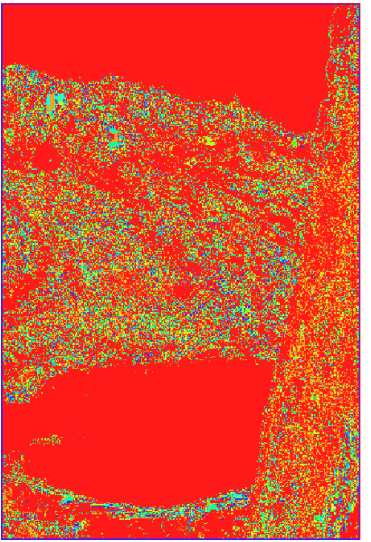

(c) Lago

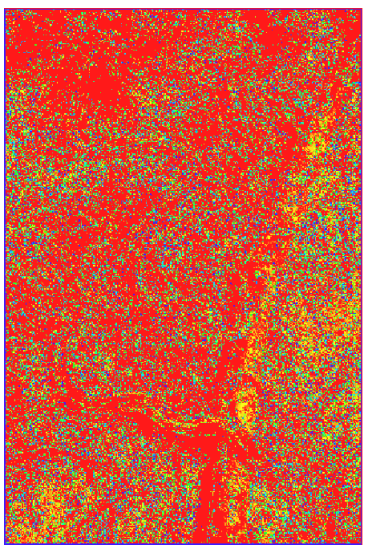

(d) Cobra

Probabilidade (\%)

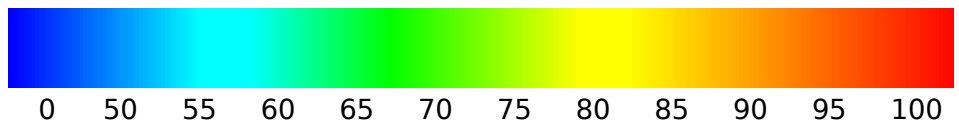

Figura 5.5: Representação dos maiores valores da matriz de probabilidade condicional correspondentes a classificação realizada pelo W-operador ilustrada na figura 5.4.

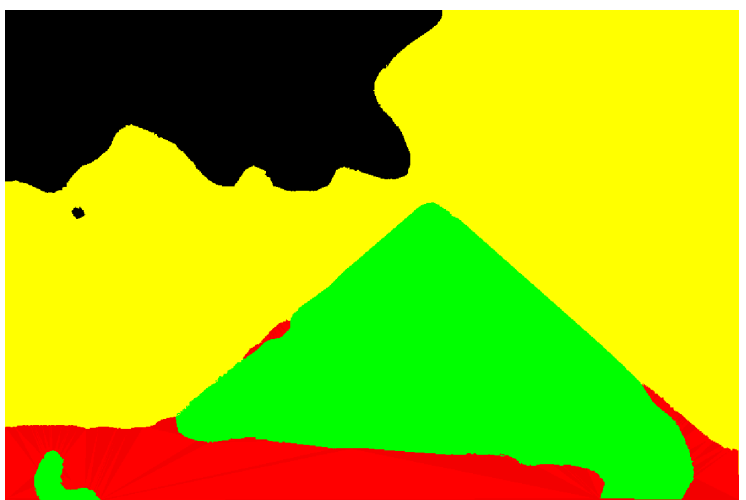

(a) Pirâmide (MAE $=6.16 \%)$

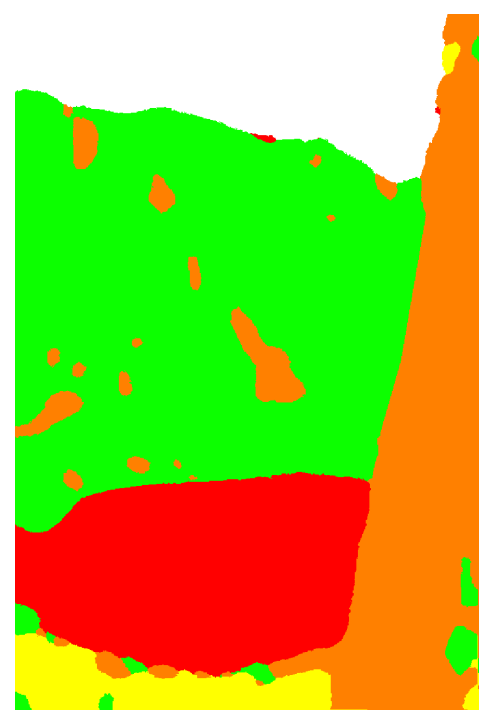

(c) Lago (MAE $=6.20 \%)$

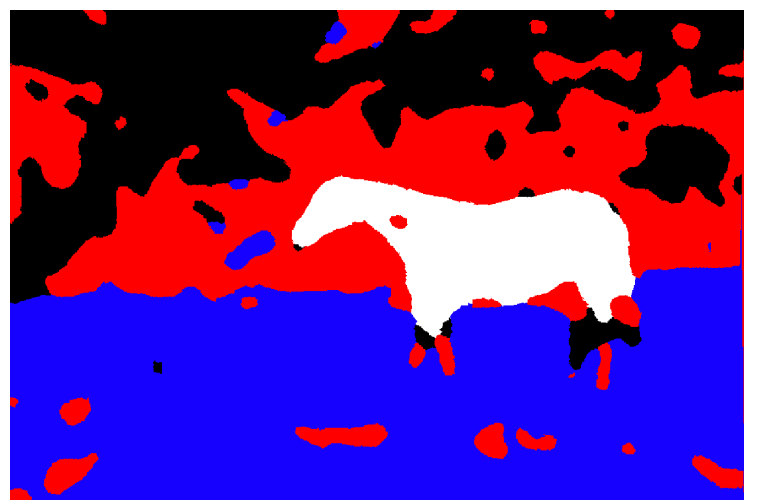

(b) Cavalo (MAE $=21.50 \%)$

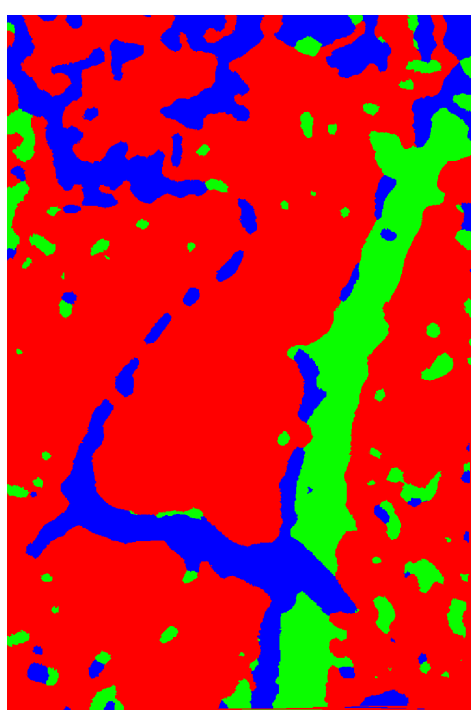

(d) Cobra (MAE $=21.17 \%$ )

Figura 5.6: Imagens geradas a partir das triangulações ilustradas na figura 5.7. 


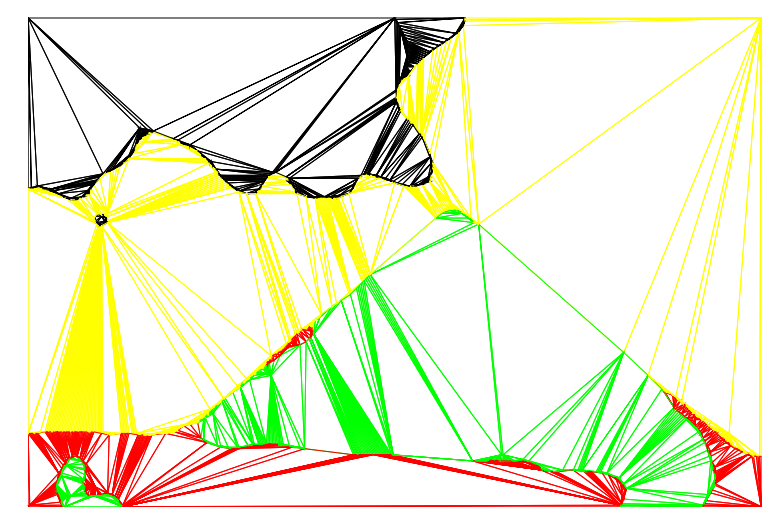

(a) Pirâmide

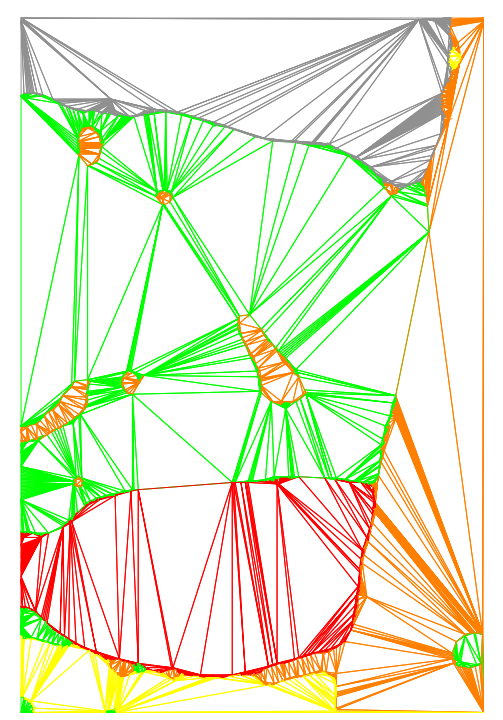

(c) Lago

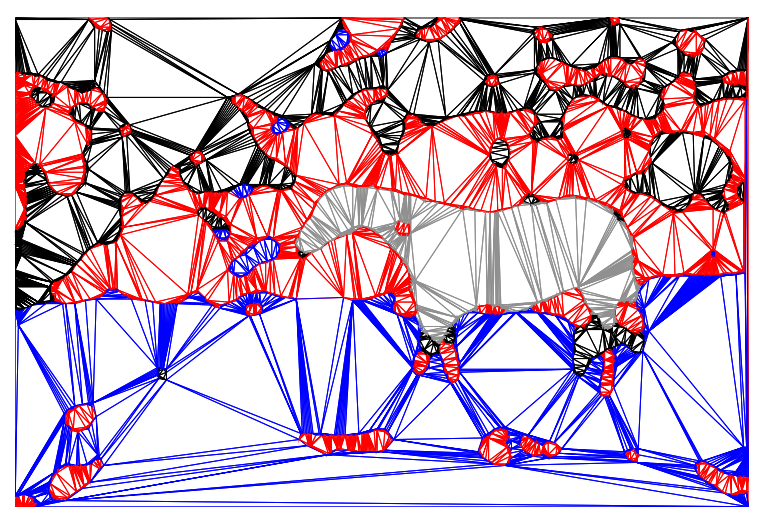

(b) Cavalo

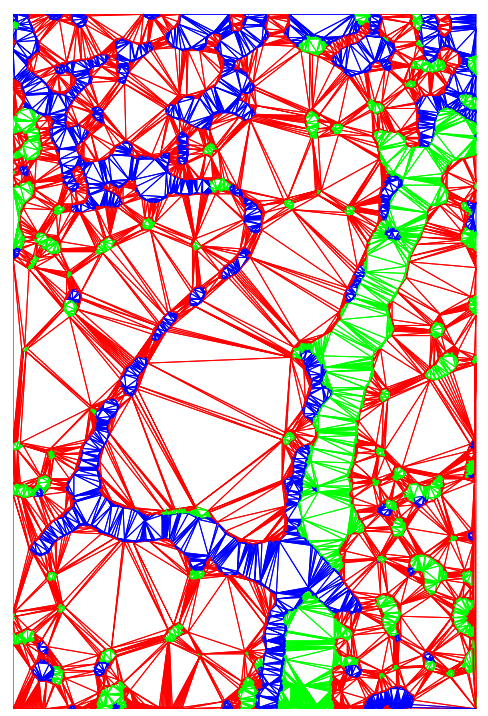

(d) Cobra

Figura 5.7: Malha triangular gerada a partir do Imesh $+\mathrm{W}$-operador. 


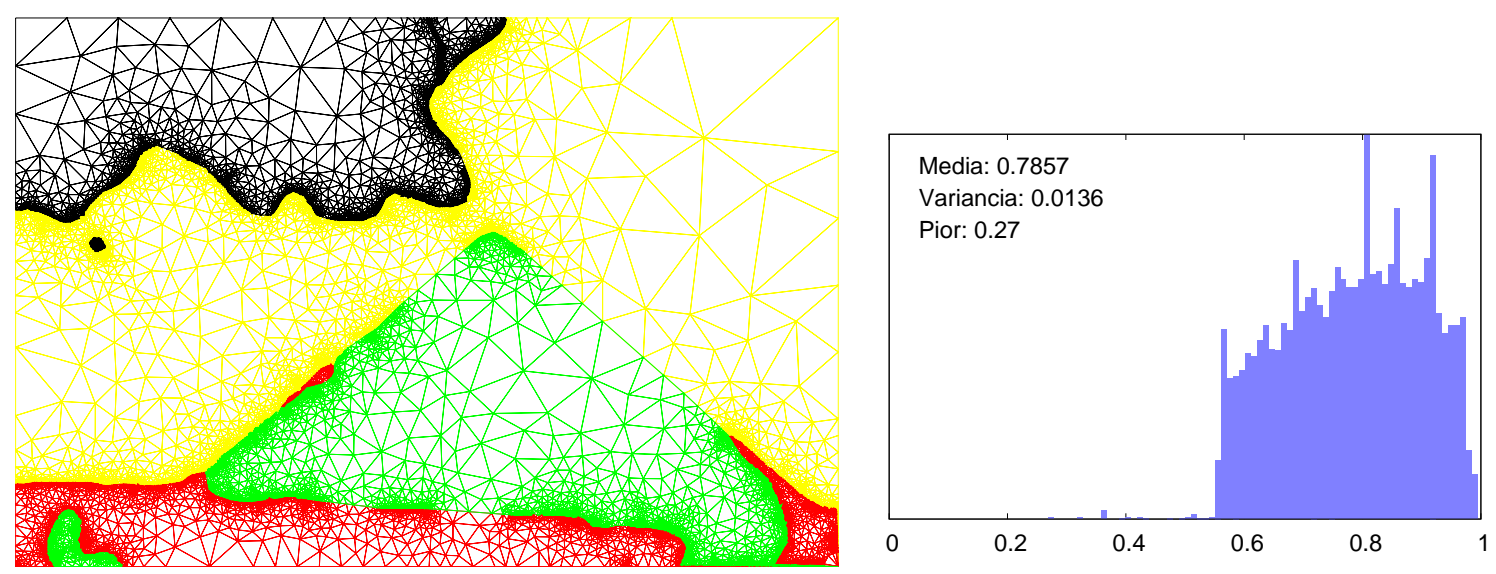

(a) Pirâmide

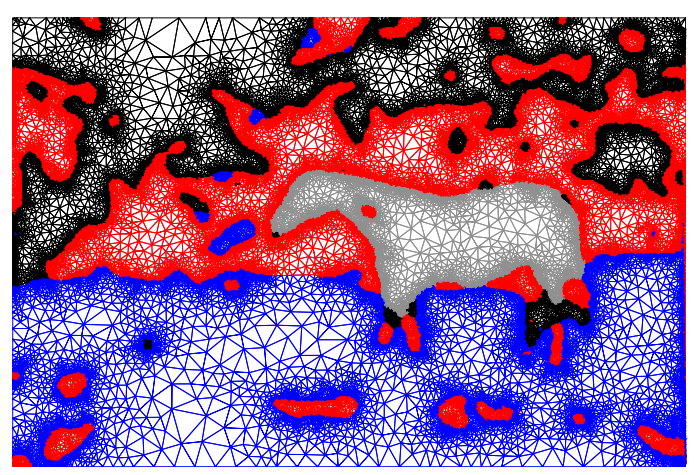

(b) Cavalo

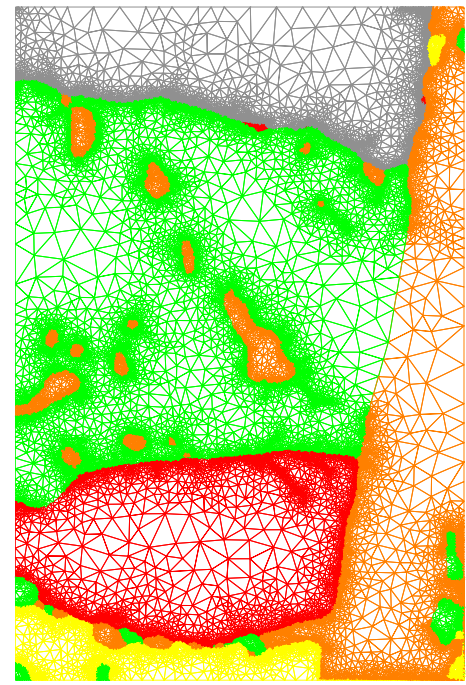

(c) Lago

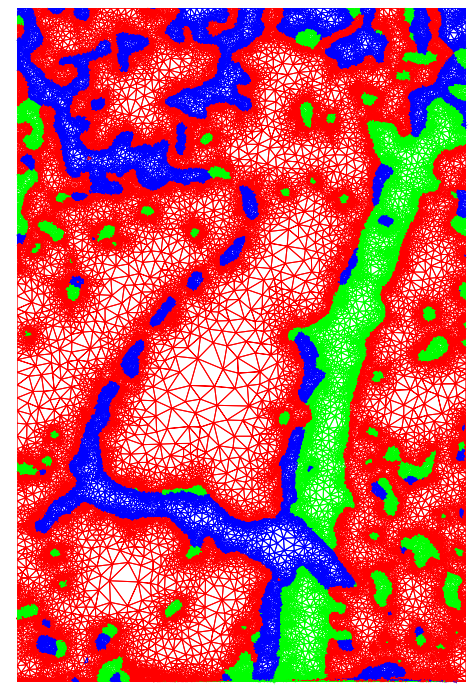

(d) Cobra

Figura 5.8: Melhoramento de malha (Ruppert) aplicado nas triangulações ilustradas nas figuras 5.7 (a,b,c,d). Em (a) temos o histograma da qualidade dos elementos da pirâmide. 


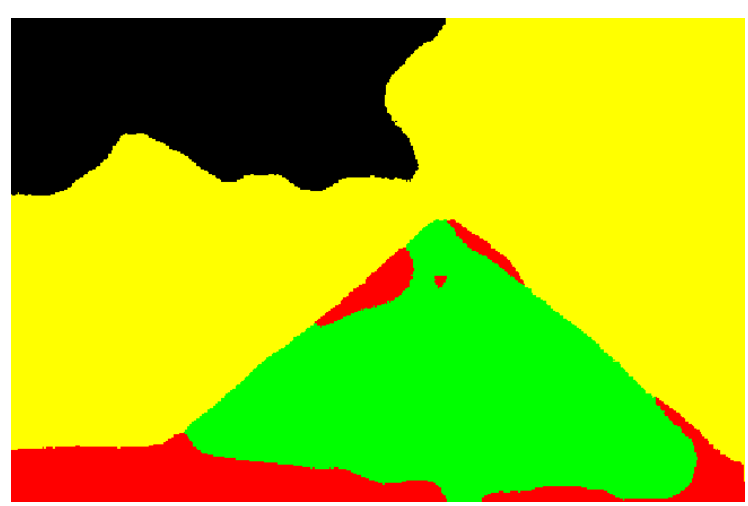

(a) Pirâmide (MAE $=9.67) \%$

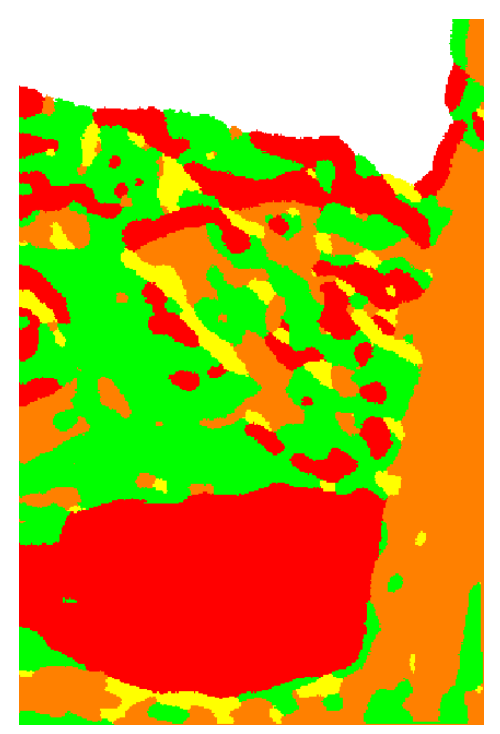

(c) Lago $(\mathrm{MAE}=30.15 \%)$

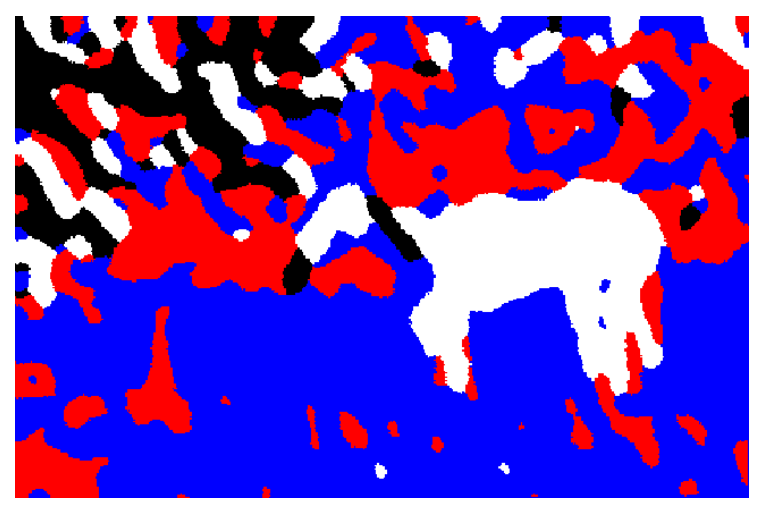

(b) Cavalo (MAE $=34.69 \%)$

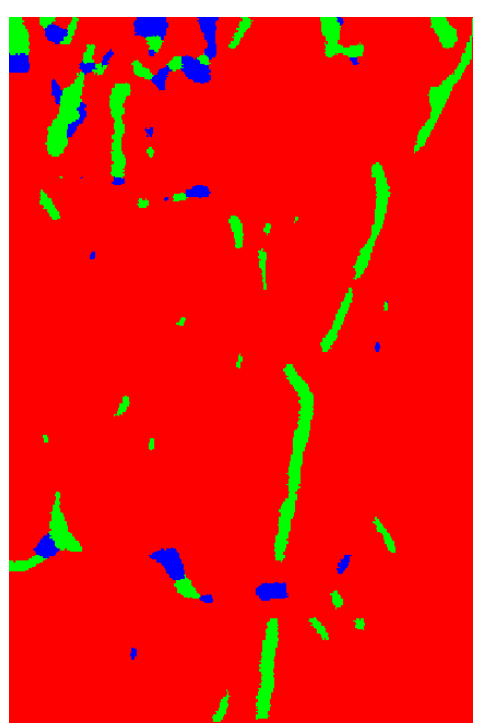

(d) Cobra $(\mathrm{MAE}=22.18 \%)$

Figura 5.9: Resultados gerados a partir do Imesh + MLP. 


\subsubsection{Imagens do VisTex dataset}

Nesta seção apresentamos os resultados gerados sobre o segundo conjunto de imagens. Estas imagens foram obtidas do VisTex Database. Os Parâmetros utilizados nestes testes foram os mesmos fixados na seção anterior: RGB+HSV, $|W|=3 \times 3, k=16$ e $d=45$. A figura 5.10 mostra as quatro imagens escolhidas e os respetivos recortes de cada classe de textura. Os resultados também mostram que as malhas, geradas pelo Imesh baseando-se nas matrizes de probabilidade condicional fornecidas pelos $\mathrm{W}$ operadores, são quase isentas de erros classificatórios cometidos pelo classificador.

As figuras 5.11, 5.12, 5.13 e 5.14 ilustram os resultados obtidos pelo classificador $\mathrm{W}$ operador e MLP, seguidos da combinação W-operador+Imesh +Ruppert para as imagens da figura 5.10. O resultado visual também indica o melhor desempenho na utilização do W-operador.

Na seção seguinte utilizaremos este mesmo conjunto de teste, mas substituiremos a abordagem baseada no refinamento de Ruppert pela abordagem proposta no capítulo 4. Desta maneira conseguiremos comparar os resultados destes dois métodos.

\subsection{Imesh+Texturas+Remalhamento}

Nesta seção apresentamos os resultados obtidos com a metodologia proposta no capítulo 4. Utilizamos nesta seção as mesmas imagens utilizadas na seção 5.1. Todas as medidas de qualidade realizada sobre triângulos estão calculadas utilizando o scaledjacobian [Knupp 2000]. Para os quadriláteros, utilizamos o shape [Knupp 2003] como medida de qualidade.

A figura 5.15 ilustra o processo inicial, execução do algoritmo Imesh utilizando o classificador por W-operador, aplicado no exemplo da pirâmide (figura 5.7a) seguido pela etapa de pré-processamento, descrita na seção 4.2.1. Na figura 5.16 temos os templates posicionados e prontos para iniciar a etapa de otimização. Nesta figura aplicamos três níveis de refinamento do template, aplicando templates com 4, 25 e 121 triângulos. Como esperado, a qualidade dos elementos da malha segue a qualidade da malha de entrada.

A etapa seguinte consiste na otimização dos pontos de controle. Na figura 5.17 encontram-se 3 etapas do processo de otimização aplicado sobre as três malhas da figura 5.16. Na primeira linha 5 iterações foram completadas. Na segunda linha outras 


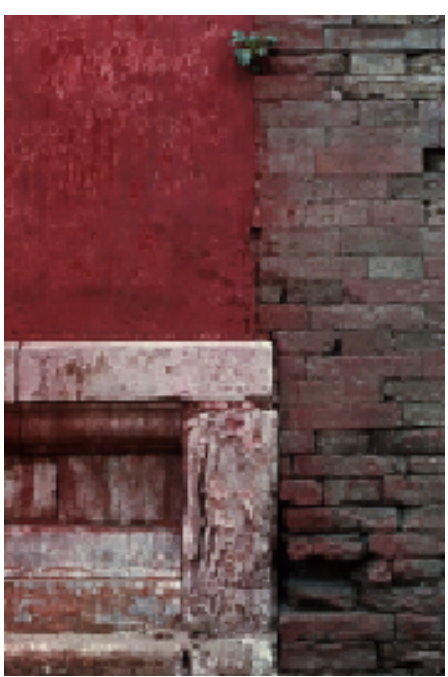

(a) Brick Paint
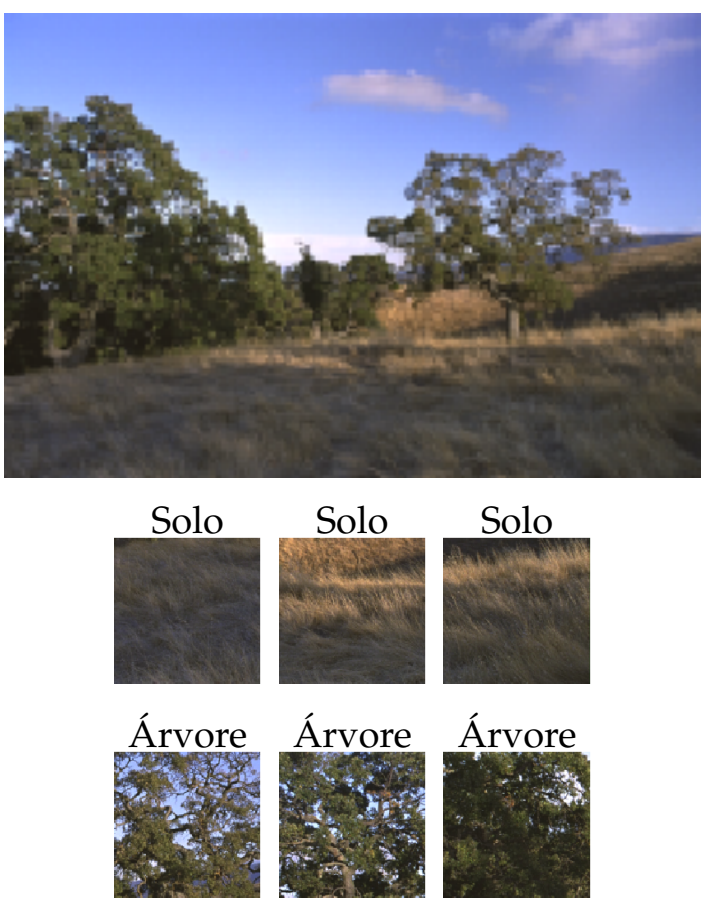

(c) Grass Land

Tijolo

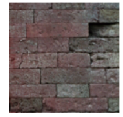

Pintura

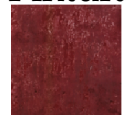

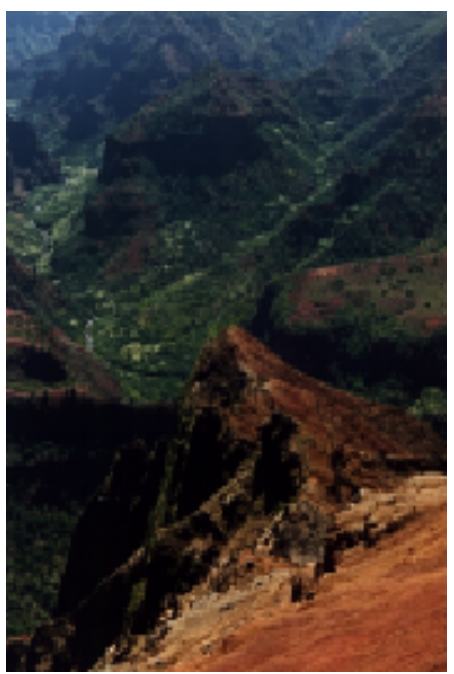

Montanha

(b) Mt Valley
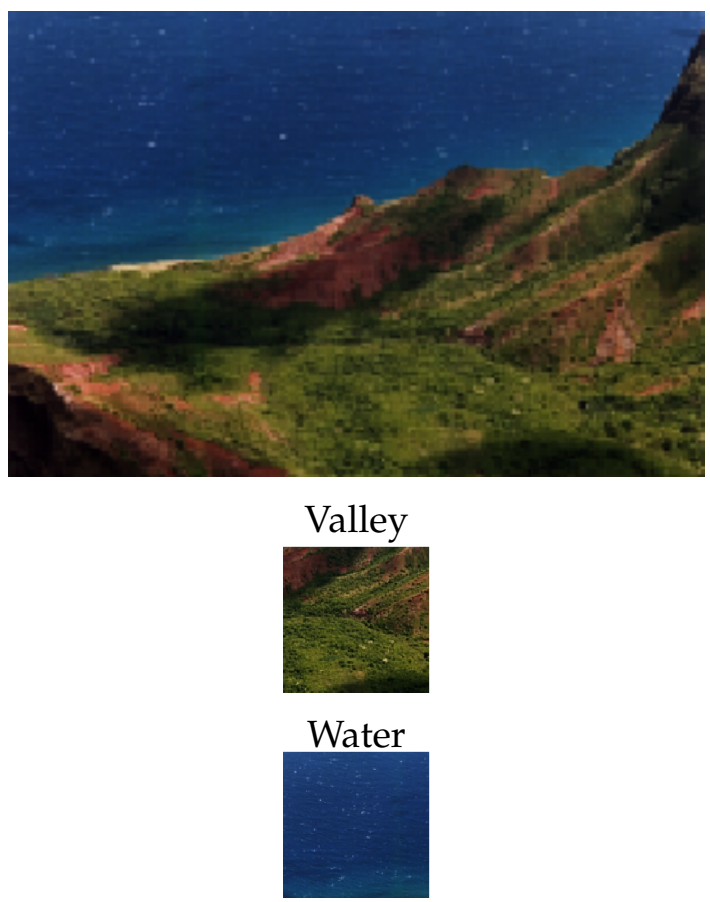

(d) Valley Water

Figura 5.10: Imagens originais selecionadas do VisTex Database e seus respectivos conjunto de treinamento (tamanho $128 \times 128$ ).

5 foram aplicadas, com a aplicação do processo de reorganização dos triângulos. Por fim, na última linha temos a estabilização da malha, com 50 iterações e 5 reorganizações realizadas. Os histogramas indicam a significativa melhora na qualidade dos elementos da malha, tendo como pior elemento o valor de 0.51 , superior ao pior elemento do refinamento de Ruppert 0.27 (figura 5.8).

Aplicamos o mesmo procedimento, mas agora utilizando o template de quadriláteros indicado na figura $4.4 \mathrm{~b}$. Ilustramos na figura 5.18 três níveis de refinamento. $\mathrm{Na}$ 


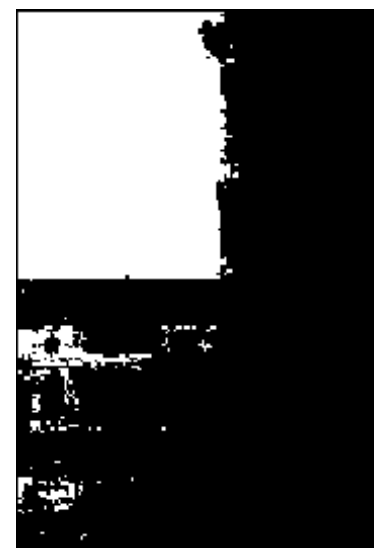

(a)

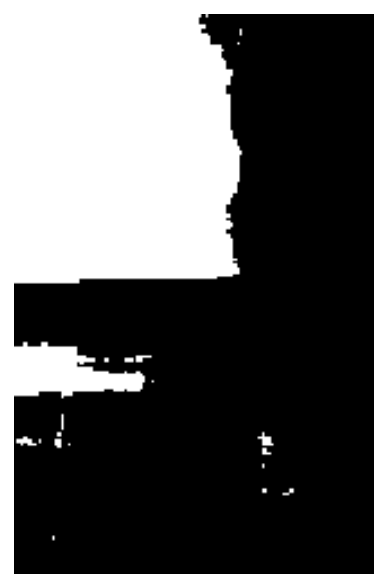

(b)

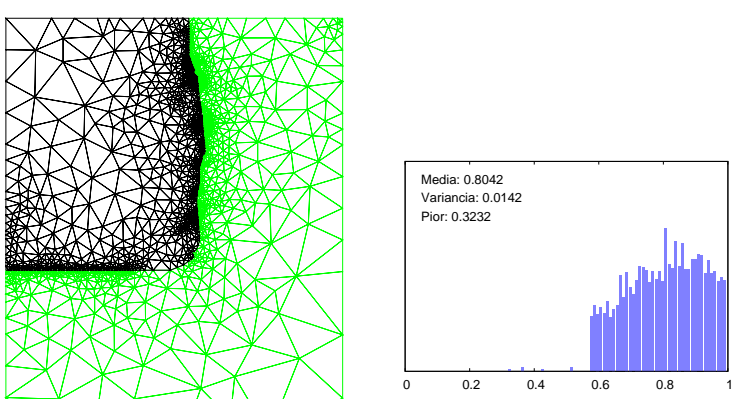

(d)

Figura 5.11: Brick Paint: (a) resultado do W-operador, (b) resultado da MLP, (c) resultado do W-operador+Imesh+Ruppert e (d) histograma da qualidade dos elementos da malha exibida em (c).

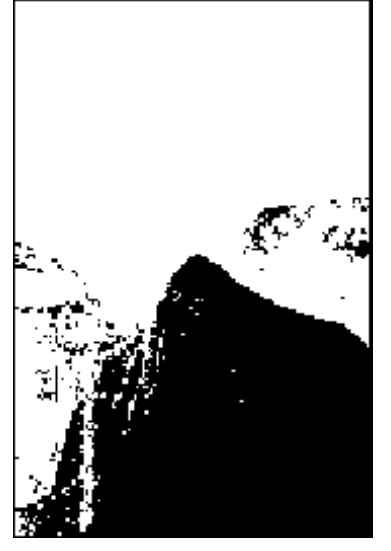

(a)

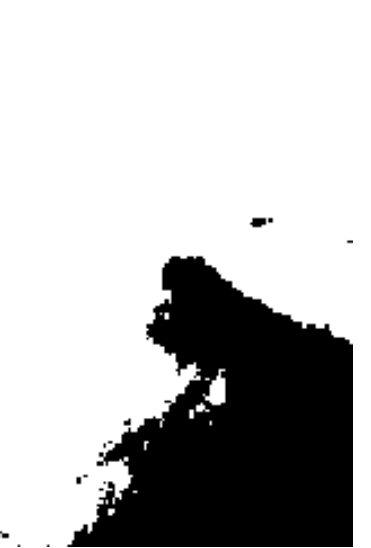

(b)

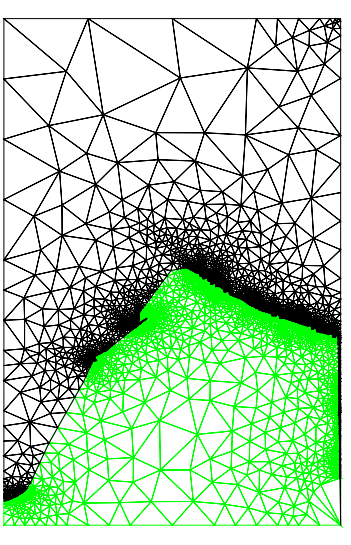

(c)

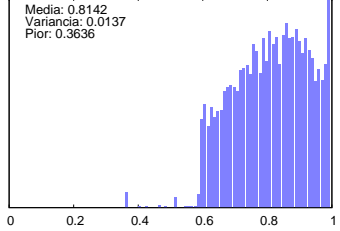

(d)

Figura 5.12: Mt Valley: (a) resultado do W-operador, (b) resultado da MLP, (c) resultado do W-operador+Imesh+Ruppert e (d) histograma da qualidade dos elementos da malha exibida em (c).

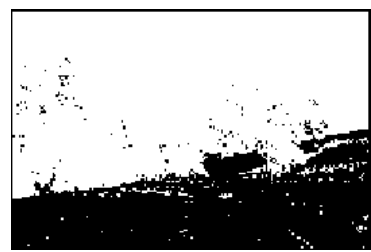

(a)

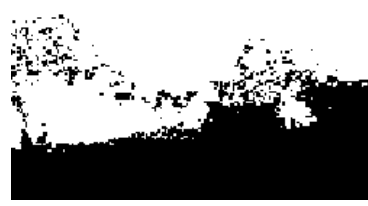

(b)

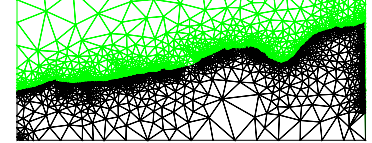

(c)

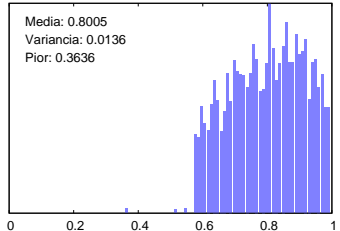

(d)

Figura 5.13: Grass Land: (a) resultado do W-operador, (b) resultado da MLP, (c) resultado do W-operador+Imesh+Ruppert e (d) histograma da qualidade dos elementos da malha exibida em (c).

figura 5.19 encontram-se os três etapas do processo iterativo de otimização dos pontos de controle. As três etapas seguem os mesmos números de iterações e reorganizações aplicados no exemplo de triângulos. Como podemos observar, todas as malhas apre- 


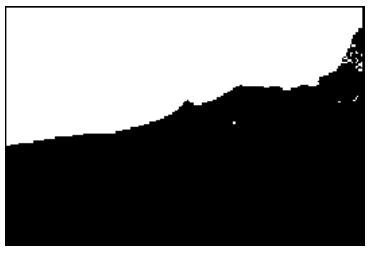

(d)

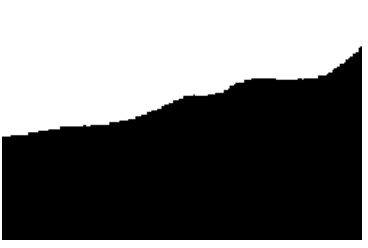

(d)

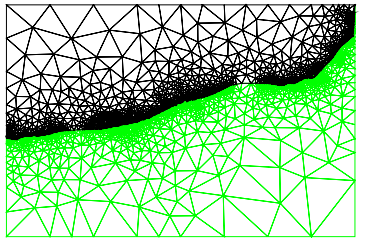

(d)

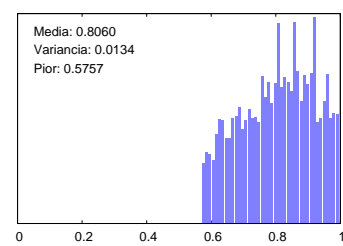

(d)

Figura 5.14: Valley Water: (a) resultado do W-operador, (b) resultado da MLP, (c) resultado do W-operador+Imesh+Ruppert e (d) histograma da qualidade dos elementos da malha exibida em (c).

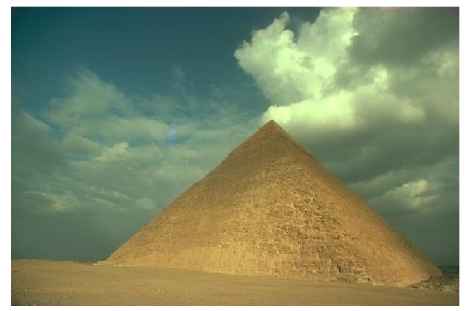

(a) Imagem original

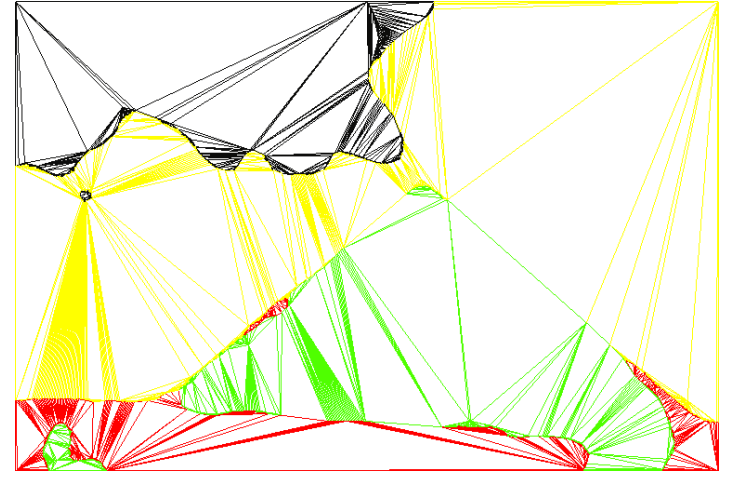

(b) Imesh $+\mathrm{W}$-operador

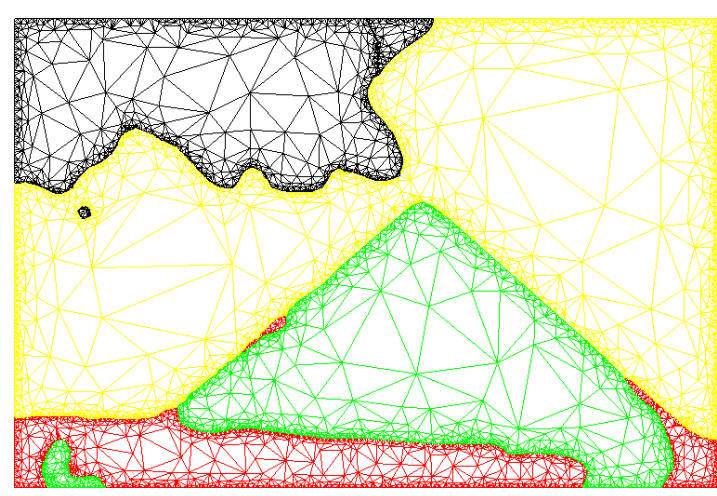

(c) Pré-processamento

Figura 5.15: Etapa iniciais: pirâmide.

sentam quadriláteros de boa qualidade.

\subsubsection{Imagens do VisTex Dataset}

Apresentamos agora o processo de remalhamento sobre as imagens do VisTex Dataset. Na figura 5.20 temos o processo inicial do exemplo da parede pintada e com tijolos, onde o Imesh + W-operador é executado sobre a imagem, seguido pelo préprocessamento da malha. Na primeira linha da figura 5.21 temos a aplicação dos dois tipos de templates seguido pela etapa de otimização dos pontos de controle. Por fim, temos os respectivos histogramas da qualidade dos elementos.

Nas figuras 5.22, 5.23, 5.24, 5.25, 5.26 e 5.27, seguimos as mesmas etapas, apli- 

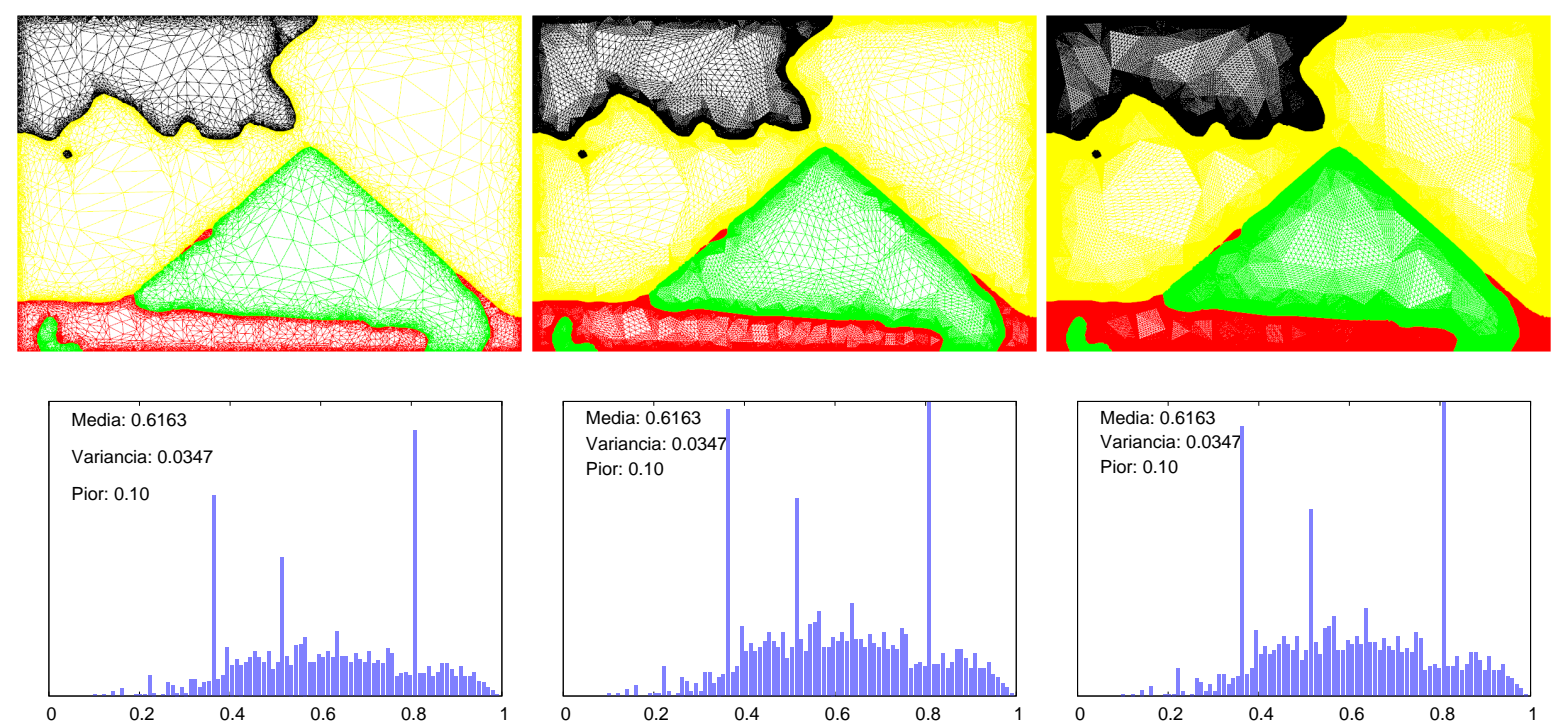

Figura 5.16: Aplicação do template de triângulos com três níveis de refinamento. Abaixo de cada refinamento encontra-se o histograma da qualidade dos elementos da respectiva malha.

cando nos demais modelos apresentados deste banco de imagens. Em todos os casos conseguimos melhorar significativamente a qualidade malha, e em comparação com a abordagem baseada no refinamento de Ruppert, apenas no exemplo grassland houve uma leve piora na qualidade do pior elemento.

\subsection{Discussão}

A abordagem baseada em templates torna flexível o processo de remalhamento, permitindo um refinamento adaptativo e geração de elementos quadrangulares. Em todos os testes realizados, conseguimos resultados bidimensionais de excelente qualidade. Partindo de uma imagem com textura até a geração de malhas triangulares e ou quadrangulares, ambas apropriadas para aplicações de simulação numérica. Não encontramos ainda tais funcionalidades em qualquer outra técnica presente na literatura.

Todos os resultados apresentados foram executados em um processador Intel(R) Core(TM)2 Quad de 2.4 GHz com 4GB de memória RAM. O tempo de processamento para a geração dos resultados apresentados estão dispostos na tabela 5.5, para os modelos triangulares, e na tabela 5.6, para os modelos de quadriláteros. O tempo total de cada teste está dividido na etapa relativa ao algoritmo Imesh e na etapa de remalhamento. Não está incluído o tempo necessário para o treinamento do classificador 

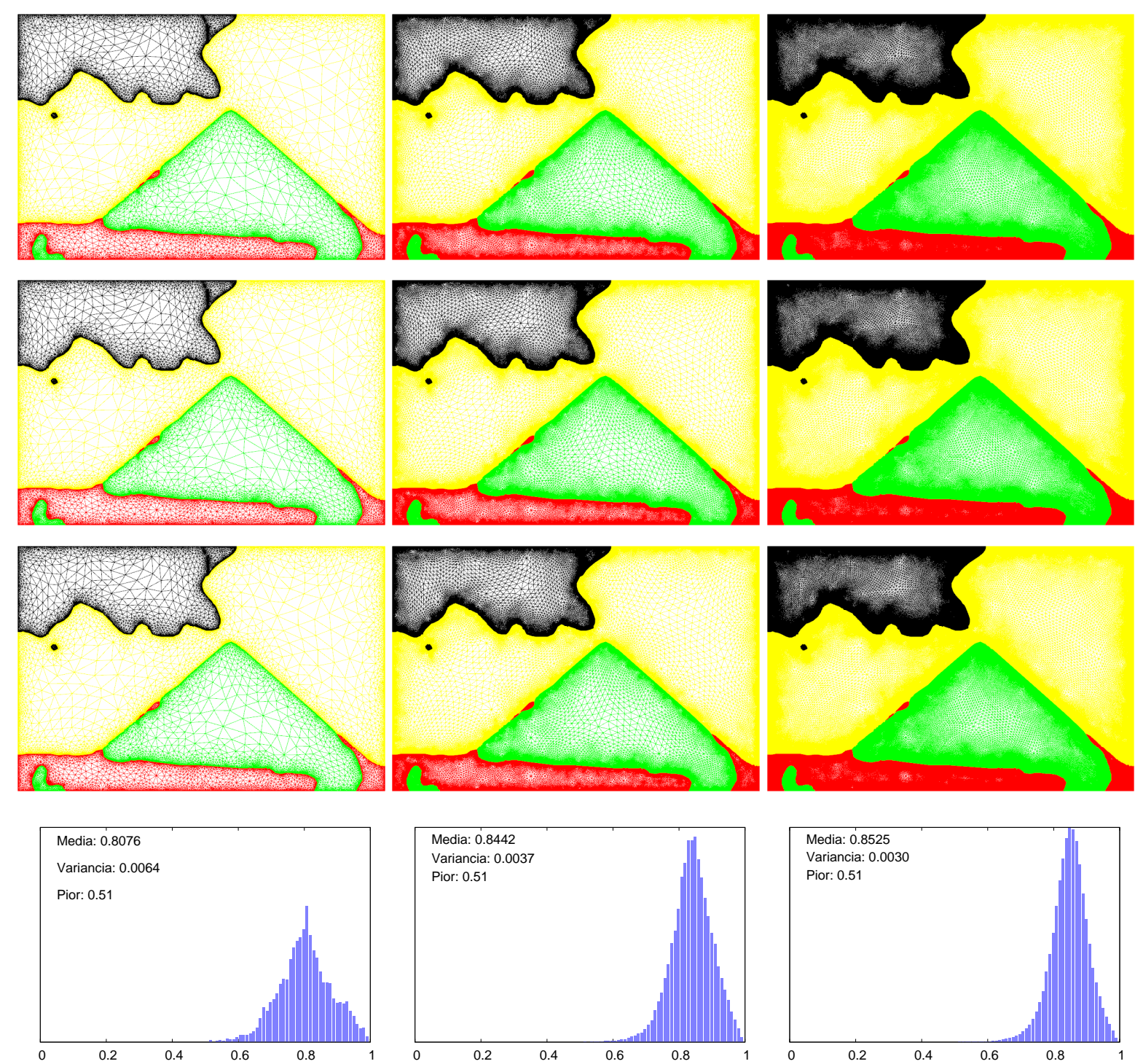

Figura 5.17: Etapas da otimização sobre as malhas da figura 5.16. Em cada coluna encontra-se um nível diferente de refinamento. 

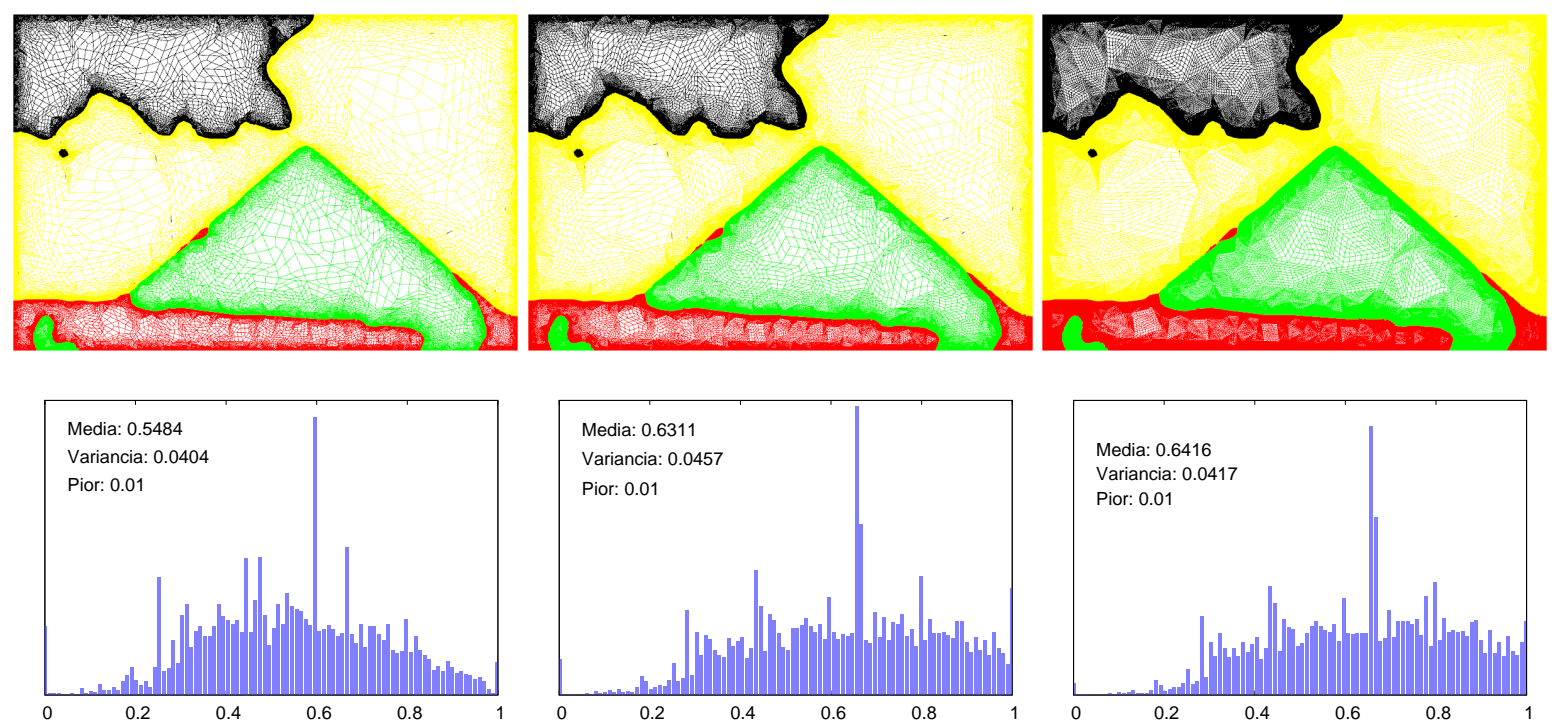

Figura 5.18: Aplicação do template de quadriláteros com três níveis de refinamento. Abaixo de cada refinamento encontra-se o histograma da qualidade dos elementos da respectiva malha.

W-operador.

Como podemos observar, o tempo de processamento requisitado pode tornar proibitivo o uso desta metodologia em malhas muito grandes. A implementação atual não realiza qualquer procedimento em paralelo, possibilidade que acreditamos tornar esta metodologia muito mais competitiva.

A etapa mais custosa computacionalmento do algoritmo é o processo de otimização dos pontos de controle. Nesta etapa, o cálculo da qualidade dos elementos representa a maior parte do tempo consumido, pois a cada movimento de um ponto de controle, todos os elementos, influenciados pelo respectivo ponto de controle, da malha regerada precisam ter suas medidas de qualidade atualizadas. Porém, este processo é altamente paralelizável, pois cada ponto de controle exerce uma influencia local sobre a malha regerada. Além disso, a topologia da malha não é alterada durante esta etapa, o que tornam as relações de vizinhança entre regiões de influência de pontos de controle fixas. Sendo assim, uma divisão da malha por processador é praticamente imediata. 

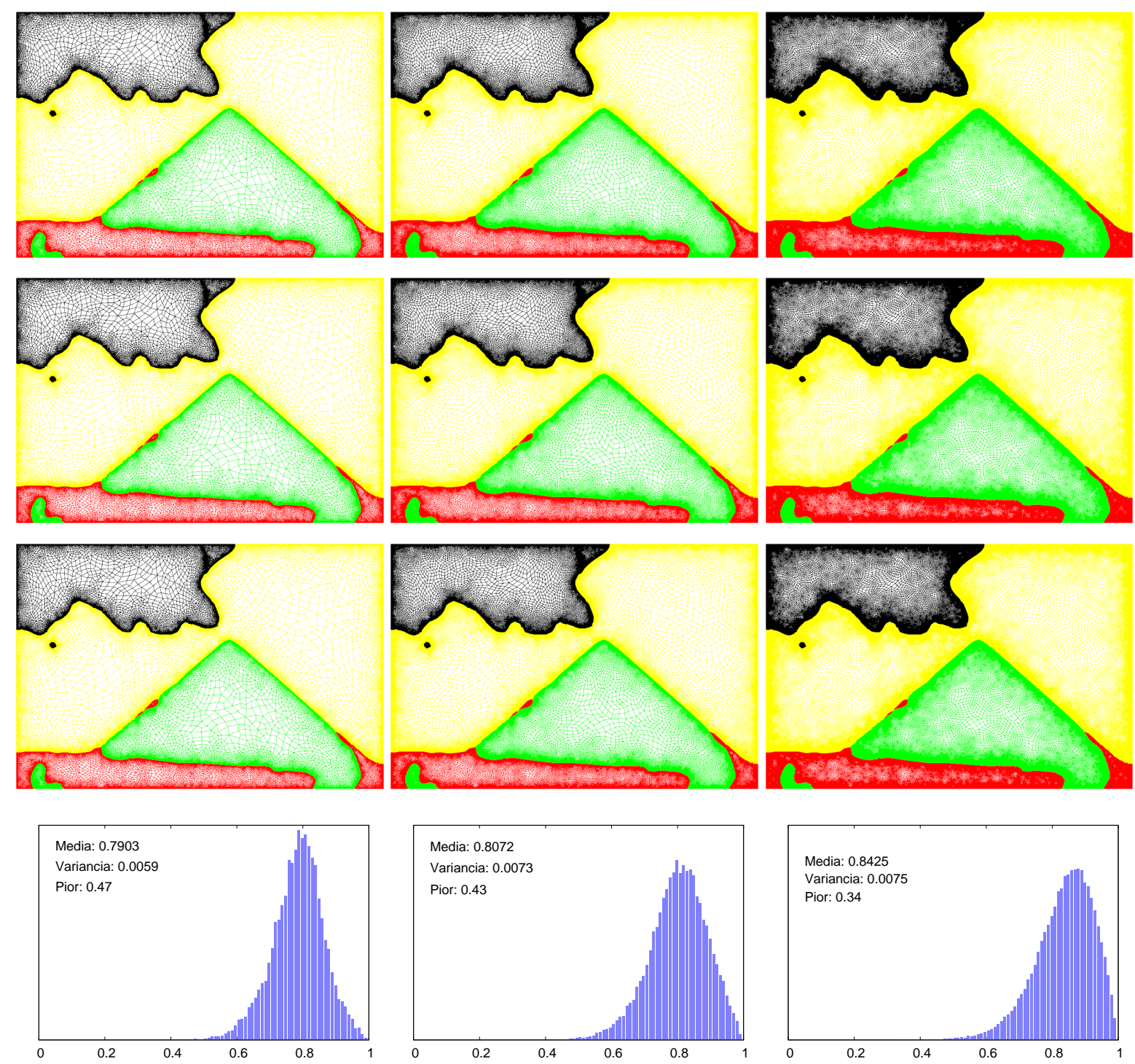

Figura 5.19: Etapas da otimização sobre as malhas da figura 5.18. Em cada coluna encontra-se um nível diferente de refinamento.
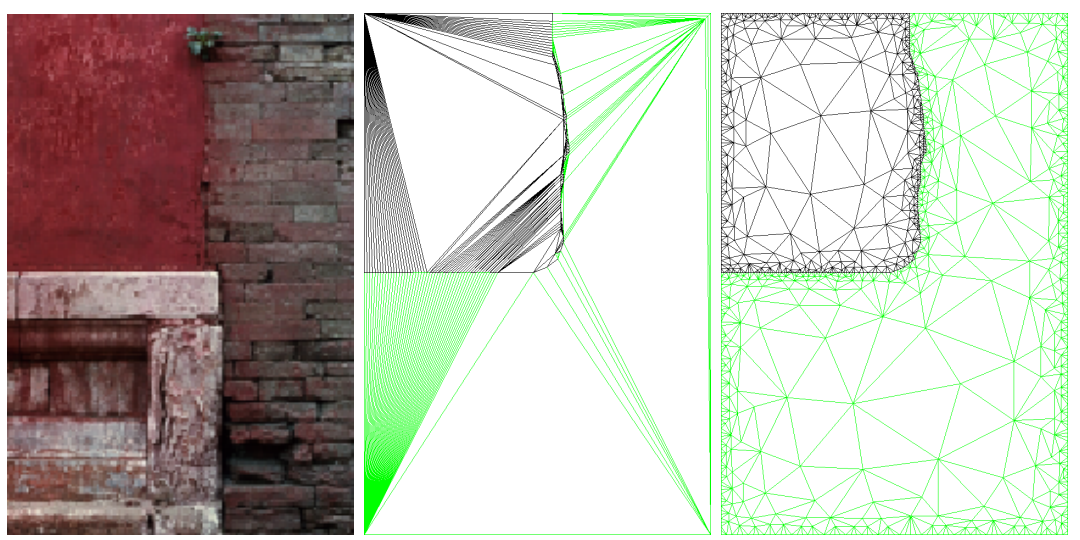

Figura 5.20: Remalhamento do exemplo Brick Paint utilizando template de triângulos e quadriláteros. 

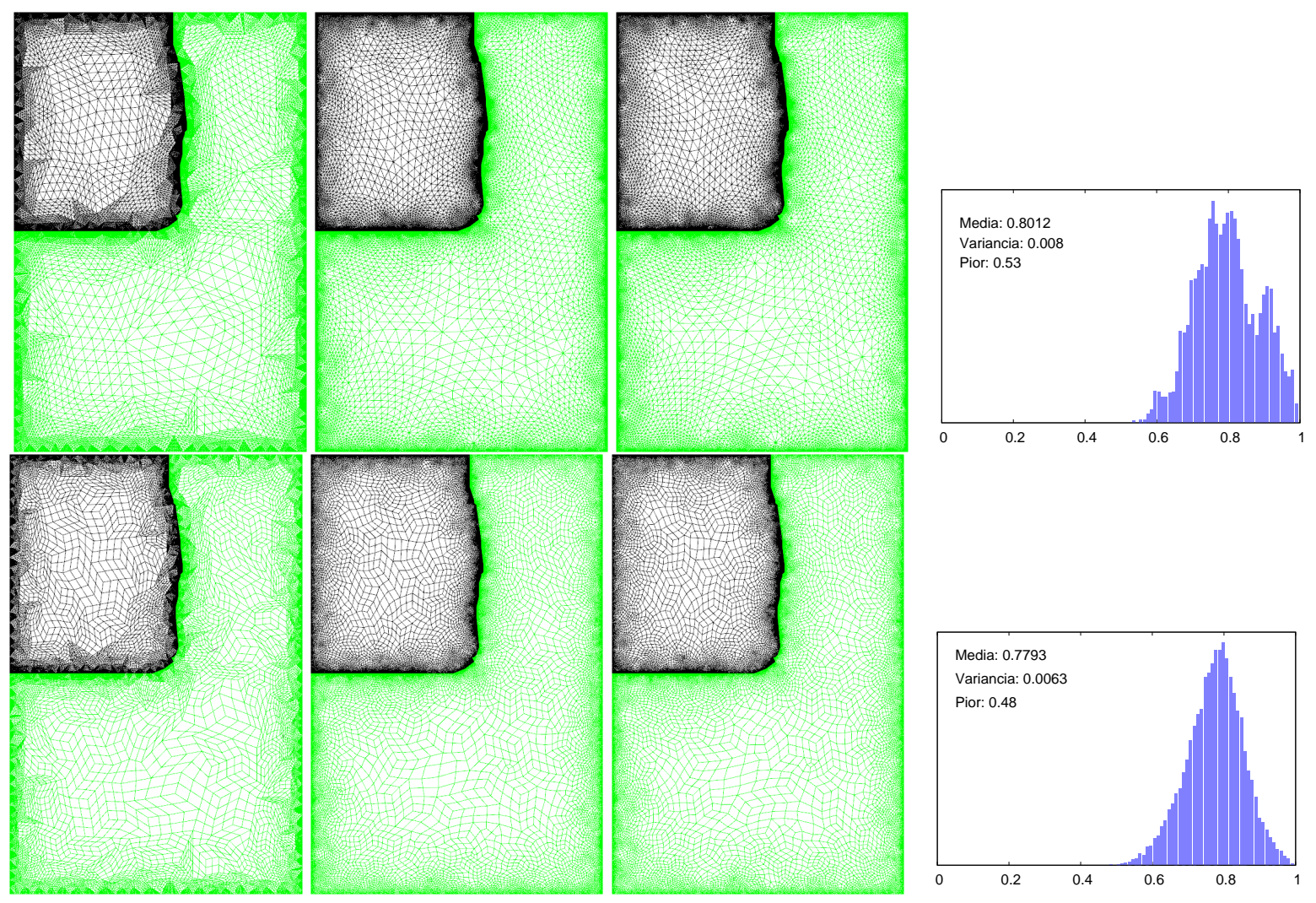

Figura 5.21: Remalhamento do exemplo Brick Paint utilizando template de triângulos e quadriláteros.
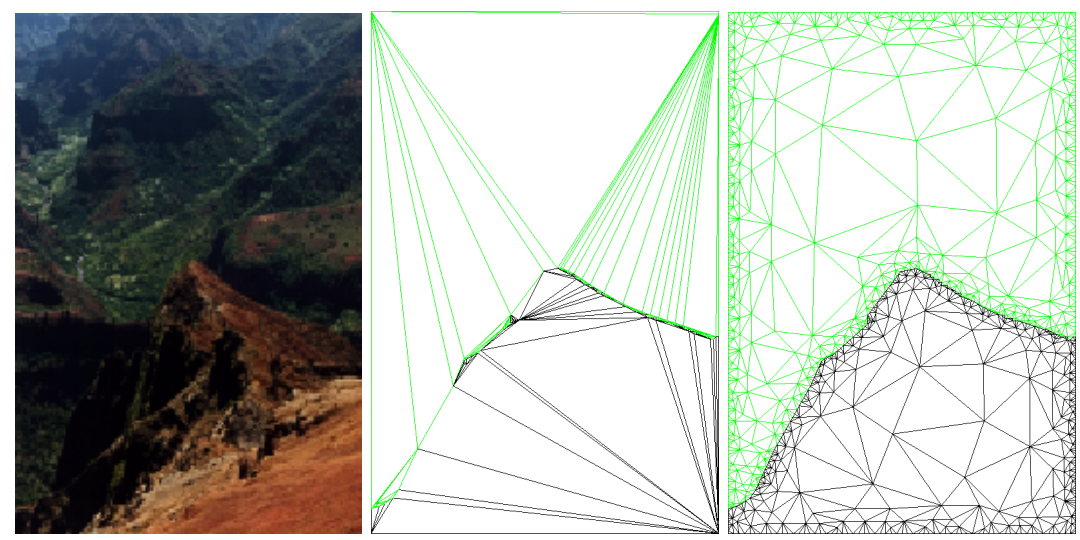

Figura 5.22: Remalhamento do exemplo Mt Valley utilizando template de triângulos e quadriláteros. 

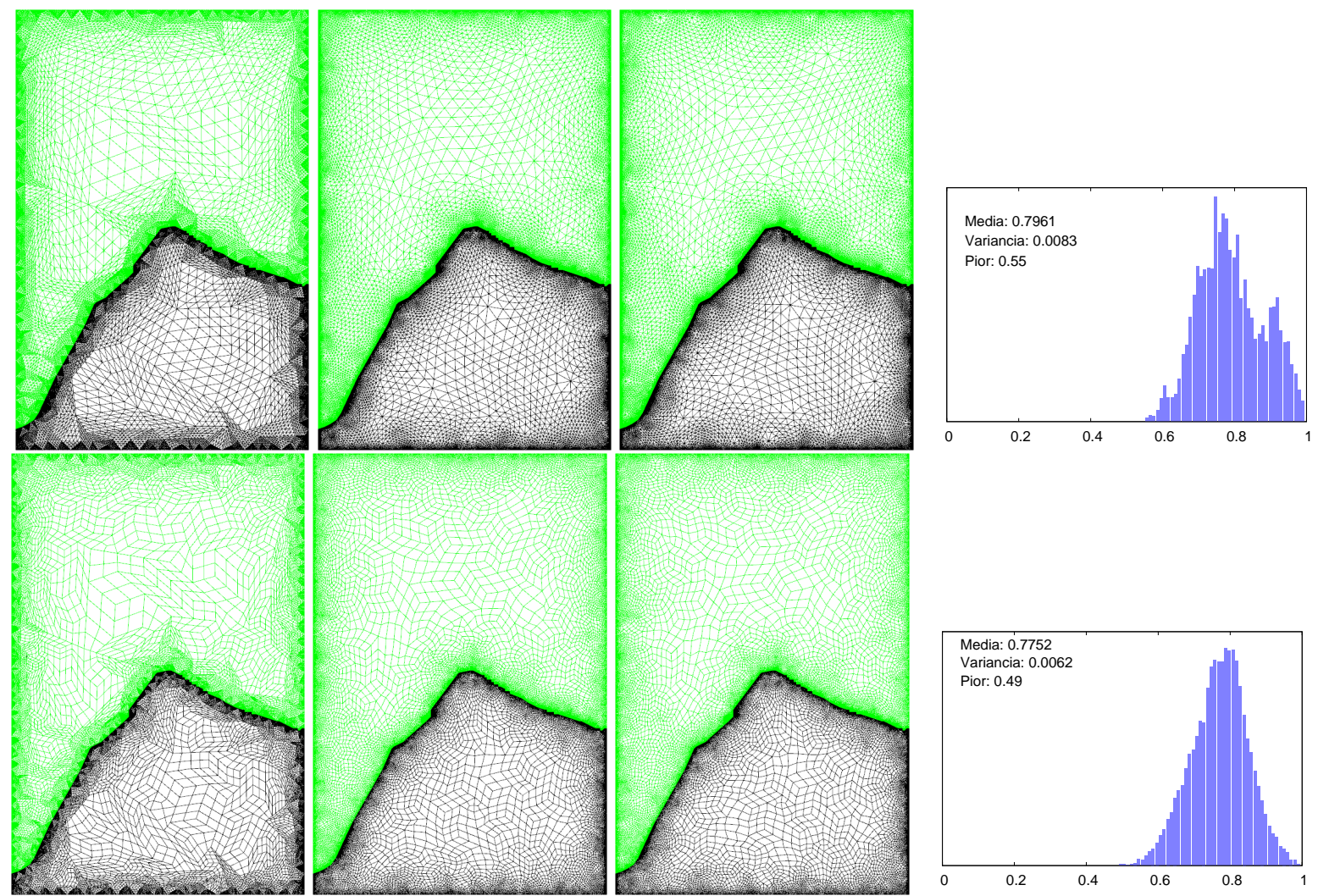

Figura 5.23: Remalhamento do exemplo Mt Valley utilizando template de triângulos e quadriláteros.
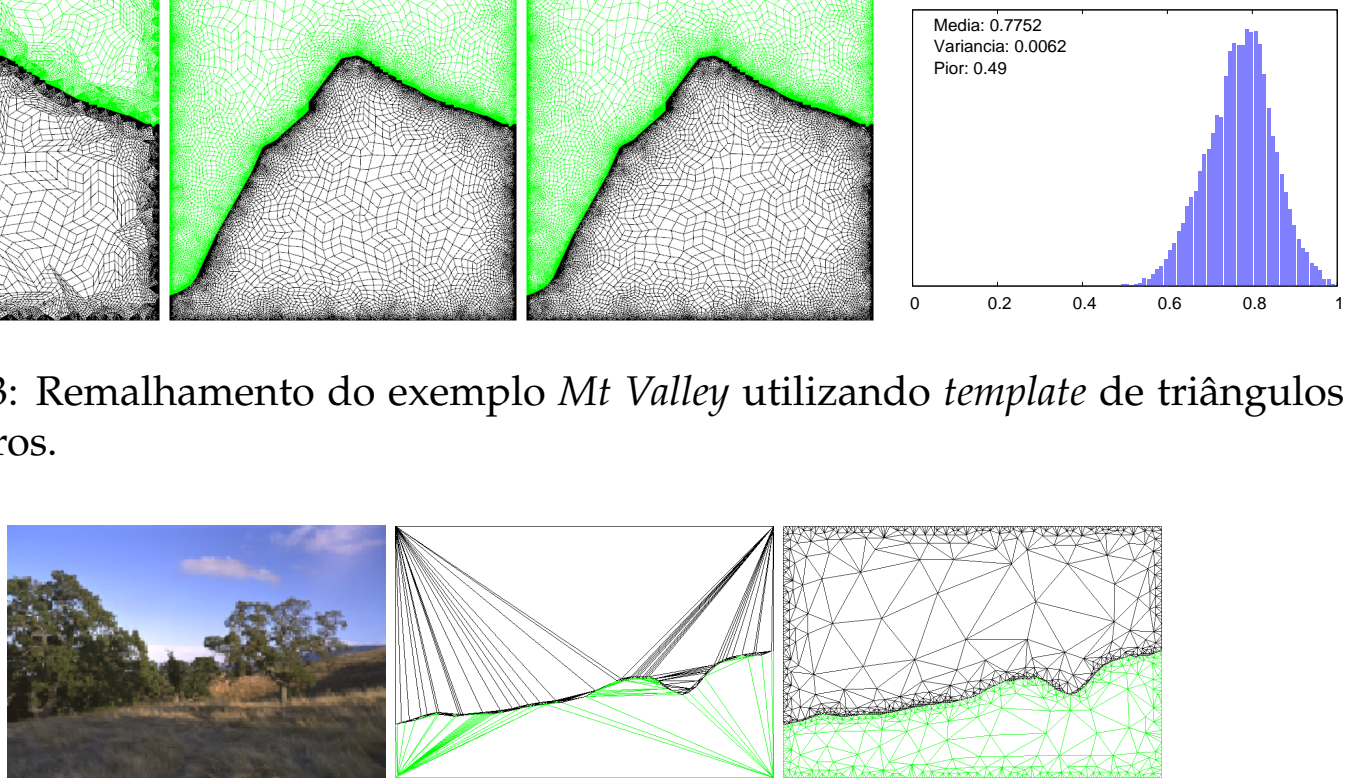

Figura 5.24: Remalhamento do exemplo Grass Land utilizando template de triângulos e quadriláteros.
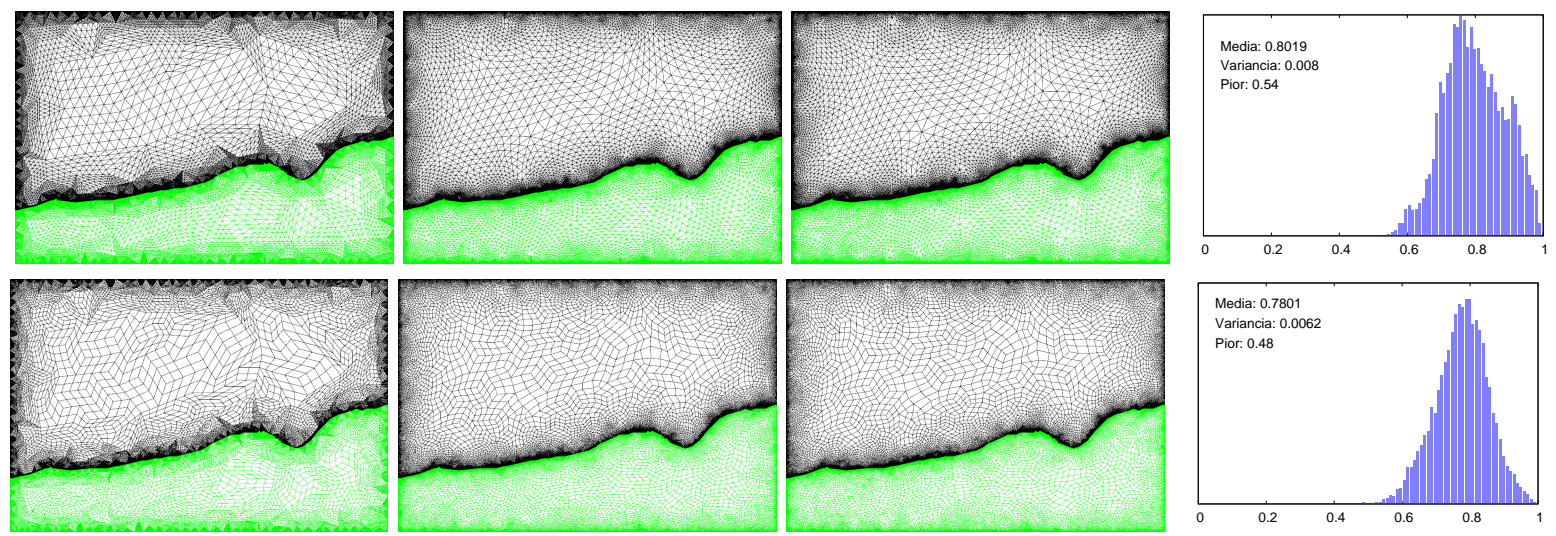

Figura 5.25: Remalhamento do exemplo Grass Land utilizando template de triângulos e quadriláteros. 

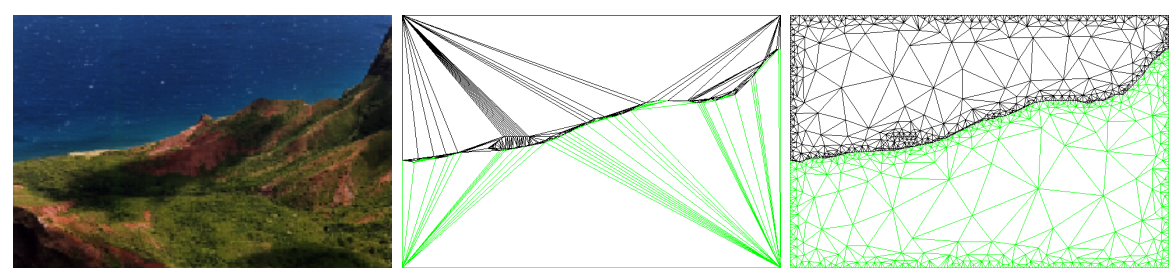

Figura 5.26: Remalhamento do exemplo Valley Water utilizando template de triângulos e quadriláteros.
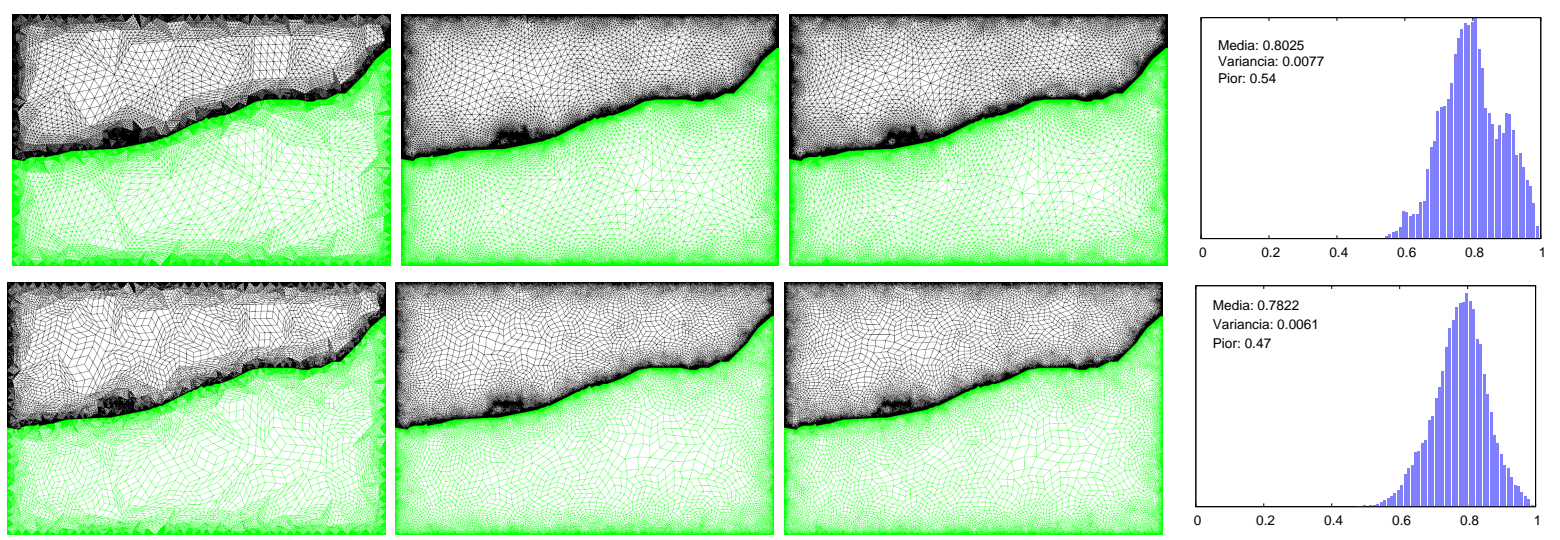

Figura 5.27: Remalhamento do exemplo Valley Water utilizando template de triângulos e quadriláteros.

\subsection{Limitações}

Embora o tempo de processamento possa ser considerado uma limitação do algoritmo, este não tem influência no resultado final obtido. Consideramos como limitações dois pontos que diretamente afetam o resultado final.

A primeira limitação do método de ramalhamento está na geração de templates dependente do grau do vértice da malha de entrada.

Outra limitação no método encontra-se no não tratamento do bordo. Durante todo o processo o bordo é estritamente respeitado, ou seja, o movimento dos pontos de controle do bordo estão limitados ao próprio bordo. Esta limitação além de influenciar o movimento ideal para a melhora da qualidade dos elementos, não permite uma melhor adaptação do bordo ao objeto real. Com alguma informação adicional do bordo, além do contido na malha de entrada, podemos não limitar o movimento dos pontos de controle que estão sobre o bordo. Este recurso permitira uma melhor representação do bordo do objeto de interesse. 


\begin{tabular}{|c|c|c|c|c|}
\hline Imagem & $\begin{array}{c}\text { Tempo (em s) } \\
\text { Imesh (sem Ruppert) }\end{array}$ & $\begin{array}{l}\mathrm{N}^{\mathrm{o}} \mathrm{de} \\
\text { triângulos }\end{array}$ & $\begin{array}{l}\text { Tempo (em s) } \\
\text { Remalhamento }\end{array}$ & triângulos /s \\
\hline \multirow{3}{*}{ Pirâmide } & \multirow{3}{*}{2.47} & 37.988 & 186,19 & 204 \\
\hline & & 237.425 & 956,09 & 248 \\
\hline & & 1.149 .137 & 6820,4 & 168 \\
\hline \multirow{3}{*}{ Brick Paint } & \multirow{3}{*}{0.48} & 6.920 & 32,81 & 211 \\
\hline & & 43.250 & 159,33 & 271 \\
\hline & & 209.330 & 733,65 & 285 \\
\hline \multirow{3}{*}{ Mt Valley } & \multirow{3}{*}{0.27} & 6.396 & 30,32 & 211 \\
\hline & & 39.975 & 149,87 & 267 \\
\hline & & 193.479 & 663,93 & 291 \\
\hline \multirow{3}{*}{ Grass Land } & \multirow{3}{*}{0.36} & 7.592 & 36,33 & 209 \\
\hline & & 47.450 & 176,76 & 268 \\
\hline & & 229.658 & 817,33 & 281 \\
\hline \multirow{3}{*}{ Valley Water } & \multirow{3}{*}{0.38} & 8.048 & 39,93 & 202 \\
\hline & & 50.300 & 205,02 & 245 \\
\hline & & 243.452 & 874,14 & 279 \\
\hline
\end{tabular}

Tabela 5.5: Tempo de processamento dos testes de template de triângulos.

\begin{tabular}{|c|c|c|c|c|}
\hline Imagem & $\begin{array}{c}\text { Tempo (em s) } \\
\text { Imesh (sem Ruppert) }\end{array}$ & $\begin{array}{c}\mathrm{N}^{\circ} \text { de } \\
\text { quadriláteros }\end{array}$ & $\begin{array}{l}\text { Tempo (em } s) \\
\text { Remalhamento }\end{array}$ & quads/s \\
\hline \multirow{3}{*}{ Pirâmide } & \multirow{3}{*}{2.47} & 92.530 & 660,28 & 140 \\
\hline & & 178.003 & 1235,79 & 144 \\
\hline & & 519.895 & 5671,76 & 92 \\
\hline \multirow{3}{*}{ Brick Paint } & \multirow{3}{*}{0.48} & 16.934 & 112,23 & 151 \\
\hline & & 32.504 & 185,12 & 176 \\
\hline & & 94.784 & 536,1 & 178 \\
\hline \multirow{3}{*}{ Mt Valley } & \multirow{3}{*}{0.27} & 15.688 & 102,14 & 154 \\
\hline & & 30.079 & 170,82 & 176 \\
\hline & & 87.643 & 472,64 & 185 \\
\hline \multirow{3}{*}{ Grass Land } & \multirow{3}{*}{0.36} & 18.560 & 124,28 & 149 \\
\hline & & 35.642 & 206,81 & 172 \\
\hline & & 103.970 & 610,83 & 170 \\
\hline \multirow{3}{*}{ Valley Water } & \multirow{3}{*}{0.38} & 19.628 & 132,29 & 148 \\
\hline & & 37.736 & 221,53 & 170 \\
\hline & & 110.168 & 685,64 & 161 \\
\hline
\end{tabular}

Tabela 5.6: Tempo de processamento dos testes de template de quadriláteros. 


\section{Conclusões}

Apresentamos neste trabalho as contribuições realizadas na melhoria do algoritmo Imesh, ao sanar duas de suas principais limitações: tratamento de imagens com texturas; e flexibilização na geração de malha incluindo maior controle no nível de refinamento e a possibilidade de gerar malhas de quadriláteros. Tais contribuições ampliam o domínio de aplicações, a medida que são considerados domínios definidos por imagens com textura e métodos numéricos para elementos não simpliciais.

Com as novas funcionalidades incorporadas durante este projeto de doutorado, a técnica Imesh se tornou uma das únicas a possibilitar a criação de malhas com qualidade que respeitam características dos objetos contidos em imagens com textura. Os resultados obtidos com a integração do algoritmo gerador de malha com o classificador W-operador mostraram-se superiores que os obtidos por processo de segmentação independente. Esta combinação reduz drasticamente o problema de ruídos na definição da textura, pois as texturas passam a ser definidas por triângulos ao invés de pixels.

A nova abordagem de remalhamento apresenta resultados bastante promissores, permitindo flexibilidade no processo de refinamento, assim como a geração de malhas quadrangulares. A qualidade da malha gerada torna apropriado o uso desta técnica em aplicações voltadas para métodos numéricos, assim como em representação de imagens. Devido à modelagem realizada pelos retalhos de Bézier, o espaço de armazenamento das informações necessárias para o remalhamento é bastante inferior ao total da malha regerada, independentemente do nível de refinamento. Tais características nos motiva a propor uma série de melhorias futuras. 


\subsection{Trabalhos futuros}

Como trabalhos futuros, acreditamos na viabilidade de duas alterações principais: otimização da implementação computacional e a adaptação para o espaço tridimensional.

Com relação a implementação, consideramos que até o momento todos os processos aqui apresentados permitem a exploração de processamento paralelo. Em diversos pontos do algoritmo, como por exemplo o processo de minimização da função energia (seção 4.2.3), presenciamos tarefas altamente paralelizáveis. Neste exemplo em questão, realizamos o movimento dos pontos de controle, que por sua vez influenciam apenas uma região local da malha. Não vemos impedimento algum na movimentação simultânea de pontos de controle, desde que suas regiões de influência não possuam intersecções. Um outro exemplo em que uma implementação mais eficiente contribuirá significativamente para um melhor desempenho da abordagem, consiste na paralelização da geração da malha baseada no algoritmo Imesh. Seguindo as propriedades de Delaunay, as alterações efetuadas são localmente influenciáveis.

A segunda alteração, objetivo pelo qual sempre justificou as escolhas realizadas até então, se refere ao remalhamento no espaço tridimensional. Acreditamos ser possível a adequação do algoritmo aqui proposto para sua execução a partir de malhas de tetraedros.

Outras limitações presentes na abordagem atual, que motivariam alterações futuras, referem-se ao tratamento especial realizado no bordo da malha. Acreditamos ser possível uma melhor aproximação do bordo do objeto de interesse durante o processo de remalhamento. 


\section{Referências Bibliográficas}

[Aurenhammer 1991] Aurenhammer, F. (1991). Voronoi diagrams-a survey of a fundamental geometric data structure. ACM Computing Surveys, 23:345-405.

[Baehmann et al. 1987] Baehmann, P. L., Wittchen, S. L., Shephard, M. S., Grice, K. R., e Yerry, M. A. (1987). Robust, geometrically based, automatic two-dimensional mesh generation. International Journal for Numerical Methods in Engineering, 24:1043-1078.

[Bajaj et al. 1996] Bajaj, C., Coyle, E., e Lin, K. (1996). Arbitrary topology shape reconstruction from planar cross sections. Graphical models and image processing, 58:524-543.

[Baumgart 1975] Baumgart, B. (1975). A polyhedron representation for computer vision. In Proceedings of the May 19-22, 1975, national computer conference and exposition, page 589-596. ACM New York, NY, USA.

[Bentley 1975] Bentley, J. (1975). Multidimensional binary search trees used for associative searching. Communications of the ACM, 189pp:509-517.

[Bern and Eppstein 1992] Bern, M. e Eppstein, D. (1992). Mesh generation and optimal triangulation, pages 23-90. World Scientific Publishing, computing edition.

[Bern and Gilbert 1992] Bern, M. e Gilbert, J. (1992). Drawing the planar dual. Information Processing Letters, 43:7-13.

[Berti 2004] Berti, G. (2004). Image-based unstructured 3d mesh generation for medical applications. In European Congress on Computational Methods in Applied Sciences and Engineering ECCOMAS, page 24-28.

[Boissonnat 1988] Boissonnat, J. D. (1988). Shape reconstruction from planar cross sections. Computer Vision, Graphics, and Image Processing, 44:1-29.

[Boissonnat et al. 2009] Boissonnat, J.-d., Pons, J.-p., e Yvinec, M. (2009). From segmented images to good quality meshes using delaunay refinement. Lecture Notes in Computer Science, 5416:13-37.

[Canann et al. 1998] Canann, S. A., Tristano, J. R., e Ansys, M. L. S. (1998). An approach to combined laplacian and optimization-based smoothing for triangular, quadrilateral, and quad-dominant meshes. Proceedings of 7th International Meshing Roundtable, pages 15-17.

[Cebral and Lohner 1999] Cebral, J. e Lohner, R. (1999). From medical images to cfd meshes. Proceedings of the 8th International Meshing, pages 321-331.

[Cebral and Lohner 2001] Cebral, J. e Lohner, R. (2001). From medical images to anatomically accurate finite element grids. Int. J. Numer. Meth. Engng, 51:985-1008. 
[Chae and Jeong 1997] Chae, S. W. e Jeong, J. H. (1997). Unstructured surface meshing using operators. Proceedings of the 6th International Meshing Roundtable, pages 281291.

[Ciampalini et al. 1997] Ciampalini, A., Cignoni, P., Montani, C., e Scopigno, R. (1997). Multiresolution decimation based on global error. The Visual Computer, 13:228-246.

[Coleman and Scotney 2005] Coleman, S. e Scotney, B. (2005). Mesh modelling for sparse image data sets. In IEEE International Conference on Image Processing 2005, volume 2, pages 1342-5. IEEE.

[Cuadros-Vargas 2006] Cuadros-Vargas, A. J. (2006). Geração de malhas volumétricas a partir de imagens.

[Cuadros-Vargas et al. 2009] Cuadros-Vargas, A. J., Lizier, M., Minghim, R., e Nonato, L. G. (2009). Generating segmented quality meshes from images. Journal of Mathematical Imaging and Vision, 33:11-23.

[Cuadros-Vargas et al. 2005] Cuadros-Vargas, A. J., Nonato, L. G., Minghim, R., e Etiene, T. (2005). Imesh: An image based quality mesh generation technique. XVIII Brazilian Symposium on Computer Graphics and Image Processing (SIBGRAPI'05), 05:341348.

[Cunha 2009] Cunha, I. L. L. (2009). Estrutura de dados mate face e aplicações em geração e movimento de malhas.

[Delaunay 1934] Delaunay, B. N. (1934). Sur la sphère vide. Bulletin of Academy of Sciences of the USSR, 7:793-800.

[Demaret et al. 2006] Demaret, L., Dyn, N., e Iske, A. (2006). Image compression by linear splines over adaptive triangulations. Signal Processing, 86:1604-1616.

[Dougherty and Barrera 2002] Dougherty, E. e Barrera, J. (2002). Pattern recognition theory in nonlinear signal processing. Journal of Mathematical Imaging and Vision, 16:181-197.

[Field 1988] Field, D. A. (1988). Laplacian smoothing and delaunay triangulations. Communications in Applied Numerical Methods, 4:709-712.

[Finkel and Bentley 1974] Finkel, R. A. e Bentley, J. L. (1974). Quad trees a data structure for retrieval on composite keys. Acta Informatica, 4:1-9.

[Fortune 1992] Fortune, S. (1992). Voronoi diagrams and Delaunay triangulations, pages 193-233. World Scientific Publishing, computing edition.

[García et al. 1999] García, M., Vintimilla, B., e Sappa, A. (1999). Efficient approximation of gray-scale images through bounded error triangular meshes. Proceedings 1999 International Conference on Image Processing (Cat. 99CH36348), 1:168-170.

[Garland and Heckbert 1995] Garland, M. e Heckbert, P. S. (1995). Fast polygonal approximation of terrains and height fields. 
[Geiger 1993] Geiger, B. (1993). Three-dimensional modeling of human organs and its application to diagnosis and surgical.

[Gevers and Smeulders 1997] Gevers, T. e Smeulders, A. (1997). Combining region splitting and edge detection through guided delaunay image subdivision. IEEE Computer Society Conference on Computer Vision and Pattern Recognition, pages 10211026.

[Hale 2001] Hale, D. (2001). Atomic images-a method for meshing digital images. In Proceedings of the 10th International Meshing Roundtable, page 185-196.

[Hoppe et al. 1993] Hoppe, H., DeRose, T., Duchamp, T., McDonald, J., e Stuetzle, W. (1993). Mesh optimization. In Proceedings of the 20th annual conference on Computer graphics and interactive techniques, volume d, page 19-26. ACM New York, NY, USA.

[Ito et al. 2006] Ito, Y., Shum, C., Shih, A. M., Soni, B. K., e Nakahashi, K. (2006). Robust generation of high-quality unstructured meshes on realistic biomedical geometry. International Journal for Numerical Methods in Engineering, 65:943-973.

[Jain 1989] Jain, A. (1989). Fundamentals of digital image processing. Prentice Hall.

[Kachouie and Alirezaie 2003] Kachouie, N. e Alirezaie, J. (2003). Texture segmentation using gabor filter and multi-layer perceptron. IEEE International Conference on Systems, Man and Cybernetics., 3:2897-2902.

[Knupp 2003] Knupp, P. (2003). Algebraic mesh quality metrics for unstructured initial meshes. Finite Elements in Analysis E Design, 39:217-241.

[Knupp 2000] Knupp, P. M. (2000). Achieving finite element mesh quality via optimization of the jacobian matrix norm and associated quantities. part ii: A framework for volume mesh optimization and the condition number of the jacobian matrix. International Journal for Numerical Methods in Engineering, 48:1165-1185.

[Kocharoen et al. 2005] Kocharoen, P., Ahmed, K. M., Rajatheva, R. M. A. P., e Fernando, W. A. C. (2005). Adaptive mesh generation for mesh-based image coding using node elimination approach. In IEEE International Conference on Communications, pages 2052-2056. Ieee.

[Lee and Lo 1994] Lee, C. e Lo, S. (1994). A new scheme for the generation of a graded quadrilateral mesh. Computers \& structures, 52:847-857.

[Lee 2003] Lee, K. (2003). An algorithm for automatic 2d quadrilateral mesh generation with line constraints. Computer-Aided Design, 35:1055-1068.

[Lizier et al. 2009] Lizier, M. A. S., Martins-Jr, D. C., Cuadros-Vargas, A. J., Cesar-Jr, R. M., e Nonato, L. G. (2009). Generating segmented meshes from textured color images. Journal of Visual Communication and Image Representation, 20:190-203.

[Lo 1989] Lo, S. (1989). Generating quadrilateral elements on plane and over curved surfaces. Computers $\mathcal{E}$ structures, 31:421-426.

[Lohner et al. 1987] Lohner, R., Morgan, K., e Zienkiewicz, O. (1987). Adaptive grid refinement for the compressible Euler equations, pages 281-297. Wiley. 
[Mäntylä 1987] Mäntylä, M. (1987). An Introduction to Solid Modeling. Computer Science Press.

[Martins-Jr et al. 2006] Martins-Jr, D. C., Cesar-Jr, R. M., e Barrera, J. (2006). W-operator window design by minimization of mean conditional entropy. Pattern Analysis and Applications, 9:139-153.

[Nowottny 1997] Nowottny, D. (1997). Quadrilateral mesh generation based on a variational method. Proceedings of the 6th International Meshing Roundtable.

[Owen 1998] Owen, S. J. (1998). A survey of unstructured mesh generation technology. In 7th International Meshing Roundtable, volume 3.

[Owen and Saigal 2000] Owen, S. J. e Saigal, S. (2000). Surface mesh sizing control. International Journal for Numerical Methods in Engineering, 47:497-511.

[Owen et al. 1999] Owen, S. J., Staten, M. L., Canann, S. A., e Saigal, S. (1999). Qmorph: an indirect approach to advancing front quad meshing. International journal for numerical methods in engineering, 44:1317-1340.

[Park et al. 2007] Park, C., Noh, J., Jang, I., e Kang, J. (2007). A new automated scheme of quadrilateral mesh generation for randomly distributed line constraints. Computer-Aided Design, 39:258-267.

[Peiró et al. 2007] Peiró, J., Formaggia, L., Gazzola, M., Radaelli, A., e Rigamonti, V. (2007). Shape reconstruction from medical images and quality mesh generation via implicit surfaces. International Journal for Numerical Methods in Fluids, 53:1339-1360.

[Persson 2004] Persson, P. (2004). Pde-based gradient limiting for mesh size functions. In Proceedings of 13th International Meshing Roundtable, page 377-387.

[Persson 2005] Persson, P. (2005). Mesh generation for implicit geometries.

[Petersen 2000] Petersen, S. (2000). Automatic generation of quadrilateral meshes for the finite element analysis of metal forming processes. Finite Elements in Analysis and Design, 35:157-168.

[Powell 1964] Powell, M. (1964). An efficient method for finding the minimum of a function of several variables without calculating derivatives. The Computer Journal, 7:155-162.

[Pudil et al. 1994] Pudil, P., Novovičová, J., e Kittler, J. (1994). Floating search methods in feature selection. Pattern Recognition Letters, 15:1119-1125.

[Rivara 2001] Rivara, M. (2001). Terminal-edges delaunay (small-angle based) algorithm for the quality triangulation problem. Computer-Aided Design, 33:263-277.

[Rizzi et al. 2007] Rizzi, S., Banerjee, P., e Luciano, C. (2007). Automating the extraction of $3 \mathrm{~d}$ models from medical images for virtual reality and haptic simulations. In IEEE International Conference on Automation Science and Engineering, 2007. CASE 2007, page 152-157. 
[Rossignac et al. 2001] Rossignac, J., Safanova, A., e Szymczak, A. (2001). 3d compression made simple: Edgebreaker with zip\&wrap on a corner-table. In Proceedings of the International Conference on Shape Modeling $\mathcal{E}$ Applications, page 278. IEEE Computer Society Washington, DC, USA.

[Ruppert 1995] Ruppert, J. (1995). A delaunay refinement algorithm for quality 2dimensional mesh generation. Journal of algorithms, 18:548-585.

[Sarkis and Diepold 2009] Sarkis, M. e Diepold, K. (2009). Content adaptive mesh representation of images using binary space partitions. IEEE transactions on image processing : a publication of the IEEE Signal Processing Society, 18:1069-79.

[Schneider and Eberly 2003] Schneider, P. J. e Eberly, D. H. (2003). Geometric Tools for Computer Graphics. Morgan Kaufmann.

[Secchi 2003] Secchi, S. (2003). An improved procedure for $2 d$ unstructured delaunay mesh generation. Advances in Engineering Software, 34:217-234.

[Shewchuk 2002] Shewchuk, J. R. (2002). Delaunay refinement algorithms for triangular mesh generation. Computational Geometry, 22:21-74.

[Shimada et al. 1997] Shimada, K., Yamada, A., e Itoh, T. (1997). Anisotropic triangular meshing of parametric surfaces via close packing of ellipsoidal. Proceedings of 6 th International Meshing Roundtable.

[Sibson 1978] Sibson, R. (1978). Locally equiangular triangulations. The Computer Journal, 21:243-245.

[Sousa et al. 2004] Sousa, F. S., Mangiavacchi, N., Nonato, L., Castelo, A., Tomé, M. F., Ferreira, V. G., Cuminato, J. A., e McKee, S. (2004). A front-tracking/front-capturing method for the simulation of 3d multi-fluid flows with free surfaces. Journal of Computational Physics, 198:469-499.

[Stroustrup 2000] Stroustrup, B. (2000). The C++ Programming Language. AddisonWesley Longman Publishing Co., Inc.

[Su 2004] Su, Y. (2004). Automatic mesh generation and modification techniques for mixed quadrilateral and hexahedral element meshes of non-manifold models. Computer-Aided Design, 36:581-594.

[Talbert and Parkinson 1990] Talbert, J. A. e Parkinson, A. R. (1990). Development of an automatic, two-dimensional finite element mesh generator using quadrilateral elements and bezier curve boundary definition. International Journal for Numerical Methods in Engineering, 29:1551-1567.

[Terzopoulos and Vasilescu 1991] Terzopoulos, D. e Vasilescu, M. (1991). Sampling and reconstruction with adaptive meshes. In IEEE Computer Society Conference on Computer Vision and Pattern Recognition, pages 70-75. IEEE.

[Čanića et al. 2005] Čanića, S., Mikelićb, A., e Tambačac, J. (2005). A two-dimensional effective model describing fluid-structure interaction in blood flow: analysis, simulation and experimental validation. Comptes Rendus Mécanique, 333:867-883. 
[Yang et al. 2003] Yang, Y., Wernick, M., e Brankov, J. (2003). A fast approach for accurate content-adaptive mesh generation. IEEE Transactions on Image Processing, 12:866-881.

[Yue 2003] Yue, Z. (2003). Finite element modeling of geomaterials using digital image processing. Computers and Geotechnics, 30:375-397.

[Zhang et al. 2007] Zhang, H., Zhao, G., e Ma, X. (2007). Adaptive generation of hexahedral element mesh using an improved grid-based method. Computer-Aided Design, 39:914-928.

[Zhang et al. 2003] Zhang, Y., Bajaj, C., e Sohn, B.-S. (2003). Adaptive and quality 3d meshing from imaging data. In Proceedings of the eighth ACM symposium on Solid modeling and applications - SM '03, page 286, New York, New York, USA. ACM Press.

[Zhang et al. 2006] Zhang, Y., Xu, G., e Bajaj, C. (2006). Quality meshing of implicit solvation models of biomolecular structures. Computer Aided Geometric Design, 23:510-530.

[Zhu et al. 2002] Zhu, J., Blacker, T., e Smith, R. (2002). Background overlay grid size functions. In Proceedings of 11th International Meshing Roundtable, page 65-74. Citeseer.

[Zuniga and Haralick 1987] Zuniga, O. e Haralick, R. (1987). Integrated directional derivative gradient operator. IEEE Transactions on Systems, Man, and Cybernetics, 17:508-517. 


\section{APÊENICE A - Estrutura de dados}

A estrutura de dados Opposite Face (OF) foi a base para toda a implementação deste projeto. O objetivo do desenvolvimento de uma nova estrutura para o armazenamento e manipulação de malhas foi o de otimizar o processo de geração de malha, priorizando os procedimentos mais requisitados. Inicialmente, nos baseamos nos trabalhos realizados na estrutura Corner Table [Rossignac et al. 2001] e CGAL ${ }^{1}$.

Uma das preocupações para a definição da estrutura foi a minimização do consumo de memória necessário para a representação da malha. Outro ponto observado foi prover facilidade de utilização e flexibilidade.

Na seção A.1 é apresentada a estrutura de dados OF. A seção A.2 detalha a implementação realizada.

\section{A.1 Estrutura}

Uma estrutura de dados topológica precisa ser capaz de representar todos os elementos de uma malha e as relações entre eles, porém utilizando-se do menor espaço de memória possível. Como em alguns outros problemas computacionais, a relação de consumo de memória e de necessidade de processamento para a interpretação dos dados podem ser inversamente proporcionais, portanto a nossa preocupação com o consumo de memória deve considerar o impacto causado no desempenho.

Considerando a restrição de memória, podemos representar um elemento de uma malha basicamente de duas maneiras: explícita ou implícita. A maneira explicita é a mais difundida, cujo modelo visa à representação do elemento por meio de uma variável, estrutura ou objeto. No outro modo de representação, obtemos o elemento desejado indiretamente, deduzindo-o de um elemento explicito como, por exemplo,

\footnotetext{
${ }^{1}$ Computational Geometry Algorithms Library - http:/ /www.cgal.org/
} 
por meio de métodos. Comparando-se as duas representações, a implícita mostra-se mais vantajosa, pois economiza memória e, em alguns casos, simplifica o modelo na medida em que o número de objetos alocados é reduzido. A estrutura OF faz uso dos dois modelos de representação, ou seja, os vértices, triângulos e tetraedros são representados explicitamente; as arestas e faces são representadas implicitamente.

Inicialmente, a estrutura OF foi projetada para representar malhas simpliciais, bidimensionais e tridimensionais, porém a estrutura pode ser estendida para dimensões superiores. Em [Cunha 2009], encontra-se uma extensão da estrutura OF, chamada de Mate-Face (MF).

Os vértices e as células (triângulos ou tetraedros) são identificados por um número - que chamaremos de identificador - inteiro, positivo e único para cada elemento. Com isso, podemos acessar diretamente um determinado elemento se associarmos a posição deste na memória com seu identificador. Os problemas decorrentes desta abordagem são descritos na seção A.2.6.

Os vértices são formados pelas suas coordenadas geométricas e pelo identificador de uma de suas células incidentes, conforme ilustra a figura A.1, com um exemplo em bidimensional.
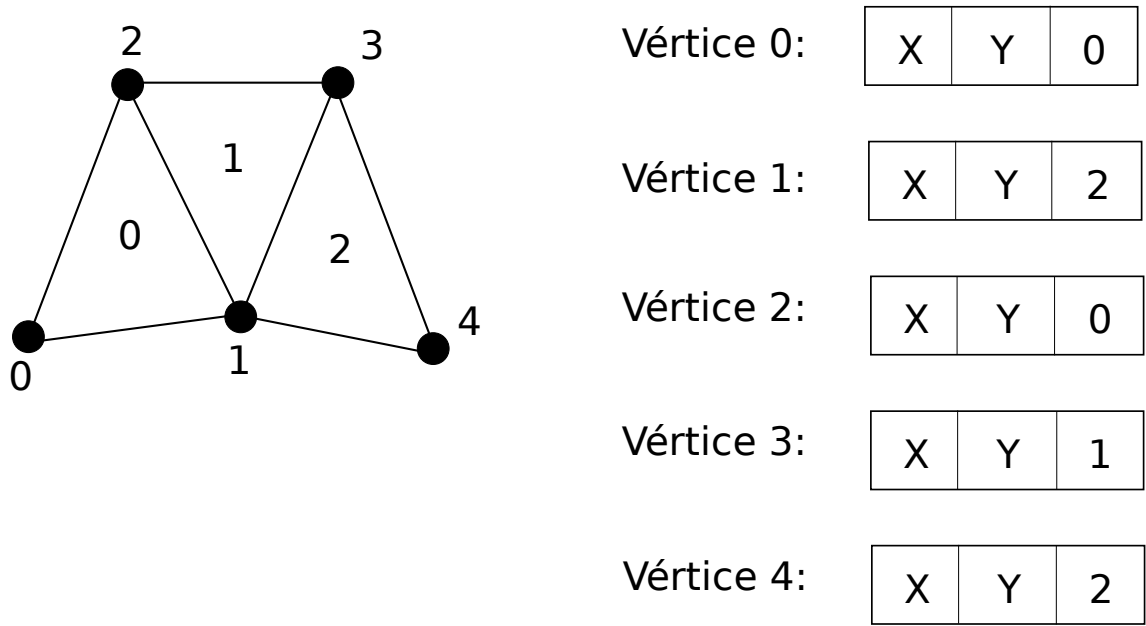

Figura A.1: Vértices bidimensionais.

Por sua vez, nas células temos os identificadores dos vértices que a formam e também os de suas células vizinhas. A relação de vizinhança considera as arestas ou faces da célula, dependendo de sua dimensão. Desta forma, no espaço bidimensional, uma célula $c_{1}$ é dita ser vizinha da célula $c_{2}$ por aresta em relação ao vértice $V$, se e somente se, $c_{1} \cap c_{2}$ for a aresta que não contém o vértice $V$. Para exemplificar, na figura A.2 temos duas células vizinhas por aresta (2D), e na figura A.3 dois tetraedros vizinhos por 
face (3D).

Como dito anteriormente, as arestas e faces são representadas implicitamente. Assim, estes elementos podem ser obtidos em relação à célula que a contém. Na seção A.2.4 ilustramos como a manipulação de arestas ou faces pode ser realizadas.

Célula 0:

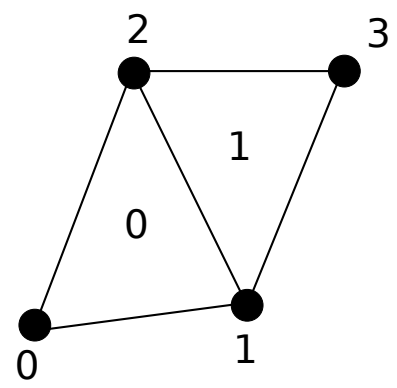

\begin{tabular}{l|c|c|c|} 
Vértices: & 0 & 1 & 2 \\
\cline { 3 - 4 } Opostas: & 1 & - & - \\
\cline { 2 - 4 }
\end{tabular}

Célula 1:

\begin{tabular}{c|c|c|c|}
\cline { 2 - 3 } Vértices: & 1 & 3 & 2 \\
\cline { 2 - 4 } Opostas: & - & 0 & - \\
\hline
\end{tabular}

Figura A.2: Células bidimensionais.

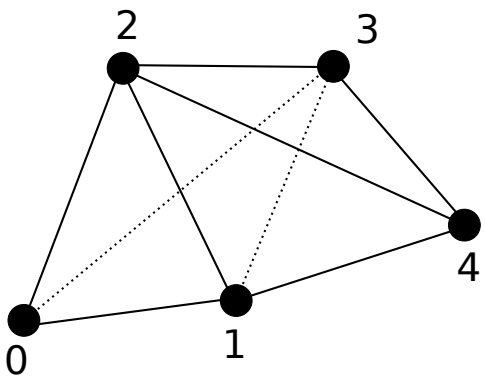

Célula 0:

\begin{tabular}{l|c|c|c|c|} 
Vértices: & 0 & 1 & 2 & 3 \\
\cline { 2 - 4 } Opostas: & 1 & - & - & - \\
\hline
\end{tabular}

Célula 1:

\begin{tabular}{l|c|c|c|c|}
\cline { 3 - 5 } Vértices: & 2 & 1 & 4 & 3 \\
\cline { 2 - 5 } Opostas: & - & - & 0 & - \\
\cline { 2 - 5 }
\end{tabular}

Figura A.3: Células tridimensionais.

Armazenando apenas esta relação de adjacência dos vértices e células conseguimos obter, com acesso direto, a maioria das informações necessárias para o bom desempenho de um algoritmo de geração de malhas. Assim, o espaço necessário para a representação de uma malha bidimensional é bastante reduzido se compararmos com as estruturas winged-edge [Baumgart 1975] e half-edge [Mäntylä 1987]. Ao todo, são necessários seis identificadores para cada triângulo (três identificadores de vértices e três dos triângulos vizinhos), um identificador para cada vértice (da célula incidente), além de suas coordenadas geométricas. Exemplificando, para uma malha com 2 milhões de triângulos e 4 milhões de vértices, são necessários aproximadamente $122 \mathrm{MB}$, conside- 
rando cada identificador ocupando 32 bits e cada coordenada, 64 bits.

Até este ponto, consideramos apenas malhas sem singularidades, mas podemos também representar uma malha com vértices singulares. Neste caso armazenamos em cada vértice não apenas um único identificador de uma das células incidentes, mas um identificador de célula para cada componente singular incidente ao vértice.

\section{A.2 Implementação}

Nesta seção discutimos os detalhes de implementação da estrutura OF, assim como apresentamos diretrizes para adequar a estrutura à aplicação desejada. A linguagem adotada foi a $\mathrm{C}++$, para mantermos a compatibilidade com os demais projetos desenvolvidos no grupo de computação gráfica. Outra característica fundamental é o desempenho oferecido e a possibilidade do uso de templates.

Todas as classes da estrutura OF dependem de parâmetros templates que precisam ser definidos no momento de sua utilização. Com isso, conseguimos criar malhas de dimensões diferentes, com dados associados em elementos distintos, bastando apenas alterar a definição do parâmetro template. Desta maneira, não são realizados testes de verificação de tipos durante a execução do algoritmo sobre a estrutura, pois esta tarefa é realizada durante a compilação. Cada classe necessita de um conjunto de parâmetros templates diferente, logo torna-se mais prático especificar um conjunto único para todas as classes da estrutura. Este conjunto deve conter todos os tipos utilizados em todas as classes, desta maneira, fica cada classe responsável por escolher os tipos que utiliza. Chamaremos este conjunto de tipos de perfil.

\section{A.2.1 Vértices}

Nos vértices encontram-se as informações geométricas da malha. Cada vértice está associado à uma posição no espaço, que é a base das operações que envolvem cálculos geométricos. No vértice também está armazenada uma referência para uma célula que o contém (identificador). No caso de vértices singulares, uma referência para uma célula de cada componente que constitui a singularidade é armazenada. Com esta informação podemos percorrer toda a malha partindo de qualquer vértice.

A classe base dos vértices é a ofVertex. Esta classe possui as coordenadas do vértice, além dos métodos e atributos herdados da ofBase, que serão descritos mais adiante. 
Os parâmetros templates necessários para esta classe são a dimensão do espaço onde o vértice está definido, que corresponde ao número de coordenadas que serão alocadas, e o perfil de tipos (seção A.2.3). Este perfil deve conter a especificação do tipo de identificador e o tipo do espaço métrico.

Para malhas com singularidades nos vértices, é necessário utilizar como vérticebase a classe ofSingularVertex, na qual uma lista de singularidades é adicionada ao vértice. Esta lista permite percorrer as células que contém um determinado vértice, de forma direta. Os parâmetros templates necessários para a classe ofSingularVertex são os mesmos da classe ofVertex.

Para simplificar o uso dos vértices, estão disponíveis na estrutura as classes ofVertex $2 D$ e ofVertex $3 D$, para o espaço bidimensional e tridimensional respectivamente. Tais classes necessitam apenas do perfil de tipos que será utilizado.

Na figura A.4 temos o diagrama UML das classes de vértices disponíveis.

\section{A.2.2 Células}

Dependendo da dimensão atribuída, as células podem representar triângulos, tetraedros ou simplexos de dimensões superiores da malha. Em cada célula são armazenadas referências para todos os vértices que a formam (três, quatro ou mais) e também para todas as células vizinhas por arestas ou faces. Os parâmetros templates necessários para a instanciação da classe ofCell são o perfil de tipos e a dimensão da célula (número de vértices formadores), ou seja, 3 para os triângulos e 4 para os tetraedros. Assim como nos vértices, para simplificação do uso das células, temos disponíveis as classes ofCell2D para os triângulos e ofCell3D para os tetraedros. Na figura A.5 temos o diagrama UML das classes células.

\section{A.2.3 Perfil de tipos}

Um perfil de tipos deve especificar o tipo do identificador que será utilizado para indexar os elementos da malha, e o tipo do espaço métrico no qual as coordenadas estão definidas. Os tipos de identificadores mais comuns são os inteiros (int) e inteiros longos (long int ou long long int). Por padrão é definido o tipo int como identificador. Para o espaço dos elementos podemos utilizar os tipos de ponto flutuante (float, double e long double) ou então alguma classe com os operadores básicos sobrecarregados (+, 


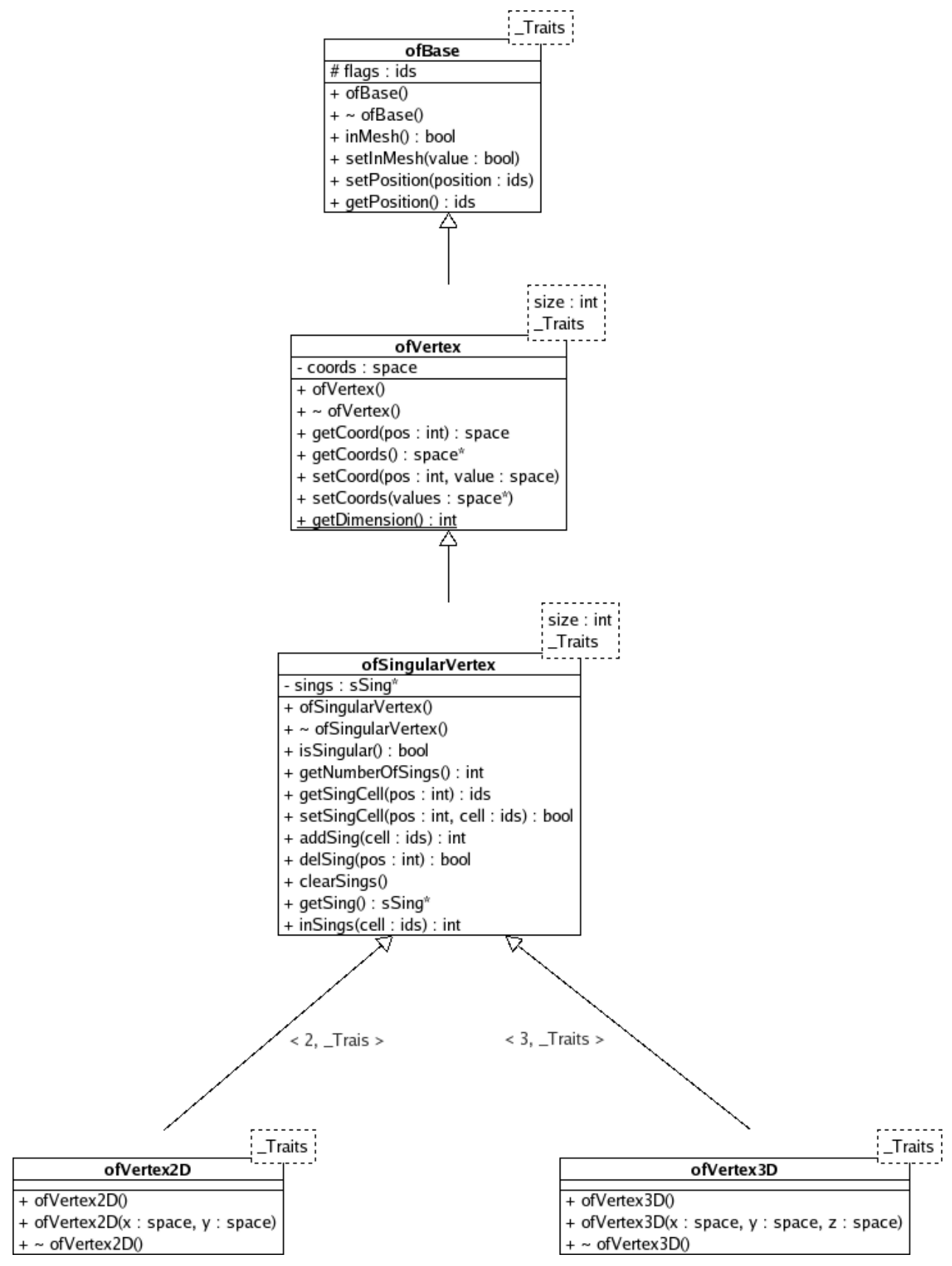

Figura A.4: Classes de vértices. 


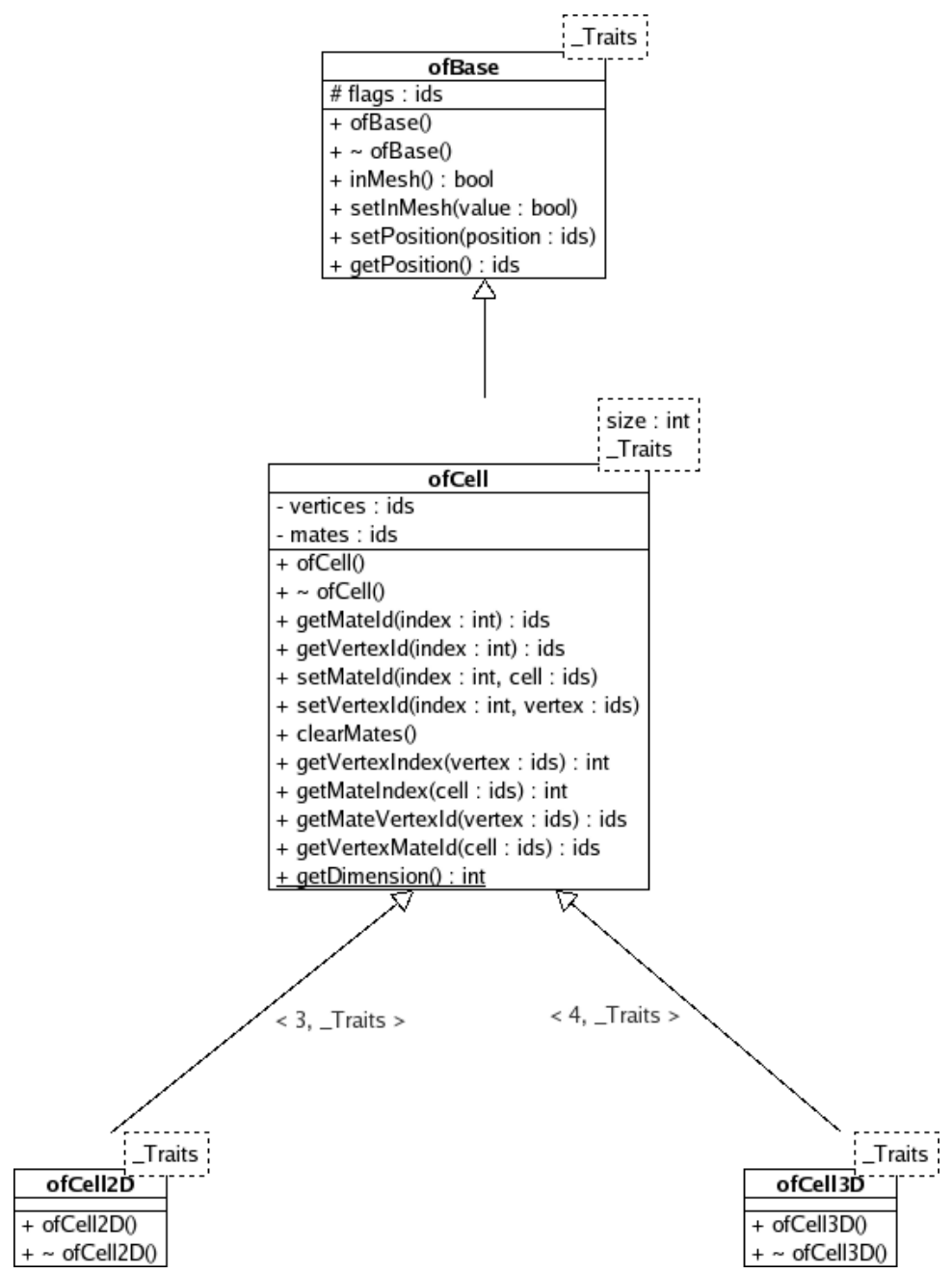

Figura A.5: Classes de células. 
$-, *, /,>,<,=, \ldots)$. O espaço métrico padrão é do tipo double. Outros tipos que precisam ser definidos em qualquer malha são os vértices e as células. Também é necessário especificar no perfil de tipos as classes que serão responsáveis pela manipulação topológica e geométrica da malha. Estas classes serão descritas mais adiante.

\section{A.2.4 Associação de dados}

Podemos utilizar qualquer outro tipo herdado (herança pública) das classes do perfil padrão para a definição da malha, pois esta alteração não afeta o funcionamento da estrutura. Este recurso é muito importante para criarmos malhas com dados associados aos elementos. Por exemplo, para criarmos uma malha cujas células possuam um vetor normal, temos que criar uma classe herdada de uma célula base (ofCell) e adicionar um vetor de ponto flutuante. Com isso, podemos adicionar métodos e atributos a qualquer elemento da malha, bastando definir os novos tipos de vértices e/ou células no perfil atribuído a esta malha.

\section{A.2.5 Malhas}

Todas as malhas suportadas pela estrutura OF são representadas pela classe base ofMesh. A especificação do tipo de malha é definida pelo tipo de vértice e pelo tipo de célula encontrados no perfil de tipos. Portanto, para criarmos uma malha bidimensional no plano, precisamos montar um perfil com o tipo de vértice ofVertex $2 D$ (ou herdado desta classe) e o tipo de célula ofCell2D. Para criarmos uma malha dada por uma superfície de triângulos devemos definir no perfil de tipos os vértices ofVertex $3 D$ e as células ofCell2D. Analogamente, para uma malha de tetraedros o tipo de vértice é ofVertex3D e o de célula ofCell3D. Outras combinações também são possíveis, como por exemplo a criação de um vértice com 4 dimensões para o uso de coordenadas homogêneas no espaço tridimensional.

Como o tipo de malha alocada pode ser alterado apenas por mudanças no perfil de tipos atribuído à classe ofMesh, é necessário especificar também o algoritmo utilizado para a manutenção da malha. Este algoritmo (ofOper) será o responsável pelas alterações necessárias na malha quando adicionarmos ou removermos algum vértice ou célula. A estrutura OF dispõe das seguintes classes de manipuladores de malhas:

- ofMesh2D: bidimensionais orientadas; 
- ofMesh3D: tridimensionais;

- ofMeshSurface: superfícies orientadas;

- ofMeshNOSurface: superfícies não orientadas.

Estas classes de manipulação são para os tipos básicos de malhas; a adição de outro tipo de informação nos vértices ou células (por exemplo, coordenadas homogêneas) não altera o funcionamento destes algoritmos. Porém, se esta alteração for desejável, é necessário implementar um algoritmo específico, que considere tais informações adicionais, e em seguida especificá-lo no perfil de tipos da malha.

As operações básicas disponíveis na malha são adição e remoção de vértices e células, e também a obtenção destes por meio do seu identificador.

A alocação dos vértices e células é feita em vetores. Com isso conseguimos acesso em tempo constante a qualquer elemento a partir do seu identificador. Para evitar o limite estabelecido no momento da alocação de um vetor, a estrutura OF utiliza uma alocação por blocos, realizada pela classe ofVector. Assim, é necessário fornecer apenas o número máximo de elementos que constituirão a malha, parâmetro fornecido no construtor. Também é gerenciada a reutilização de espaços vazios, operação necessária para o caso de malhas dinâmicas onde várias inserções e remoções são realizadas.

A classe ofMesh permite acesso paralelo aos seus métodos, ou seja, podemos adicionar, remover ou acessar vértices ou células simultaneamente. Com esse recurso, podemos desenvolver algoritmos paralelos e utilizar todo o recurso computacional disponível nos computadores multiprocessados. Para habilitar o suporte ao paralelismo é necessário compilar a estrutura com a definição OF_THREADS informada ao compilador.

\section{A.2.6 Vetor de elementos}

Uma das vantagens em utilizar um identificador para referenciarmos cada elemento da malha é que podemos associá-lo com a posição de memória do elemento. Por exemplo, se colocarmos todos os vértices em um vetor, podemos numerá-los de acordo com a posição de cada vértice no vetor. O primeiro problema desta abordagem é o limite imposto pelo tamanho da alocação do vetor. Outro problema é observado quando queremos remover algum elemento do vetor. Para contorná-los e tirar proveito do acesso direto à memória, utilizamos um vetor alocado em partes com geren- 
ciamento de posições vazias. Assim, blocos de memória são alocados dinamicamente, na medida em que novos elementos são inseridos na malha.

Estes blocos são indexados em um vetor de ponteiros. A posição de um bloco no vetor de ponteiros é a divisão inteira do identificador do elemento pelo tamanho do bloco, e a posição do elemento dentro do bloco é deduzida pelo resto desta divisão. Desta maneira, ainda temos um limite estabelecido no momento em que alocamos o vetor de ponteiros, mas em geral conseguimos definir uma ordem de grandeza do número de elementos de uma malha.

Todo elemento inserido neste vetor deve herdar da classe base da estrutura (ofBase), pois nesta classe se encontra a estrutura necessária para realizarmos o gerenciamento de posições vazias. Na figura A.6 temos o esquema da alocação deste vetor.

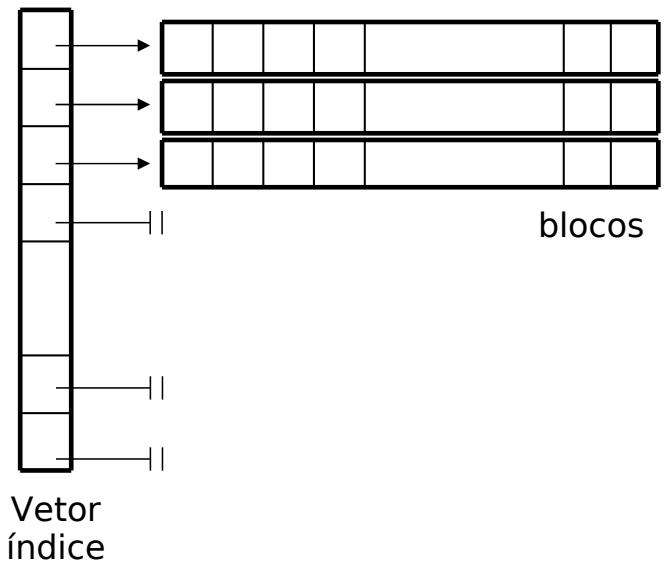

Figura A.6: Vetor de alocação por blocos.

\section{A.2.7 Cálculos geométricos}

A estrutura OF concentra todos os cálculos geométricos na classe ofGeometric. $\mathrm{O}$ propósito desta classe é tornar flexível a alteração dos cálculos realizados pela estrutura e pelos algoritmos implementados sobre a OF. É necessário especificá-la no perfil de tipos, podendo ser substituída por outra classe, com a mesma interface. Tal recurso se torna importante para a utilização de primitivas geométricas calculadas com aritmética exata.

Vale ressaltar que a estrutura OF só realiza cálculos geométricos nas malhas que exigem células orientadas, ou nos algoritmos implementados como, por exemplo, a triangulação de Delaunay e o refinamento de Ruppert. 
Dentre os métodos disponíveis na classe ofGeometric estão:

- inLeft: Verifica em qual semi-espaço se encontra um ponto (com relação a uma reta definida por dois pontos;

- inCircle: Verifica se um ponto está dentro ou fora do circuncirculo definido por um triângulo;

- dist: Calcula a distância entre dois pontos;

- dot: Calcula o produto escalar;

- getCircuncircle: Retorna as coordenadas do circuncirculo de um triângulo;

- inDiametralCircle: Verifica se um ponto esta dentro ou fora do círculo diametral de uma aresta;

- orientation: Orienta três pontos no espaço bidimensional;

\section{A.2.8 Operações topológicas}

As operações topológicas realizadas na estrutura OF estão divididas em duas classes: ofOper e ofTopology. Na classes ofOper estão as operações de adição e remoção de células como dito na seção A.2.5. Já na classe ofTopology encontram-se as demais operações topológicas que podem ser efetuadas. O flip de arestas realizado pelo algoritmo de flipping [Sibson 1978] da triangulação de Delaunay está implementado nesta classe. O objetivo desta classe específica é de permitir a fácil substituição destes algoritmos na estrutura, visto que esta classe é mais um parâmetro do perfil de tipos (sTopology).

\section{A.2.9 Iteradores}

Alguns padrões de acesso a malhas são freqüentemente utilizados, como por exemplo obter a estrela de um vértice, ou então percorrer todas as células ou vértices da malha. Visando à simplificação e padronização do acesso aos elementos que possuem alguma relação entre si, foi implementada uma classe de iteradores (ofIterator). Podem ser encontrados na estrutura OF os seguintes iteradores:

- ofVerticesIterator: percorre todos os vértices da malha; 
- ofCellsIterator: percorre todas as células da malha;

- ofVertexStarIterator2D, ofVertexStarIteratorNO2D, ofVertexStarIterator3D, ofVertexStarIteratorNOSurface: percorre todas as células que contém um determinado vértice (estrela);

- ofMateCelliterator: percorre todas as células vizinhas de uma determinada célula (por aresta ou vértice comuns);

- ofCellVerticeIterator: percorre todos os vértices de uma célula;

- ofBoundaryCelliterator2D, ofBoundaryCellCIterator2D: percorre todas as células que possuem uma aresta ou vértice no bordo.

Estes iteradores exigem como parâmetro template apenas o perfil de tipos. No construtor é necessário informar o endereço correspondente à malha que será percorrida.

O método para percorrer os elementos da malha não altera a estrutura em si, logo podemos instanciar os iteratores de acordo com a necessidade específica da aplicação, inclusive considerando alguma informação adicional inserida nos elementos. Assim, outras relações podem ser criadas, bastando apenas herdar da classe ofIterator e adicionar o algoritmo específico.

\section{A.2.10 Interface com arquivos}

É possível carregar malhas diretamente de arquivos para a estrutura OF por meio das classes herdadas de ofReader. Atualmente, existem leitores de arquivo no formato VTK $^{2}$ (unstructured grid e polydata), OFF ${ }^{3}$, OF (seção A.2.11) e WRL ${ }^{4}$. Todos os leitores operam sobre o método virtual read, padronizando assim o acesso a malhas armazenadas em arquivos. Uma malha armazenada na estrutura OF pode ser escrita em um arquivo por meio dos escritores herdados de ofWriter: ofVtkWriter, ofOffWriter e ofOfWriter, para o formato VTK (unstructured grid), OFF e OF, respectivamente. Tanto nos leitores quanto nos escritores, é necessário passar como parâmetro template apenas o perfil de tipos.

\footnotetext{
${ }^{2}$ The Visualization Toolkit - http:/ / www.vtk.org/

${ }^{3}$ Geomview - http://www.geom.uiuc.edu/software/geomview/

${ }^{4}$ http://www.w3.org/Submission/WRL/
} 


\section{A.2.11 Formato OF}

Visando tornar mais eficiente a manipulação de arquivos, definimos um formato próprio de arquivo para armazenarmos uma malha da estrutura OF. Neste formato são armazenadas também as relações de vizinhança, além das informações geométricas. Desta maneira, conseguimos carregar uma malha em média quatro vezes mais rápido. Em compensação, necessitamos de mais espaço em disco. Como utilizamos a representação binária, temos arquivos menores que qualquer outro formato ascii, como o VTK e OFF, mesmo armazenando mais informações. Na figura A.7 temos os campos de um arquivo no formato OF. O primeiro campo indica a versão do arquivo, em ascii, seguido pelo tamanho da variável coordenada e o tamanho do identificador. Os demais campos do cabeçalho descrevem o tipo de vértice e célula. Após estes dados, o arquivo está pronto para o armazenamento da malha. São listadas todas as coordenadas dos vértices e em seguida as informações das células — vértices que a formam e identificadores de suas vizinhas. Por último, segue a lista de identificadores das células que incidem em cada vértice.

\begin{tabular}{|l|r|}
\hline \multicolumn{2}{|c|}{ OF-BINARYVV1.0 } \\
\hline Tamanho da coordenada & Tamanho do identificador \\
\hline Dimensão Vértice & Dimensão Célula \\
\hline Número de Vértices & Número de Células \\
\hline $\mathrm{X} 1, \mathrm{Y} 1, \mathrm{Z} 1$ & \\
\hline$\ldots$ & $\mathrm{Op} 1, \mathrm{Y} 2, \mathrm{Op} 2$ \\
\hline $\mathrm{v} 1, \mathrm{~V} 2, \mathrm{v} 3, \ldots$ & \\
\hline$\cdots$ & \\
\hline $\operatorname{sing} 1, \operatorname{sing} 2, \operatorname{sing} 3, \ldots$ & \\
\hline$\cdots$ & \\
\hline
\end{tabular}

Figura A.7: Formato binário de arquivo (OF).

\section{A.2.12 Estruturas auxiliares}

$\mathrm{Na}$ estrutura OF encontramos um conjunto de estruturas simples utilizadas em implementações gerais. Seguindo o mesmo padrão de programação da OF, estas estruturas precisam ser instanciadas com o tipo de objeto que será armazenado. No caso 
das estruturas que exigem ordenação (por exemplo, kd-tree [Bentley 1975]), é necessário fornecer também a condição de comparação. No vetor de elementos (ofVector), o elemento passado como template deve ser herdado da classe ofBase, pois nesta classe se encontram os métodos e atributos necessários para o gerenciamento de elementos removidos. As estruturas atualmente disponíveis são:

- ofList: Lista de elementos;

- ofVector: Vetor de elementos (alocação por blocos);

- ofKdTree: Arvore binária kd-tree;

- ofStack: Pilha de elementos; 